\title{
Nanosize effects in the magnetic properties of the two layered hydroxides of nickel
}

James D. Rall

West Virginia University

Follow this and additional works at: https://researchrepository.wvu.edu/etd

\section{Recommended Citation}

Rall, James D., "Nanosize effects in the magnetic properties of the two layered hydroxides of nickel" (2011). Graduate Theses, Dissertations, and Problem Reports. 3411.

https://researchrepository.wvu.edu/etd/3411

This Dissertation is protected by copyright and/or related rights. It has been brought to you by the The Research Repository @ WVU with permission from the rights-holder(s). You are free to use this Dissertation in any way that is permitted by the copyright and related rights legislation that applies to your use. For other uses you must obtain permission from the rights-holder(s) directly, unless additional rights are indicated by a Creative Commons license in the record and/ or on the work itself. This Dissertation has been accepted for inclusion in WVU Graduate Theses, Dissertations, and Problem Reports collection by an authorized administrator of The Research Repository @ WVU.

For more information, please contact researchrepository@mail.wvu.edu. 
NANOSIZE EFFECTS IN THE MAGNETIC PROPERTIES OF THE TWO LAYERED HYDROXIDES OF NICKEL

\author{
by \\ James D. Rall \\ Dissertation submitted to the Eberly College of Arts and Sciences \\ at West Virginia University \\ in partial fulfillment of the requirements \\ for the degree of
}
Doctor of Philosophy
in
Physics

Approved by

Mohindar S. Seehra, Ph.D., Committee Chairperson Wathiq Abdul-Razzaq, Ph.D.

Mikel Holcomb, Ph.D.

James P. Lewis, Ph.D.

Lloyd Carroll, Ph.D.

Department of Physics

Morgantown, West Virginia

2011

Keywords: Nanoparticles, Layered Hydroxide Metals, Surface Spin 


\title{
ABSTRACT \\ NANOSIZE EFFECTS IN THE MAGNETIC PROPERTIES OF THE TWO LAYERED HYDROXIDES OF NICKEL
}

\begin{abstract}
James D. Rall
Investigations of properties of materials with lower lattice dimensionality (one and two dimensions) often provides good opportunity to advance physics since solutions to corresponding theoretical models are more easily obtained. In this work, results on magnetic properties of two quasi two-dimensional (2D) systems viz. the layered hydroxides of nickel, $\beta-\mathrm{Ni}(\mathrm{OH})_{2}$ and $\alpha-\mathrm{Ni}(\mathrm{OH})_{2}$, are reported. For $\beta-\mathrm{Ni}(\mathrm{OH})_{2}$, there have been conflicting reports in the literature whether the magnetic ordering is ferromagnetic or antiferromagnetic. For the less stable $\alpha-\mathrm{Ni}(\mathrm{OH})_{2}$ with the larger spacing between the layers, the nature of magnetism is largely unexplained. Therefore, the results and their interpretation present here contribute significantly to the understanding of the magnetic properties of these quasi 2D systems.

Synthesis of the two hydroxides were done by the sol-gel and hydrothermal techniques followed by structural characterizations by x-ray diffraction (XRD), transmission electron microscopy (TEM)/scanning electron microscopy (SEM), thermogravimetric analysis (TGA) and FTIR spectroscopy. Magnetic properties were investigated using an in-house SQUID magnetometer for the temperature range of $2 \mathrm{~K}$ to $350 \mathrm{~K}$ in magnetic fields up to $\pm 65 \mathrm{kOe}$. Additional magnetic studies on $\beta-\mathrm{Ni}(\mathrm{OH})_{2}$ for $\mathrm{H}$ up to $180 \mathrm{kOe}$ were carried out at the National High Magnetic Field Laboratory (NHMFL) in Tallahassee, Fl.

For the $\beta$-phase with the formula $\mathrm{Ni}(\mathrm{OH})_{2} \bullet 0.144 \mathrm{H}_{2} \mathrm{O}$, the lattice constants of the hexagonal lattice are $\mathrm{a}=3.12 \AA$ and $\mathrm{c}=4.67 \AA$. Temperature dependence of the magnetization showed a two step transition: ferromagnetic (FM) ordering of the (001) layers with exchange coupling $\mathrm{J}_{1} / \mathrm{k}_{\mathrm{B}}=3.25 \mathrm{~K}$ at $25 \mathrm{~K}$ followed by $3 \mathrm{D}$ antiferromagnetic (AFM) ordering at $\mathrm{T}_{\mathrm{N}}=23 \mathrm{~K}$ triggered by the interplane AFM exchange constant $\mathrm{J}_{2} / \mathrm{k}_{\mathrm{B}}=-0.32 \mathrm{~K}$. Both bulk-like and nanosize $\beta-\mathrm{Ni}(\mathrm{OH})_{2}$ show a magnetic field induced metamagnetic transition to ferromagnetism at $\mathrm{H}_{\mathrm{C} 2} \simeq 55 \mathrm{kOe}$. In the nanosize $\beta-\mathrm{Ni}(\mathrm{OH})_{2}$ only, a second weaker transition at $\mathrm{H}_{\mathrm{C} 2} / 2$ is observed which is shown to be due to magnetic field induced flipping of the surface $\mathrm{Ni}^{2+}$ spins observable only on the nanosize particles. The associated magnetic moment per $\mathrm{Ni}^{2+}$ spin is determined to be $2.92 \mu_{\mathrm{B}}\left(3.33 \mu_{\mathrm{B}}\right)$ for nanosize (bulk) $\beta-\mathrm{Ni}(\mathrm{OH})_{2}$. The observed saturation magnetization $\mathrm{M}_{\mathrm{S}}=118 \mathrm{emu} / \mathrm{g}$ above $150 \mathrm{kOe}$ is shown to be consistent with the theoretical model of AFM order and metamagnetic transition to $\mathrm{FM}$ order above $\mathrm{H}_{\mathrm{C} 2}$.

The two samples of $\alpha-\mathrm{Ni}(\mathrm{OH})_{2}$ studied here give nearly identical results for characterization and magnetization. The sample with formula $\mathrm{Ni}(\mathrm{OH})_{1.23}\left(\mathrm{CH}_{3} \mathrm{COO}\right)_{0.77} \bullet 0.141$ $\mathrm{H}_{2} \mathrm{O}$ gives a hexagonal lattice with $\mathrm{a}=3.01 \AA$ and $\mathrm{c}=8.6 \AA$. The morphology, based on the SEM images, shows a flower-like structure with petal thickness of $\sim 10 \mathrm{~nm}$, while the particle is larger, around $200 \mathrm{~nm}$.

The temperature variation of the magnetization in the $\alpha$-phase shows a peak temperature at $16 \mathrm{~K}$ for $\mathrm{H}=50 \mathrm{Oe}$ corresponding to $2 \mathrm{D}$ ferromagnetic ordering. As such, the $\mathrm{M}$ vs. T ZFC data for $\mathrm{T}>50 \mathrm{~K}$ was fit to the $2 \mathrm{D}$ triangular Ising lattice $\mathrm{S}=1$ high temperature series giving
\end{abstract}


$\mathrm{g}=2.29$ and the in-plane ferromagnetic interaction of $\mathrm{J}_{1} / \mathrm{k}_{\mathrm{B}} \simeq 4.38 \mathrm{~K}$. Based on the Heisenberg $2 \mathrm{D}$ to $3 \mathrm{D}$ transition of the ordering temperature, the interplanar exchange interaction was determined to be $J_{2} / k_{B} \simeq 0.14 \mathrm{~K}$. The ac susceptibility gives evidence for two magnetic regimes below the $2 \mathrm{D}$ FM ordering at $T_{c} \simeq 16 \mathrm{~K}$. For temperatures below $T_{p} \simeq 8 \mathrm{~K}$ particle size effects are seen with a blocking temperature highly dependent on the applied magnetic field and the measuring frequency. The system also exhibits magnetic annealing behavior due to surface spin interactions below $\mathrm{T}_{\mathrm{m}} \simeq 3.5 \mathrm{~K}$, giving rise to exchange bias and hysteresis loop characteristic of pinned spins. 


\section{DEDICATION}

The author wishes to dedicate his dissertation to his beautiful wife, Jennifer R. Cauthon, for all of her support and encouragement throughout the years. 


\section{ACKNOWLEDGMENTS}

The author wishes to express his gratitude to his advisor, research collaborators, committee members, professors in the physics department, friends, and family. To Dr. Mohindar S. Seehra, thank you for the opportunity to work with such an outstanding member of the scientific community. You have given me a tremendous amount of support throughout the years and have developed my skills in experimental physics. To Dr. Naresh Shah and Dr. Gerald Huffman from the University of Kentucky, thank you for the time and effort put toward obtaining TEM and SEM images of the samples. To Dr. Eun Choi, your help and guidance at the National High Magnetic Field Laboratory was invaluable in obtaining some of the conclusive results. To my committee members: Dr. Wathiq Abdul-Razzaq, Dr. Mikel Holcomb, Dr. James P. Lewis, and Dr. Lloyd Carroll, thank you for your time and efforts put towards this dissertation. I have gained a lot of my physics knowledge from the professors in the Department of Physics at West Virginia University. Through the great diversity of the graduate professors, I have observed many different teaching styles to help me further towards my goals in life, thank you. To my closest friends: Guerau, Vivek, and Mattias, thank you for your friendship throughout this journey. To my parents: David and Vicki Rall, my siblings: Nicole, Tim, and Matthew Rall, thank you for the encouragement all of you have shown me throughout my life including undergraduate and graduate school. Finally I

would like to thank the U. S. Department of Energy and the National High Magnetic Field Laboratory for supporting this project. 


\section{Table of Contents}

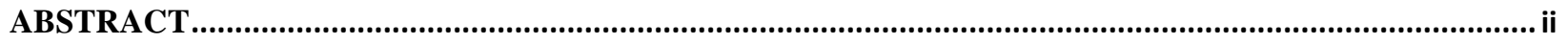

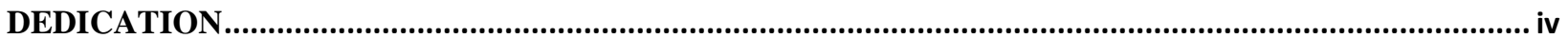

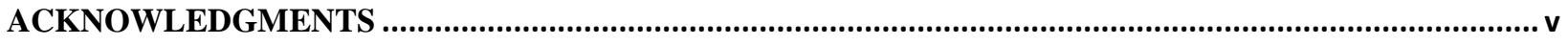

TABLE OF CONTENTS ................................................................................................................................ vi

LIST OF FIGURES........................................................................................................................................... viii

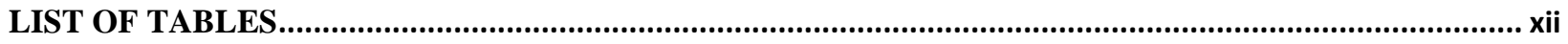

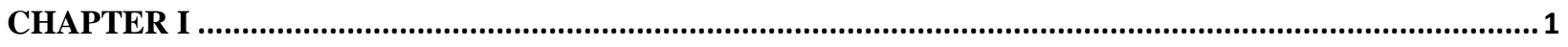

1.1 ELECTROCHEMICAL PROPERTIES OF NICKEL(II) HYDROXIDE ..................................................

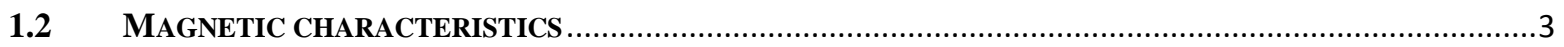

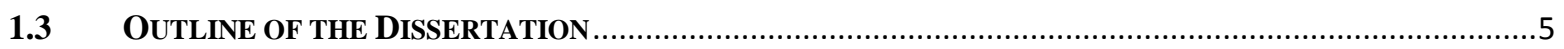

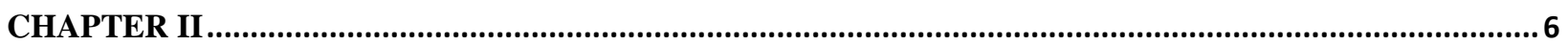

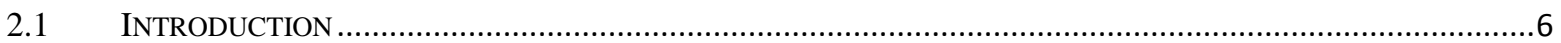

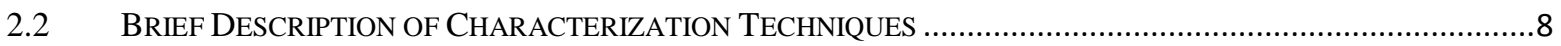

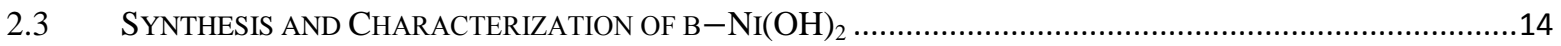

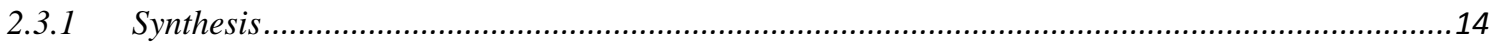

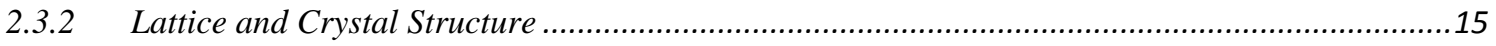

2.3.3 Sample Morphology and Particle Size ………........................................................................19

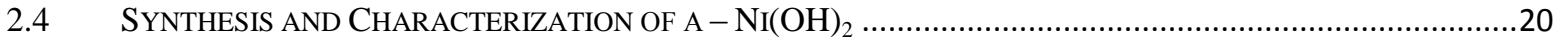

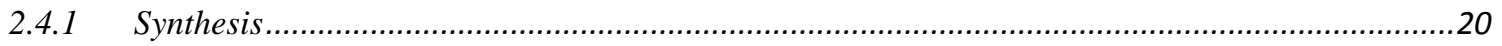

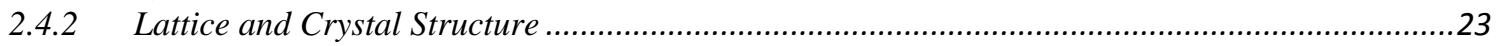

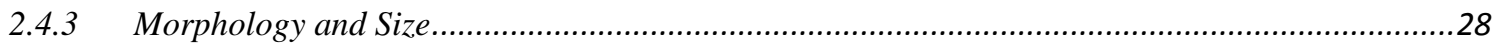

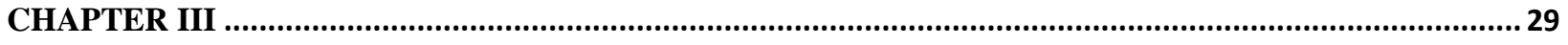

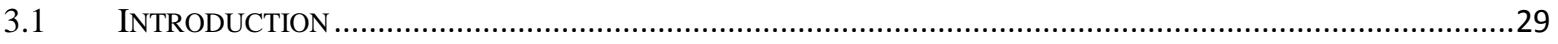

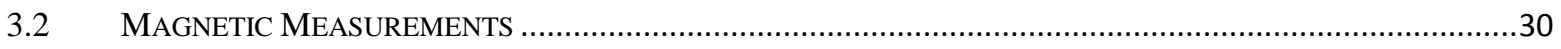

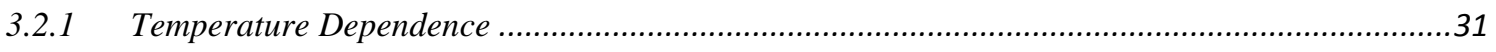

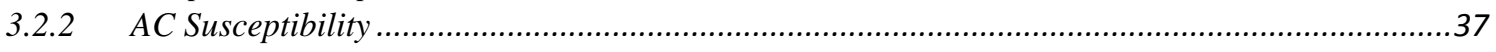

3.2.3 Magnetic Field Dependence of Magnetization.........................................................................

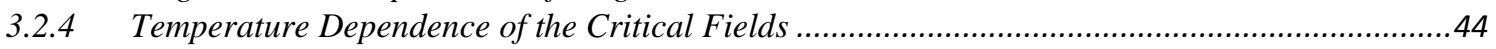

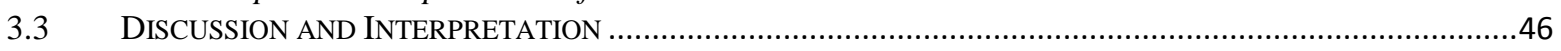

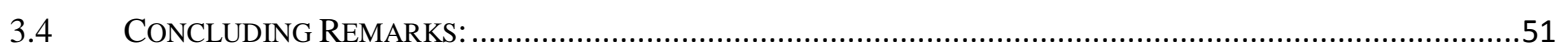

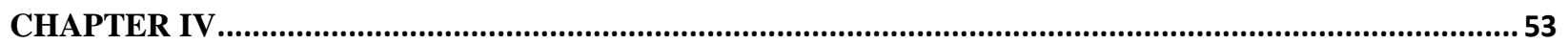

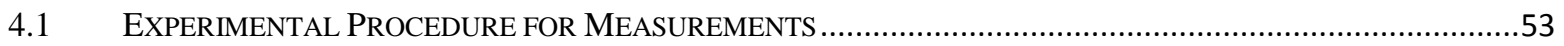

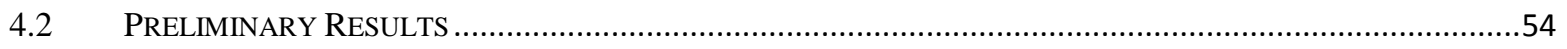

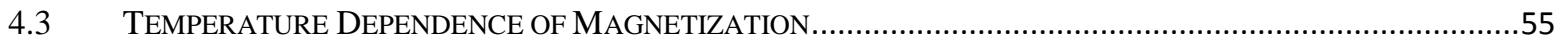

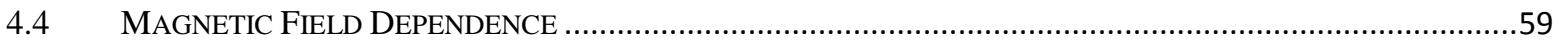

4.5 TEMPERATURE DEPENDENCE OF THE CRITICAL FIELD FOR METAMAGNETISM......................................59

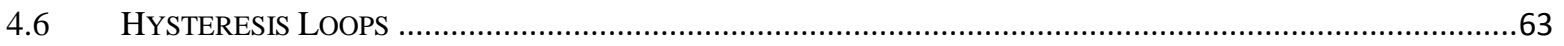

4.7 TEMPERATURE AND MAGNETIC FIELD DEPENDENCE OF AC SUSCEPTIBILITY …..................................67

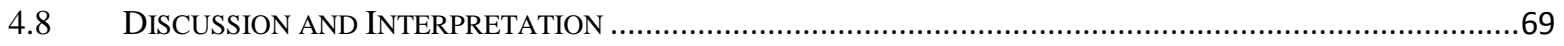

4.8.1 Temperature Dependence of Paramagnetic Susceptibility.........................................................69

4.8.2 High Temperature Series (HTS) Fit ………....................................................................... 71 


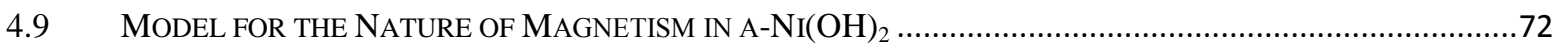

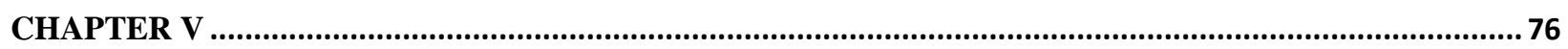

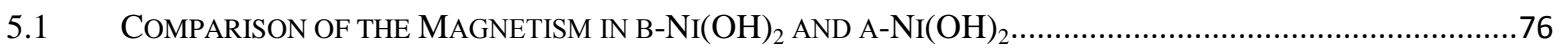

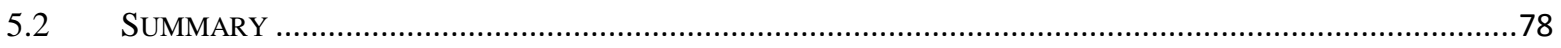

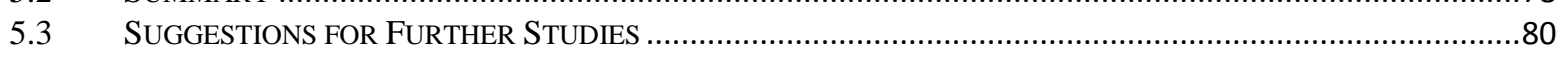

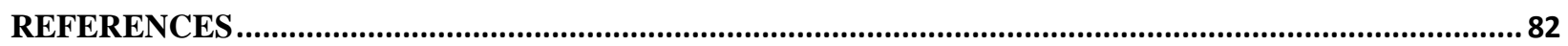

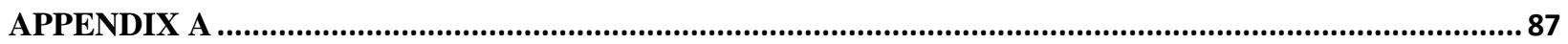

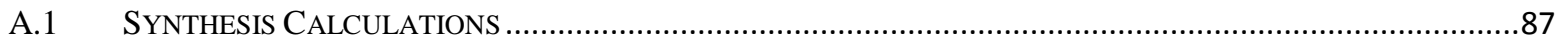

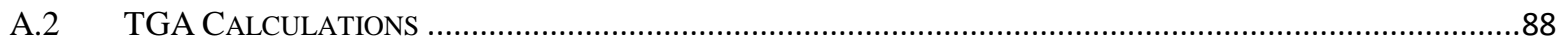

A.3 TEMPERATURE PROGRAMMED REDUCTION (TPR) …................................................................. 


\section{LIST OF FIGURES}

Fig. $2.1 \quad \mathrm{Ni}(\mathrm{OH})_{2}$ in the $\mathrm{CdI}_{2}$ structure.

Fig. 2.2 X-ray spectrum from a copper cathode ray tube.

Fig. 2.3 X-ray tube diagram [Scholtz, 2000].

Fig. 2.4 Typical FTIR setup.

Fig. 2.5 Electron gun diagram [Materials Science and Engineering Department].

Fig. 2.6 SEM column diagram [Materials Science and Engineering Department].

Fig. 2.7 Summary of preparations for bulk-like $\beta-\mathrm{Ni}(\mathrm{OH})_{2}$, sample $\beta$-B.

Fig. 2.8 XRD pattern of sample $\beta$-A and sample $\beta$-B of $\beta-\mathrm{Ni}(\mathrm{OH})_{2}$.

Fig. 2.9 TGA results of sample $\beta$-A and sample $\beta$-B. Inset shows the XRD of the TGA resultant of sample $\beta$-A.

Fig. 2.10 FTIR spectra of sample $\beta$-A and sample $\beta$-B in the $\mathrm{KBr}$ pellet form. See text for IR band descriptions.

Fig. 2.11 TEM images of sample $\beta$-A at magnifications (a) $100 \mathrm{kx}$, (b) $600 \mathrm{kx}$, and (c) SAED $300 \mathrm{kx}$.

Fig. 2.12 Synthesis procedure of $\alpha-\mathrm{Ni}(\mathrm{OH})_{2}$ for sample $\alpha$-A (sample $\left.\alpha-\mathrm{B}\right)$.

Fig. 2.13 Sample development while using the vacuum oven. See text for differing conditions.

Fig. 2.14 Sample progression using the stainless steel autoclave. See text for the different conditions.

Fig. 2.15 XRD pattern of sample $\alpha$-A (EG5) and sample $\alpha$-B (EG14).

Fig. 2.16 Low angle XRD for sample $\alpha$-B.

Fig. 2.17 FTIR of sample $\alpha$-A and sample $\alpha$-B for $\alpha-\mathrm{Ni}(\mathrm{OH})_{2}$.

Fig. 2.18 TGA of (a) sample $\alpha$-A and (b) sample $\alpha$-B; XRD of (c) sample $\alpha$-A and (d) sample $\alpha$-B after TGA; FTIR of (e) sample $\alpha$-A and (f) sample $\alpha$-B after TGA.

Fig. 2.19 SEM image of sample $\alpha$-A.

Fig. 3.1: $\quad$ Temperature variation of magnetization of samples $\beta$-A and $\beta$ - $\mathrm{B}$ for $\mathrm{H}=100$ Oe. 
Fig. 3.2: $\quad$ Plots of inverse susceptibility vs. temperature for (a) sample $\beta$-A and (b) sample $\beta$-B.

Fig. 3.3: $\quad M(T)$ for sample $\beta$-B with $H=$ (a) 30, (b) 100, and (c) 500 Oe.

Fig. 3.4: $\quad$ Temperature variation of (a) $\chi \mathrm{T}$ and (b) $\frac{\partial(\chi \mathrm{T})}{\partial \mathrm{T}}$ for the data in Fig. 3.3.

Fig. 3.5: $\quad$ Temperature variation of (a) magnetization and (b) $\chi \mathrm{T}$ of sample $\beta$ - $\mathrm{A}$ for $\mathrm{H}=50$, 100, 200, 400, 500, 800, 1100, 1400, 1700, 2000, 20000, and 30000 Oe.

Fig. 3.6: (a) Plots of the computed $\frac{\partial(\chi \mathrm{T})}{\partial \mathrm{T}}$ using the data in Fig. 3.5 at different magnetic fields to determine $T_{1}$ and $T_{2}$; (b) applied magnetic field dependence of $T_{1}$ and $T_{2}$.

Fig. 3.7: $\quad$ AC susceptibility measurements for sample $\beta$-A (a) without an applied DC field and (b) with an applied DC field of $\mathrm{H}_{\mathrm{DC}}=500$ Oe.

Fig. 3.8: $\quad$ ZFC hysteresis loop at $\mathrm{T}=5 \mathrm{~K}$ for sample $\beta$-B.

Fig. 3.9: $\quad$ ZFC hysteresis loops at $\mathrm{T}=2,3,4,5$, and $7 \mathrm{~K}$ for sample $\beta$-A.

Fig. 3.10: $\quad$ ZFC hysteresis loops at $\mathrm{T}=10,11,13,15,16$, and $19 \mathrm{~K}$ for sample $\beta$-A.

Fig. 3.11: $\quad$ ZFC hysteresis loops at $\mathrm{T}=20,22,25,28$, and $34 \mathrm{~K}$ for sample $\beta$-A.

Fig. 3.12: $\quad \mathrm{FC}(\mathrm{H}=25 \mathrm{kOe})$ hysteresis loops at $\mathrm{T}=2,4,6,8,10,12$, and $14 \mathrm{~K}$ for sample $\beta$-A.

Fig. 3.13: $\quad \mathrm{FC}(\mathrm{H}=25 \mathrm{kOe})$ hysteresis loops at $\mathrm{T}=16,18,20,22,24$, and $26 \mathrm{~K}$ for sample $\beta$-A.

Fig. 3.14: Temperature dependence of the coercivity and exchange bias for sample $\beta$-A while cooling it in $\mathrm{H}=0$ Oe (ZFC) and in $\mathrm{H}=25 \mathrm{kOe}(\mathrm{FC})$.

Fig. 3.15: Temperature variation of the remanence $\mathrm{M}_{\mathrm{r}}$ from the hysteresis loops of Fig. $3.9-$ 3.13 .

Fig. 3.16: Magnetic field dependent magnetization and susceptibility for sample $\beta$-A acquired at WVU and taken at temperatures $\mathrm{T}=2,4,6,8,11,14,17,20,21,22$, 23 , and $24 \mathrm{~K}$.

Fig. 3.17: $\quad \mathrm{M}(\mathrm{H})$ and $\chi(\mathrm{H})$ for sample $\beta$-B obtained at $\mathrm{WVU}$ and taken at temperatures $\mathrm{T}=5$, $10,14,18,21$, and $24 \mathrm{~K}$.

Fig. 3.18: $\quad \chi(\mathrm{H})$ for sample $\beta$-A acquired at NHMFL from 0 to $180 \mathrm{kOe}$ at temperatures $\mathrm{T}=0.5,0.6,0.75,2,5,6,8,9,10,11,12.5$, and $14 \mathrm{~K}$.

Fig. 3.19: The NHMFL data at $\mathrm{T}=2 \mathrm{~K}$ after cleaning the noise in (a) $\chi(\mathrm{H})$ and (b) $\mathrm{M}(\mathrm{H})$. The WVU data is shown for the normalization of the NHMFL magnetization. 
Fig. 3.20: $\quad$ Normalized critical magnetic fields for (a) sample $\beta$-B and (b) sample $\beta$-A. (c) Schematic representation of the evolution of the system from antiferromagnetic to ferromagnetic with an applied magnetic field.

Fig. 4.1 Preliminary temperature dependent magnetization data for sample $\alpha$-A.

Fig. 4.2 Thermal variation of magnetization for sample $\alpha$-A.

Fig. 4.3 Thermal variation of magnetization for sample $\alpha$-B.

Fig. 4.4 Temperature dependence of $\mathrm{M}(\mathrm{ZFC})$ in different applied magnetic fields: $\mathrm{H}=20$, $50,100,150,200,250,300,350,400,450,500,600,700,800,1200$, and 1800 Oe. The inset shows the $\mathrm{H}$ dependence of $\mathrm{T}_{\mathrm{p}}$.

Fig. 4.5 Temperature dependence of $\chi \mathrm{T}$ and ${ }^{\partial}(\chi \mathrm{T}) / \partial \mathrm{T}$ for different $\mathrm{H}$ using the data in Fig. 4.4 .

Fig. 4.6 Magnetic field dependence of the three characteristic temperatures $T_{1}, T_{0}$, and $T_{2}$, defined in Fig. 4.5.

Fig. 4.7 Magnetic field variation of magnetization at differing temperatures of $\mathrm{T}=2,10$, $15,120,220$, and $320 \mathrm{~K}$.

Fig. 4.8 Magnetic field variation for sample $\alpha$-B of magnetization at $T=$ (b) 2, 3, 4, 5, 6, (a) $9,12,15$, and $18 \mathrm{~K}$ and (c) magnetic susceptibility at $\mathrm{T}=2,3,4,5$, and $6 \mathrm{~K}$.

Fig. $4.9 \quad 1 / \mathrm{H}$ vs. $\mathrm{T}$ for sample $\alpha-\mathrm{A}$ at $\mathrm{T}=2 \mathrm{~K}$. $\mathrm{M}_{\mathrm{S}}$ is determined when $1 / \mathrm{H} \rightarrow 0$.

Fig. 4.10 Low magnetic field variation of magnetization at $\mathrm{T}=4,5,6,7,8,9,10,12,14$, and $16 \mathrm{~K}$.

Fig. 4.11 Magnetic field variation of susceptibility $\left(\chi=\frac{\partial \mathrm{M}}{\partial \mathrm{H}}\right)$ at different temperatures. The inset shows the temperature variation of the critical field $\left(\mathrm{H}_{\mathrm{C}}\right)$.

Fig. 4.12 Hysteresis curves at $\mathrm{T}=2,3,4$, and $5 \mathrm{~K}$.

Fig. 4.13 Hysteresis curves at $\mathrm{T}=6,7,8$, and $9 \mathrm{~K}$.

Fig. 4.14 Hysteresis curves at $\mathrm{T}=10,11,12,13$, and $15 \mathrm{~K}$.

Fig. 4.15 Exchange bias curves cooling in $\mathrm{H}=5 \mathrm{kOe}$ at $\mathrm{T}=2$, 4, and $6 \mathrm{~K}$.

Fig. 4.16 Exchange bias curves cooling in $\mathrm{H}=5 \mathrm{kOe}$ at $\mathrm{T}=8,10$, and $12 \mathrm{~K}$.

Fig. 4.17 Temperature variation of the coercivity $\mathrm{H}_{\mathrm{C}}$, and exchange bias $\mathrm{H}_{\mathrm{eb}}$ for sample $\alpha-\mathrm{A}$ in $\mathrm{ZFC}$ and $\mathrm{FC}(5 \mathrm{kOe})$. 
Fig. 4.18 AC susceptibility of sample $\alpha-\mathrm{A}$ at $\mathrm{H}_{\mathrm{DC}}=0,500,800$, and 2000 Oe with $\mathrm{f}=0.1$, 1.0, 100, 500, and/or $1000 \mathrm{~Hz}$.

Fig. 4.19 AC susceptibility of sample $\alpha-B$ at $H_{D C}=20,100$, and 800 Oe with $f=10$ and $550 \mathrm{~Hz}$.

Fig. 4.20 Curie - Weiss fit to $\chi^{-1}$ vs. T for sample $\alpha$-A.

Fig. 4.21 $\chi-\chi_{\mathrm{o}}$ for sample $\alpha$-A with $\mathrm{H}=50$ Oe. The high temperature data is fit to the HTS of Eq. (4.1). The inset shows the exact same fit to the $\left(\chi-\chi_{0}\right)^{-1}$ vs. T data.

Fig. 5.1 Temperature variation of magnetization for sample $\beta$-A and sample $\alpha$-A.

Fig. 5.2 $\mathrm{M}$ vs. $\mathrm{H}$ data for $\alpha-\mathrm{Ni}(\mathrm{OH})_{2}$ and $\beta-\mathrm{Ni}(\mathrm{OH})_{2}$ at $\mathrm{T}=2 \mathrm{~K}$.

Fig. 5.3 Hysteresis curves for both phases at low and higher temperatures.

Fig. A.1 Temperature Programmed Reduction of sample $\beta$-A. 


\section{LIST OF TABLES}

Table 2.1 Average size of both $\beta$ samples from XRD patterns.

Table 2.2 Theoretical line positions.

Table 4.1 Leading coefficients of HTS. 


\section{CHAPTER I}

\section{Introduction}

Nickel(II) hydroxides, viz. $\alpha-\mathrm{Ni}(\mathrm{OH})_{2}$ and $\beta-\mathrm{Ni}(\mathrm{OH})_{2}$, belong to a unique class of materials known as layered hydroxide metals (LHM) in which the metal atoms are confined to the c-plane layers in the hexagonal structure. There is a great deal of interest in LHMs due to the easy impregnation of organic, inorganic or biological molecules between the layers to alter their magnetic properties [Rabu \& Drillon, 2003] and to create multifunctional devices [Demessence, Rogez, \& Rabu, 2006]. The incorporation of these molecules leads to a longer spacing between the basal planes modifying the physical properties including electrochemical and magnetic properties. In addition, LHMs are also affected by size reduction from 3 dimensions (3D) to two dimensions (2D) and to zero dimensions (0D) in the case of nanoparticles [Brechignuc, Houdy, \& Lehmani, 2007]. The reduction of size increases the role of surface atoms whose fraction increases with the decrease in dimensions. These two effects, viz. molecular absorption and size, provide rich avenues for the control of the properties of LHMs.

\subsection{Electrochemical properties of nickel(II) hydroxide}

A major source of interest in nickel(II) hydroxide is because of their applications as a positive electrode material in secondary cells [Falk \& Salkind, 1969]. Most likely this results from the reaction:

$$
\beta-\mathrm{Ni}(\mathrm{OH})_{2}+(\mathrm{OH})^{-} \rightleftharpoons \mathrm{NiOOH}+\mathrm{H}_{2} \mathrm{O}+e^{-}
$$


Although the release of an electron is generally thought of as 1:1, not every mole of nickel(II) hydroxide provides a free electron due to a lack of pathways for the hydrogen to escape. With XRD simulation, electrochemical studies of the efficiency has been performed on stacking faults and disorder in $\beta-\mathrm{Ni}(\mathrm{OH})_{2}$ by Jayashree, Kamath, and Subbanna [2000], which showed an increase in the reversible discharge capacity from $180 \mathrm{mAh} / \mathrm{g}$ for crystalline $\beta-\mathrm{Ni}(\mathrm{OH})_{2}$ to $400 \mathrm{mAh} / \mathrm{g}$ for badly crystalline $\beta-\mathrm{Ni}(\mathrm{OH})_{2}$. More recently, Ramesh and Kamath [2008] reported an increase from $0.4 \mathrm{e} / \mathrm{Ni}$ in $\beta-\mathrm{Ni}(\mathrm{OH})_{2}$ to $0.9 \mathrm{e} / \mathrm{Ni}$ in $\beta-\mathrm{Ni}(\mathrm{OH})_{2}$ with stacking faults. Both studies attribute the increase in efficiency to more accessible hydrogen atoms caused by the disorder. Another factor into electrochemical performance is size effects. Kiani, Mousavi, and Ghasemi [2010] confirmed a $12 \%$ increase in the discharge capacity when the particle size is reduced from micron size to $18 \mathrm{~nm}$ of $\beta-\mathrm{Ni}(\mathrm{OH})_{2}$. This increase in capacity from micron to nanoparticles is likely due to the increase of surface area with active sites.

There are two known forms of $\mathrm{Ni}(\mathrm{OH})_{2}$ : stable $\beta-\mathrm{Ni}(\mathrm{OH})_{2}$ and less stable $\alpha-\mathrm{Ni}(\mathrm{OH})_{2}$ with larger inter-layer spacing. Although the theoretical capacitance of $\alpha-\mathrm{Ni}(\mathrm{OH})_{2}$ is almost double compared to the traditional $\beta-\mathrm{Ni}(\mathrm{OH})_{2}$, it still has two major disadvantages: (i) it spontaneously converts to the $\beta$-form in a strong alkali solution and (ii) its density is lower than that of $\beta-\mathrm{Ni}(\mathrm{OH})_{2}$, which negates the increase in capacitance. The conversion of $\alpha-\mathrm{Ni}(\mathrm{OH})_{2}$ to $\beta-\mathrm{Ni}(\mathrm{OH})_{2}$ has been prevented by doping $\alpha-\mathrm{Ni}(\mathrm{OH})_{2}$ with aluminum [Dai, Li, Xiao, Wang \& Reisner, 2000] and yittrium [Ren, Zhou, Gao, \& Yan, 2006]. However, with the increase in stabilizing agents, the gain of discharge capacitance from $\beta-\mathrm{Ni}(\mathrm{OH})_{2}$ is reduced. The use of $\alpha-\mathrm{Ni}(\mathrm{OH})_{2}$ may also allow incorporation of other organic compounds to increase the basal spacing. Cheng and Hwang [2009] used sodium dodecyl sulfate to increase the c-axis from $4.6 \AA$ to $24.7 \AA$ with a significant increase in electrochemical performance attributed to the 
accessibility of the $\mathrm{OH}^{-}$group in $\alpha-\mathrm{Ni}(\mathrm{OH})_{2}$. Although the stability of $\alpha-\mathrm{Ni}(\mathrm{OH})_{2}$ has improved, the problem of lower density has been briefly addressed by Wang, Luo, Parkhutik, Millan, and Matveeva [2003] by combining the $\alpha$-phase and $\beta$-phase to increase the capacitance while maintaining an intermediate density.

\subsection{Magnetic characteristics}

Magnetic ordering in concentrated magnetic materials is mainly classed into three categories: ferromagnetic (FM), antiferromagnetic (AFM), and ferrimagnetic. Ferromagnetic order occurs when all the spins tend to align parallel to each other below a characteristic ordering temperature (Curie temperature, $\mathrm{T}_{\mathrm{c}}$ ). Ferromagnetism is usually associated with having a spontaneous magnetization even without an applied magnetic field below $\mathrm{T}_{\mathrm{c}}$. Antiferromagnetism occurs when nearest neighbor spins interact in such a way as to align antiparallel to each other with equal magnitude on each spin below the Néel temperature $\mathrm{T}_{\mathrm{N}}$. In this case, the magnetization is zero even though there is magnetic ordering in the system. Ferrimagnetism results when nearest neighbor spins align antiparallel to each other while having different magnitudes, thus resulting in a spontaneous magnetization although somewhat weaker than that in the FM case. Even though these interactions are constant in temperature, the system exhibits properties of the magnetic ordering only below the ordering temperature because of the role of the thermal energy in disordering the system.

The magnetic properties of bulk $\beta-\mathrm{Ni}(\mathrm{OH})_{2}$ has been briefly discussed by Takada, Bando, Kiyama, Miyamoto and Sato [1966]; Miyamoto [1966]; Enoki and Tsujikawa [1975]; and Szytula, Murasik, and Balanda [1966]. Through these studies, $\beta-\mathrm{Ni}(\mathrm{OH})_{2}$ was found to be an 
antiferromagnet with alternating layers of $\mathrm{Ni}^{2+}$ spin up and spin down along the c-axis. This system also has a metamagnetic (spin-flip) transition to ferromagnetism near $55 \mathrm{kOe}$. However, there is little information about particle size effects in this system. The work presented in this dissertation will study size effects in $\beta-\mathrm{Ni}(\mathrm{OH})_{2}$.

Due to the layered structure of the metal hydroxides, magnetic properties can be changed based on the basal spacing between the metallic $\left(\mathrm{Ni}^{2+}\right)$ layers. In fact, Laget, Rouba, Rabu, Hornick, and Drillon [1996] successfully modified the magnetic properties of a sister compound, $\mathrm{Co}(\mathrm{OH})_{2}$, by tuning the interlayer spacing using select organic molecules. With the increase in interlayer spacing, more fundamental properties can be investigated including dimensional transitions [de Jongh, 1990]. With the use of interlayer modification, change in magnetism due to different interactions (ie exchange, superexchange, dipole-dipole, etc.) among the layers can also be investigated.

While the magnetic properties of $\beta-\mathrm{Ni}(\mathrm{OH})_{2}$ have been studied in some detail, $\alpha-\mathrm{Ni}(\mathrm{OH})_{2}$ has had only a few inconclusive reports. The first initial finding by Rouba, Rabu, Ressouche, Regnault, and Drillon [1996] showed $\alpha-\mathrm{Ni}(\mathrm{OH})_{2-\mathrm{x}}\left(\mathrm{NO}_{3}\right)_{\mathrm{x}}$ with $\mathrm{c}=6.9 \AA$ to have $1 \mathrm{D}$ and $2 \mathrm{D}$ ferromagnetic properties while the authors suggested that the system behaves as a disordered or spin glass system at low temperatures. A brief report showed $\alpha-\mathrm{Ni}(\mathrm{OH})_{2}$ with $\mathrm{c}=23 \AA$ to be consistent with a 2D ferromagnetic domain sheet system with a dipolar interaction between the layers [Kurmoo et al., 1999]. The intra-layer spacing was investigated using different anion species between the layers. The investigators did not see any relationship between the ordering temperature $\left(\mathrm{T}_{\mathrm{c}} \sim 17 \mathrm{~K}\right)$ and the c/a value [Taibi et al., 2002]. Although these initial studies give 
some indication of the magnetic ordering in $\alpha-\mathrm{Ni}(\mathrm{OH})_{2}$, more detailed examination are carried out here and described in detail in this dissertation.

\subsection{Outline of the Dissertation}

The rest of this dissertation is arranged as follows: the synthesis procedures of both bulk $\beta-\mathrm{Ni}(\mathrm{OH})_{2}$ and $\alpha-\mathrm{Ni}(\mathrm{OH})_{2}$ samples are presented in chapter II along with the characterization of these samples and $\beta-\mathrm{Ni}(\mathrm{OH})_{2}$ nanoparticles obtained from Alfa Aesar through the use of powder x-ray diffraction (XRD), thermogravimetric analysis (TGA), infrared spectroscopy (IR), transition electron microscopy (TEM), and scanning electron microscopy (SEM). Chapter III gives details of the magnetic properties of bulk and nanoparticles of $\beta-\mathrm{Ni}(\mathrm{OH})_{2}$ obtained through the use of the in-house superconducting quantum interference device (SQUID) magnetometer and the use of the high 18 Tesla magnetometer from the National High Magnetic Field Laboratory (NHMFL) at Florida State University. Discussion of the results is described after the experimental data. These results show a clear indication of the effects of particle size and sample morphology on the magnetic properties. Chapter IV gives experimental results and discussion of the magnetic properties of $\alpha-\mathrm{Ni}(\mathrm{OH})_{2}$ which shows a distinct difference from the nature of magnetic ordering in $\beta-\mathrm{Ni}(\mathrm{OH})_{2}$. Chapter $\mathrm{V}$ gives a direct comparison of the magnetic properties between the two phases of $\mathrm{Ni}(\mathrm{OH})_{2}$, summarizes the general results of this dissertation, and lists possible future studies. 


\section{CHAPTER II \\ Synthesis and Characterization}

\subsection{Introduction}

Before discussing the magnetic properties of $\beta-\mathrm{Ni}(\mathrm{OH})_{2}$ and $\alpha-\mathrm{Ni}(\mathrm{OH})_{2}$, it is essential to describe the procedure used in the synthesis and characterization of the sample for phase purity. The synthesis of nickel(II) hydroxide has been accomplished through many different techniques to get both phases and different sizes. In this work, the bulk-like sample of $\beta-\mathrm{Ni}(\mathrm{OH})_{2}$ was synthesized using hydrothermal techniques after precipitation, while nanosize sample was purchased from Alfa Aesar. The $\alpha-\mathrm{Ni}(\mathrm{OH})_{2}$ samples were prepared using a hydrothermal process described later in this chapter. After preparation of the samples, their chemical phases were determined using X-ray diffraction (XRD), thermogravimetric analysis (TGA), and Fourier-transform infrared spectroscopy (FTIR). The sample sizes are determined using a

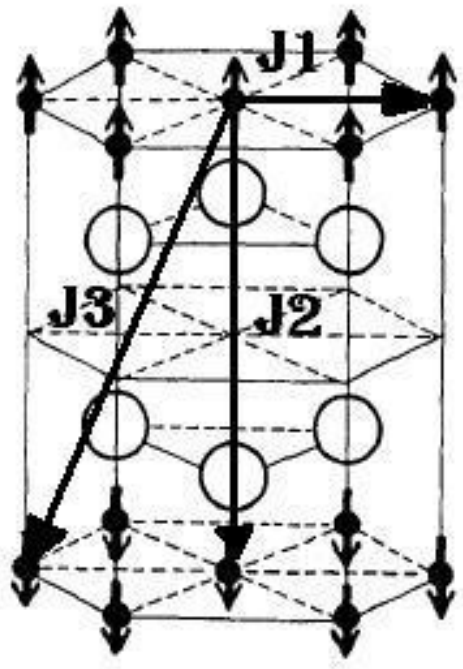
combination of XRD, transmission electron microscopy (TEM), and scanning electron microscopy (SEM). The basics of these techniques are described below before the results from characterizing the samples are presented.

Nickel(II) hydroxide crystallizes in the $\mathrm{CdI}_{2}$ structure (Fig. 2.1) and belongs to the layered hydroxide metals (LHM) [Poul,

Figure 2.1: $\mathrm{Ni}(\mathrm{OH})_{2}$ in the $\mathrm{CdI}_{2}$ structure. 
Jouini, \& Fiévet, 2000]. Due to the layering, these compounds are generally distinguished between two phases, viz. alpha $(\alpha)$ and beta $(\beta)$. The difference between the two phases is the elongated c-axis due to the intrinsic disorder in the $\alpha$-phase from the incorporation of anionic species between the layers. For $\alpha-\mathrm{Ni}(\mathrm{OH})_{2}, \mathrm{c}=8.2 \AA$ between the layers was obtained using nitrates [Genin, Delahaye-Vidal, Portemer, Tekaia-Elhsissen, \& Figlarz, 1991] while c $=24.7 \AA$ spacing between the layers was obtained using sulfate anions [Cheng \& Hwang, 2009]. This crystallite tunability has also been observed in other LHMs, such as $\mathrm{Co}(\mathrm{OH})_{2}$ [Laget et al., 1996]. However, with the incorporation of anionic species, the sample also contains many disorders which are also seen in non-metallic layered systems such as graphite [Babu \& Seehra, 1996; Seehra \& Pavlovic, 1993]. These disorders have been extensively studied using the DIFFaX program, which has been used to simulate $\mathrm{Mg}(\mathrm{OH})_{2}$ samples [Radha, Kamath, \& Subbanna, 2003] as well as $\mathrm{Ni}(\mathrm{OH})_{2}$ samples [Ramesh \& Kamath, 2008]. These studies have shown that stacking faults occur even in the "crystalline" form. The three main disorders are turbostraticity, interstratification, and stacking faults. Turbostraticity is the shifting from layer to layer such that the nickel atoms are not directly above each other. This broadens the $(k, k, 0)$ lines in the PXRD pattern. Interstratification is the random incorporation of water molecules between the layers. This effect tilts the layers affecting the c-parameter within the layers. Interstratification broadens the $(0,0, \ell)$ lines. Stacking faults is the random changes in the c-parameter between the layers, and it broadens the $(h, 0, \ell)$ reflections. Although these disorders are apparent in LHM samples, further investigation of these effects are not necessary for studying the magnetic properties. 


\subsection{Brief Description of Characterization Techniques}

Thermogravimetric analysis (TGA) does not only serve to determine the decomposition temperature, but it can also give percent composition of the material. For example, water percentage is determined from the decrease of weight around $100{ }^{\circ} \mathrm{C}$. In TGA a pan with the sample is heated at a given rate and the weight as a function of temperature is recorded. Typically the product of the result is determined using x-ray diffraction methods, and the initial composition and defects can be determined by reverse calculation. The decomposition of pure nickel(II) hydroxide to nickel(II) oxide, Eq. (2.1), in air is around $250{ }^{\circ} \mathrm{C}$ with a weight loss of $19.4 \%$ (appendix A).

$$
\mathrm{Ni}(\mathrm{OH})_{2} \underset{250^{\circ} \mathrm{C}}{\stackrel{\text { Air }}{\longrightarrow}} \mathrm{NiO}+\mathrm{H}_{2} \mathrm{O}(\mathrm{g})
$$

$\mathrm{X}$-ray diffraction (XRD) is used to determine many physical properties including crystal structure and particle size. Before describing these calculations, the production of $\mathrm{x}$-rays to obtain the pattern is discussed. X-rays are produced using a x-ray tube in which a typical wavelength spectra is shown in Fig. 2.2 from a copper cathode ray tube. The x-ray tube (Fig. 2.3) consists of three main parts, the filament, the accelerating grid, and the anode. Electrons are

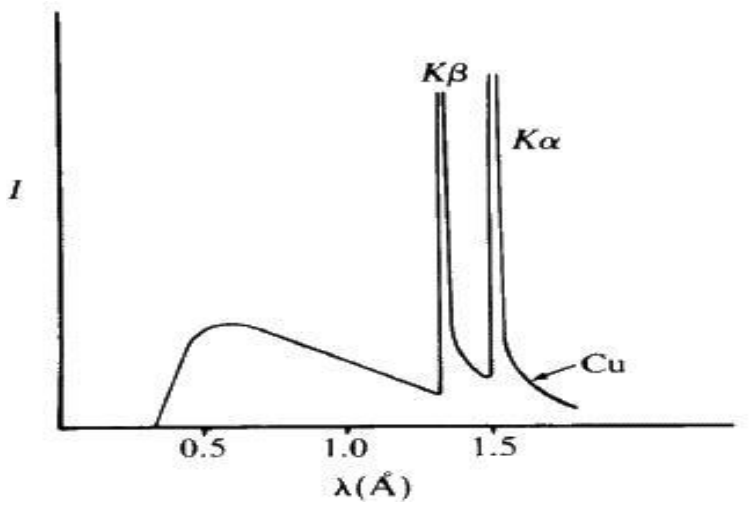

Figure 2.2: X-ray spectrum from a copper cathode ray tube.

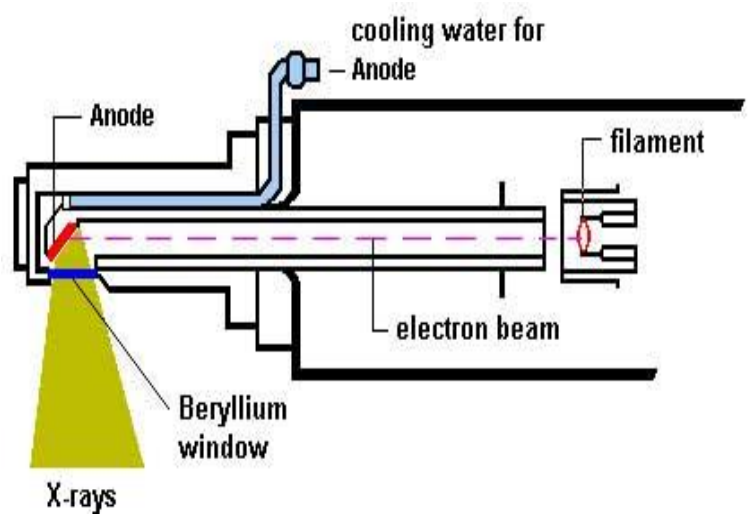

Figure 2.3: X-ray tube diagram [Scholtz, 2000]. 
ejected from the filament because of the current, I, being supplied to the filament. The free electrons from the filament pass through the accelerating grid which has a voltage difference with the anode, V. The electrons are accelerated to the anode and strike the anode with energy, eV. The electrons go through two processes when hitting the anode: (i) scattering and (ii) electron emission from the anode. The energy released through the scattering of the incoming electrons depends on the angle of incidence and can range from zero to the maximum energy allowed, eV. The energy due to scattering is emitted through the form of heat in the anode and emission of x-rays. Since the heat constitutes $\sim 98 \%$ of this energy, water cooling is needed to prevent damage to the anode. The x-rays $(\sim 1-2 \%)$ given off by this process will have wavelengths relating to zero and maximum energy through Eq. (2.2).

$$
E=\frac{h c}{\lambda}, \lambda=\frac{h c}{E}=\frac{h c}{e V}
$$

The minimum wavelength corresponds with the maximum energy while there is no upper limit to the wavelength. This scattering process is responsible for the continuous nature of the spectra given off. The incoming electron can also lose its energy by removing the inner shell electrons. This excited state will quickly rearrange to the ground state by replacing the vacancy with a higher shell electron and emit radiation in the form of $\mathrm{x}$-rays. This process results in the sharp lines in the spectrum seen in Fig. 2.2 and is only dependent on the target material. The Rigaku XRD machine uses a copper anode with a current of $30 \mathrm{~mA}$ and a voltage of $40 \mathrm{kV}$ resulting in $\lambda_{\min }=0.31 \AA, K_{\alpha}=1.54185 \AA$, and $K_{\beta}=1.39217 \AA$.

XRD patterns give information on the lattice, crystal structure, and particle size of the powder. The overall lattice structure of the sample determines the position of the XRD pattern lines. The intensity of these lines depends both on the elemental atom and the positional 
arrangement of these atoms within the unit cell. In fact due to the position of certain atoms in the unit cell, certain lines may disappear $(\mathrm{I} \sim 0)$. From these intensities and peak positions, the crystal structure can be determined accurately. Although the intensity of the peaks depends on the crystal structure, the broadening of these peaks depend both on the grain size and the disorders described above. The size broadening is described by the Williamson-Hall equation [Williamson \& Hall, 1953]:

$$
\beta_{\text {ukt }} \cos \theta=\frac{\mathrm{K}_{o} \lambda}{\mathrm{L}_{\text {abe }}}+\eta \sin \theta
$$

with $\beta$ being the full width at half maximum (FWHM) in radians corrected for instrumental broadening, $\theta$ the angle at which the peak occurs, $\lambda$ the wavelength of the $\mathrm{x}$-rays used, $\mathrm{K}_{\mathrm{o}}$ a constant, $\eta$ the stress/strain in the sample, and $\mathrm{L}_{k \ell \ell}$ the sample length along the $(k k \ell)$ direction. Typically $\mathrm{L}_{\text {kh }}$ is determined by plotting $\beta \cos \theta$ vs. $\sin \theta$. However, for nickel(II) hydroxide samples with the hexagonal lattice, $\mathrm{K}_{\mathrm{o}}$ differs between the in-plane and out-of-plane reflection lines. This reduces the number of peaks where the typical determination of $\mathrm{L}_{\text {ake }}$ is not suitable. The broadening can also be used as an indication of the morphology through the non-uniform broadening between peaks and within the peaks. These differences will be discussed when examining the XRD patterns directly. 
Whereas XRD provides information on the particle size and crystal structure of a sample and TGA provides some information of the chemical formula of a material, these techniques are unable to determine the nature of different groups present in a sample. IR spectroscopy filled this gap by providing useful information on the chemical groups/elements present in our sample through their vibrational/bending frequencies. Even though the initial IR spectrographs cycled through wavelengths individually, more recently Fourier-Transform IR (FTIR) spectrometers make it easier and quicker to get the IR spectrum of a sample by measuring all wavelengths simultaneously. The typical FTIR spectrometer is shown in Fig. 2.4. Here the laser beam (a) goes through a beam splitter with one beam (b) going to a stationary mirror and the other beam (c) to a movable mirror. These two beams reflect off the mirrors and they $(\mathrm{d}, \mathrm{e})$ recombine to create a new beam at the

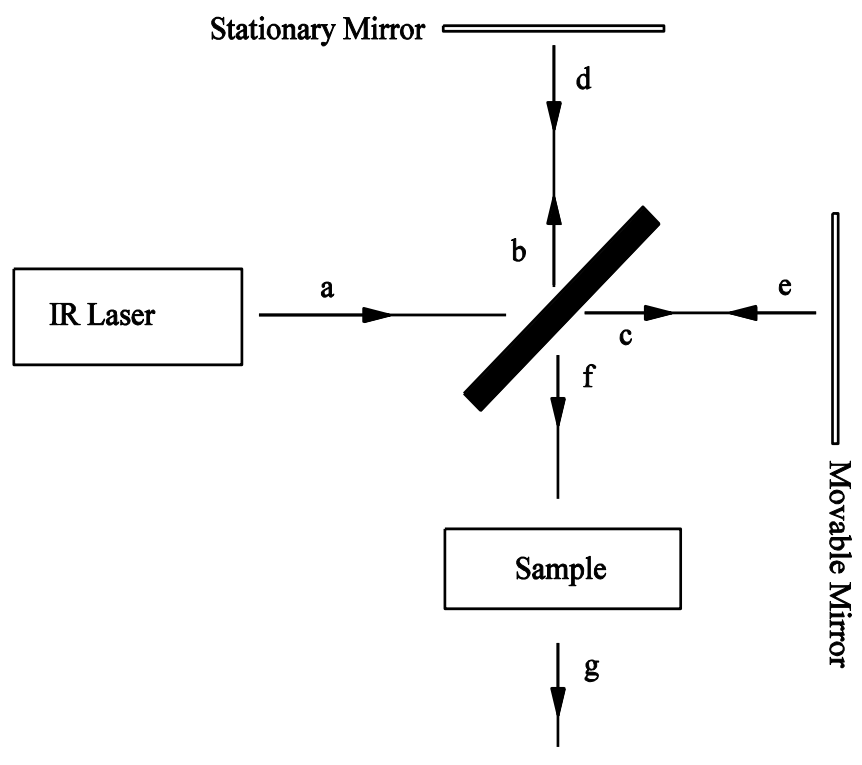
beam splitter. The beam (f) now

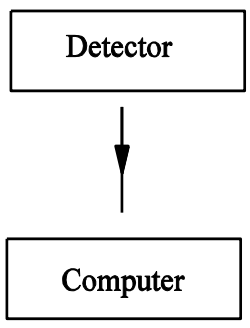
Figure 2.4: Typical FTIR setup. contains all $\lambda$ due to the wavelength differences by the movable mirror. This beam (f) travels through the sample where it loses energy to the sample then the beam $(\mathrm{g})$ continues to the detector. The detector sends the signal to the computer which performs the Fourier transform to obtain the spectrum. 
The simple harmonic model for the frequency of an IR mode is of a two mass system connected with a spring. The resonant frequency at which this system will vibrate Eq. (2.4) is related to both the spring constant $(\mathrm{k})$ and the reduced mass $(\mu)$.

$$
v=\frac{1}{2 \pi}\left(\frac{k}{\mu}\right)^{1 / 2}
$$

Therefore, the specific bond (ie single, double, triple, etc.) and atomic elements/compounds can be directly determined through FTIR. In fact, molecules can usually be distinguished between free floating and surface adsorbed molecules due to the changes in the reduced mass. The molecules can vibrate in two different modes. They can compress $(v)$ and bend $(\delta)$.

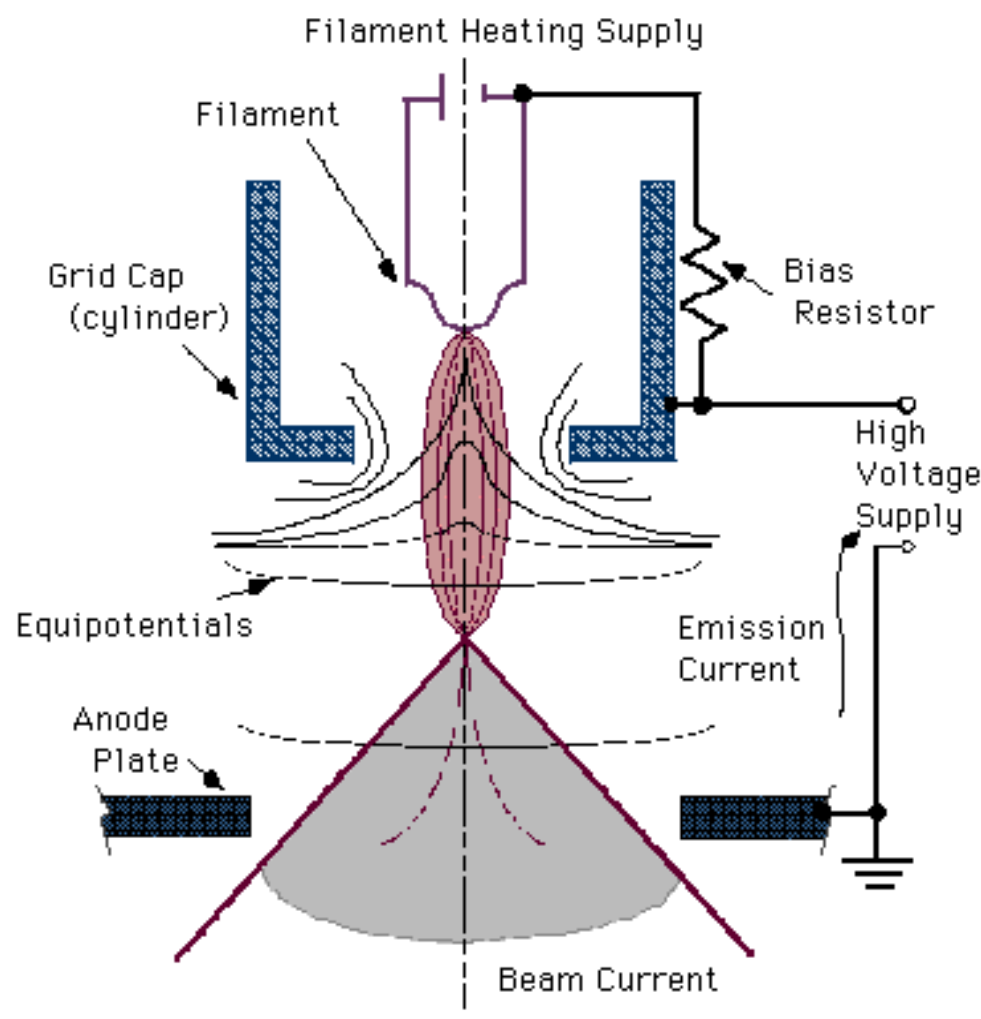

Figure 2.5: Electron gun diagram [Materials Science and Engineering Department].
Transmission electron microscopy (TEM) and scanning electron microscopy (SEM) are used to determine size, morphology, and phase purity. Both systems initially produce and focus electrons through an electron gun and electromagnetic lenses. The electron gun (Fig. 2.5) creates electrons from heating a filament where the electrons immediately undergo acceleration to the anode. After reaching the anode, the electrons are positioned in a 
uniform front toward the aperture which focuses the electrons to a single stream. From here, the electrons in TEM are projected onto the sample. After passing through the sample, the scattered and unaffected electrons are focused by an objective lens, which creates a 1:1 image of the sample. This image is then magnified using a projector lens to create the images usually observed for TEM. Between the objective and projector lens, an image of both the bright field and dark field regions can be obtained to determine crystal structure and phases similar to XRD [Owens \& Poole, 2008].

SEM consists of using the electron gun as the electron source, see Fig. 2.5. The stream of electrons from the electron gun passes through the magnetic lenses (scanning coil) to direct the electrons across the sample. The electrons reflect off the sample and the collected secondary electrons form the images typically seen (Fig. 2.6). Although the topography (images) are taken from the secondary electrons, there are other scattering mechanisms which produces other byproducts with differing information. These include x-rays (bulk composition), Auger electrons (surface composition), cathodoluminescence (electrical information), primary backscattered electrons (atomic and topographical) [mse.iastate.edu/microscopy].

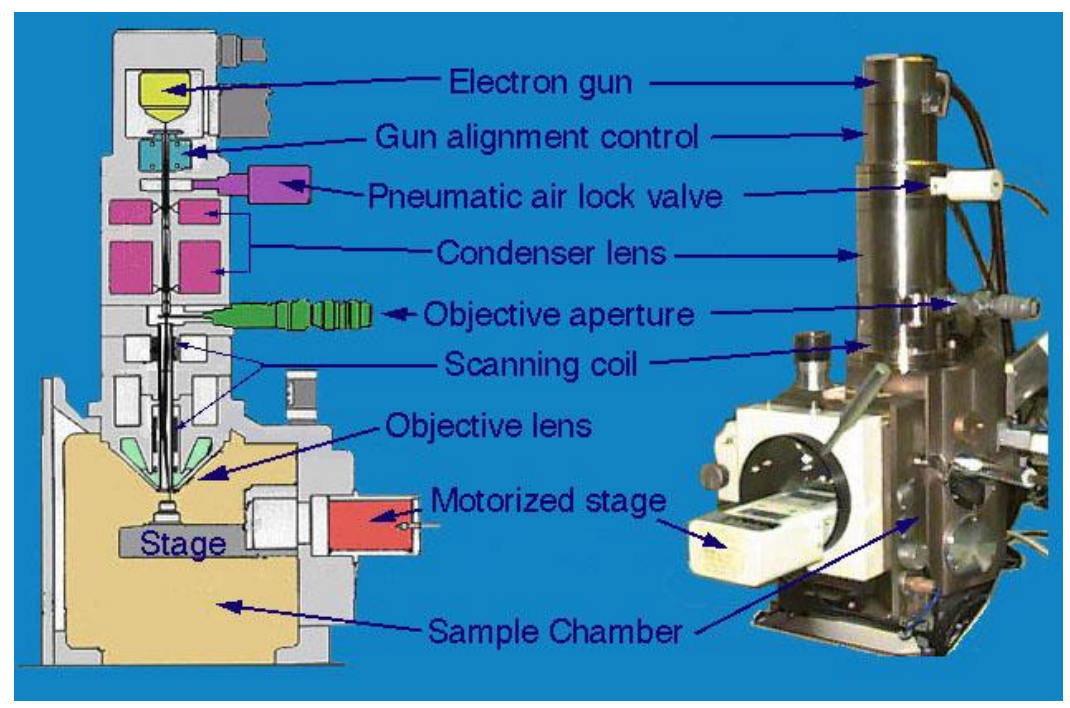

Figure 2.6: SEM column diagram [Materials Science and Engineering Department]. 


\subsection{Synthesis and Characterization of $\beta-\mathrm{Ni}(\mathrm{OH})_{2}$}

\subsubsection{Synthesis}

A commercial sample of $\beta-\mathrm{Ni}(\mathrm{OH})_{2}$ from Alfa Aesar was used without any modification to it (sample $\beta$-A). Sample $\beta$-B was prepared hydrothermally from a precipitated solution following the procedure described by Miyamoto [Miyamoto, 1976]. The precursor of sample $\beta$-B is obtained through precipitation of $4 \mathrm{M} \mathrm{NaOH}$ within aqueous solution of $0.1 \mathrm{M} \mathrm{Ni}\left(\mathrm{NO}_{3}\right)_{2}$ until $\mathrm{pH} \sim 14$ is reached, Eq. (2.5).

$$
\mathrm{Ni}\left(\mathrm{NO}_{3}\right)_{2}+2 \mathrm{NaOH} \rightleftharpoons \mathrm{Ni}(\mathrm{OH})_{2}+2 \mathrm{Na}\left(\mathrm{NO}_{3}\right)
$$

The calculations of the amount of each chemical used in the synthesis are given in appendix A. The precipitate and solution were transferred to a $300 \mathrm{ml}$ stainless steel autoclave by Parr Instruments. The solution and precipitate were heated to $310{ }^{\circ} \mathrm{C}$ and held at this temperature for four hours. The autoclave was then cooled to room temperature naturally. The precipitate was separated from the solution by centrifugation. The precipitate was washed twice with deionized water, once with ethanol, and dried at room temperature overnight. Fig. 2.7 shows the summary of synthesis of bulk-like $\beta-\mathrm{Ni}(\mathrm{OH})_{2}$ sample $\beta$ - $\mathrm{B}$. 


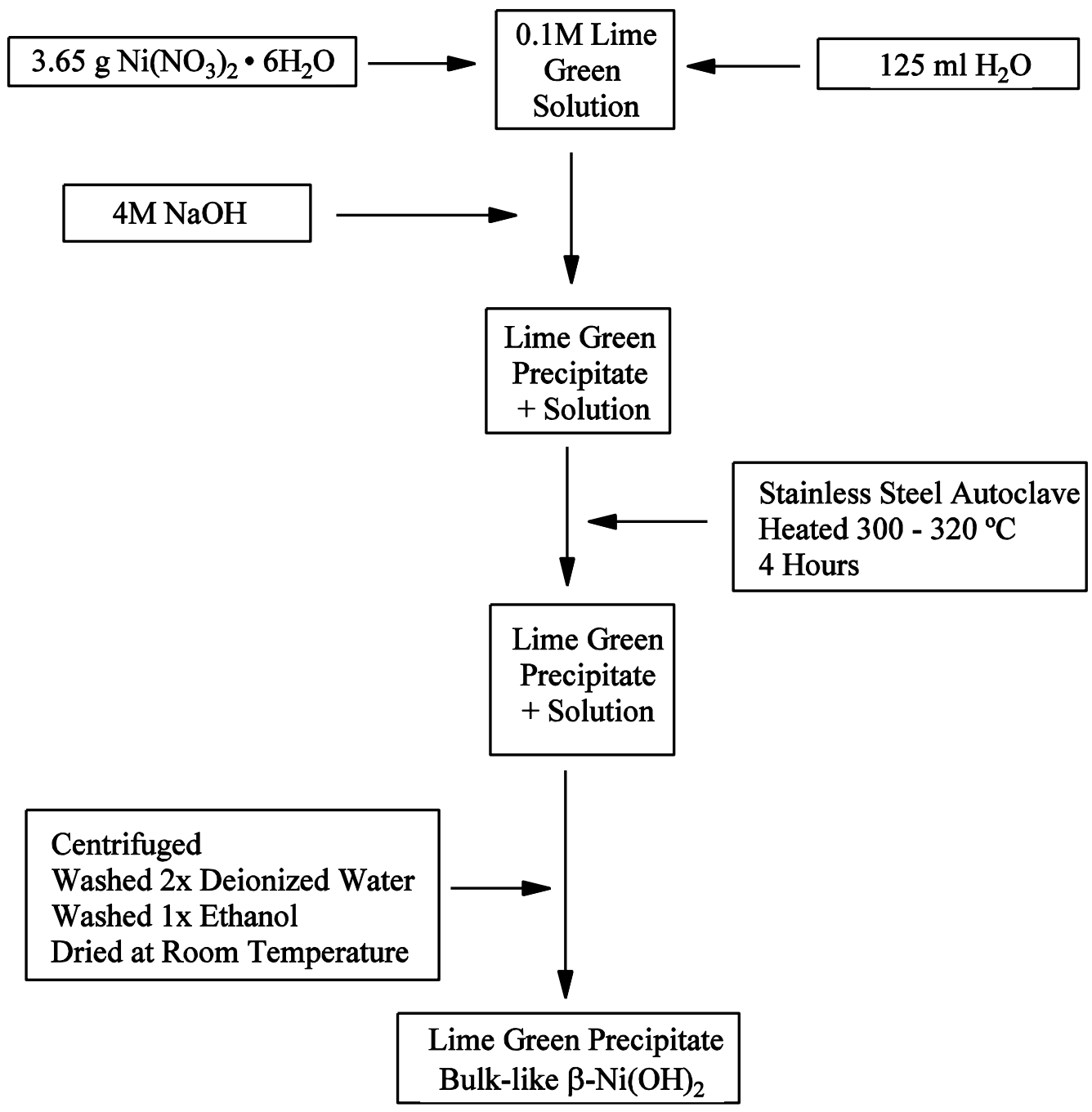

Figure 2.7: Summary of preparations for bulk-like $\beta$-Ni(OH $)_{2}$, sample $\beta$-B.

\subsubsection{Lattice and Crystal Structure}

XRD patterns of both samples are shown in Fig. 2.8. The position of the lines gives a hexagonal lattice with $\mathrm{a}=3.12 \AA, \mathrm{c}=4.67 \AA$. The crystal structure is known to form in a hexagonal lattice with two layers of hydroxyl groups between the nickels which are situated at the lattice points (Fig. 2.1). The broadening of the peaks in sample $\beta$-A is mainly due to the particle size effects of the powder with indication of non-uniformity of the particle morphology. 
The widths of the lines for sample $\beta$-B is attributed to instrumental and disorder inherent in the sample as discussed at the beginning of the chapter. Sample $\beta$-B is assumed to be bulk-like due to the narrow lines. In fact, the (003) line is resolved while also seeing an increased resolution of the (200), (103), and (201) lines. A lower estimate of the size will be evaluated later in this section. Both samples show no evidence of the $\alpha$-phase.

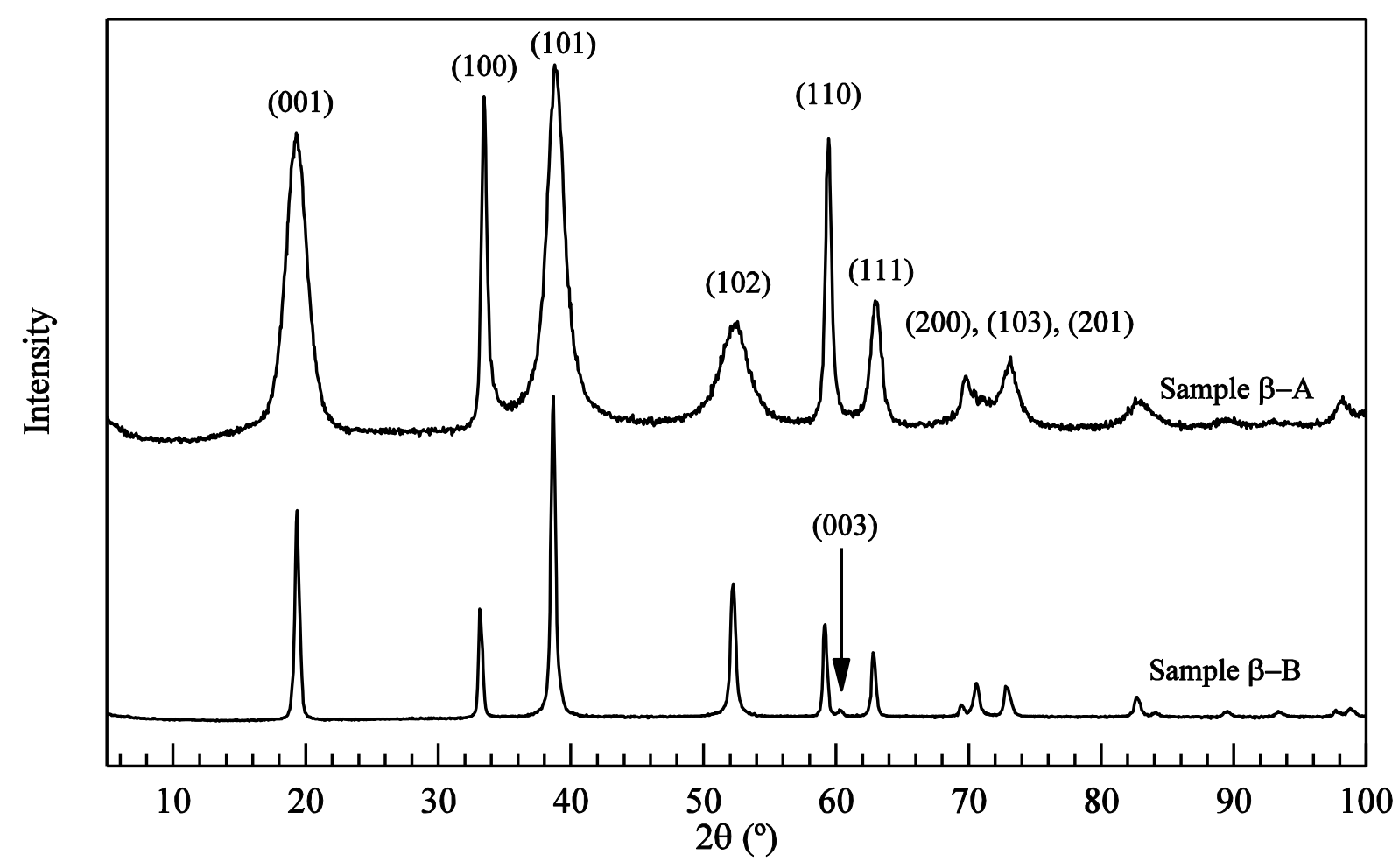

Figure 2.8: XRD pattern of sample $\beta$-A and sample $\beta$-B of $\beta-\mathrm{Ni}(\mathrm{OH})_{2}$.

Even though the $\beta$-phase is apparent from the XRD pattern, it does not provide any details of the possible defects or species present in the sample. The TGA of sample $\beta$-A and sample $\beta$-B is shown in Fig. 2.9 with a $5{ }^{\circ} \mathrm{C} / \mathrm{min}$ heating rate between $25-500{ }^{\circ} \mathrm{C}$ on a Mettler TG50 apparatus. The transition temperature is shifted slightly from sample $\beta$-A to sample $\beta$-B. The sample seems to go through 2 transitions from the initial phase through a weight loss near $100{ }^{\circ} \mathrm{C}$ and the larger weight loss between $250-270{ }^{\circ} \mathrm{C}$. The final product of both samples is characterized with XRD and shows the expected $\mathrm{NiO}$ byproduct. The inset shows the XRD of 
the end product of sample $\beta$-A. The $1.5-2.5 \%$ decrease between room temperature and $200{ }^{\circ} \mathrm{C}$ is attributed to surface water on the samples. This will be confirmed below with the FTIR results. For the 2.73 and $1.92 \%$ decrease would result in 0.144 and 0.101 moles of $\mathrm{H}_{2} \mathrm{O}$ to one mole of $\mathrm{Ni}(\mathrm{OH})_{2}$ for sample $\beta$-A and sample $\beta$-B, respectively (see appendix A).

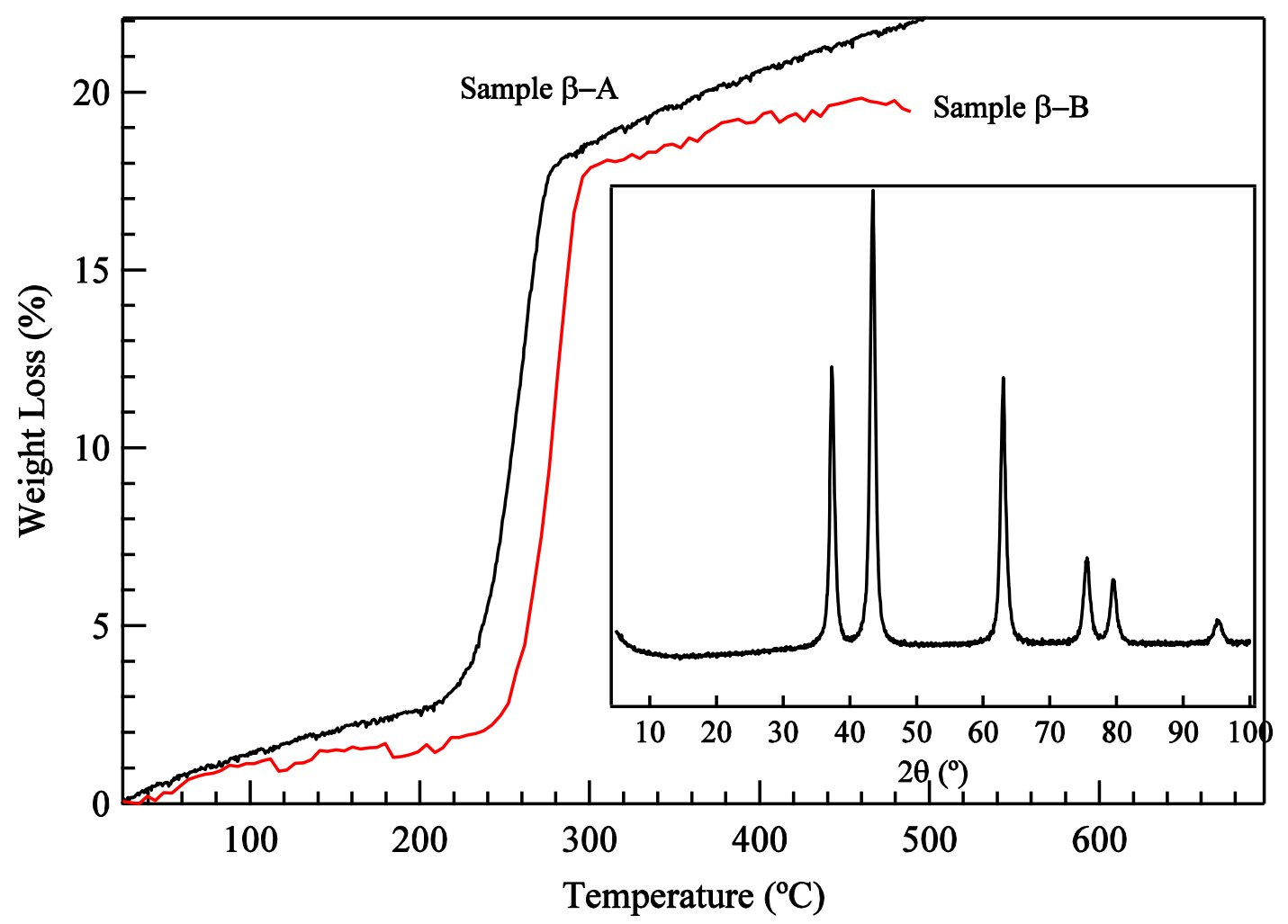

Figure 2.9: TGA results of sample $\beta$-A and sample $\beta$-B. Inset shows the XRD of the TGA resultant of sample $\beta$-A.

Although TGA indicates additional molecules present in the sample, it does not distinguish between different molecules. The temperature at which the weight loss takes place gives an indication of the molecules, and the infrared spectroscopy was used to verify the additional substances. FTIR was performed on both sample $\beta$-A and sample $\beta$-B (Fig. 2.10). The spectra observed from each sample are nearly identical. The increased broad water band around $3448 \mathrm{~cm}^{-1}$ indicates there is more water adsorbed on the surface of sample $\beta$-A. The IR bands can 
typically be assigned from the literature [Olivia et al,1982; Yang et al, 2007; Seehra, Roy, Raman, \& Manivannan, 2004]. The sharp $3633 \mathrm{~cm}^{-1}$ band is the stretching of the $\mathrm{OH}$ group $\left(v_{\mathrm{O}-\mathrm{H}}\right)$; the broad band centered around $3448 \mathrm{~cm}^{-1}$ and $1627 \mathrm{~cm}^{-1}$ from adsorbed water $\left(\delta_{\mathrm{H}_{2} \mathrm{O}}\right)$; the $1385 \mathrm{~cm}^{-1}$ band to Ni-O stretching $\left(v_{\mathrm{Ni}-\mathrm{O}}\right)$; the $547 \mathrm{~cm}^{-1}$ band to bending $\mathrm{OH}$ group $\left(\delta_{\mathrm{O}-\mathrm{H}}\right)$; and the $445 \mathrm{~cm}^{-1}$ band to Ni-O bending $\left(\delta_{\mathrm{Ni}-\mathrm{O}}\right)$. There is one unexplained $1026 \mathrm{~cm}^{-1}$ band which shows up in both samples. The IR spectra do not support the incorporation of any impurities other than the adsorbed water molecules on the surface of the samples. Combining with the analysis of TGA and FTIR, the samples are assigned a general molecular formula of $\beta$ - $\mathrm{Ni}(\mathrm{OH})_{2} \bullet n \mathrm{H}_{2} \mathrm{O}$ with $\mathrm{n}=0.144$ and 0.101 for sample $\beta$-A and sample $\beta$ - $\mathrm{B}$, respectively.

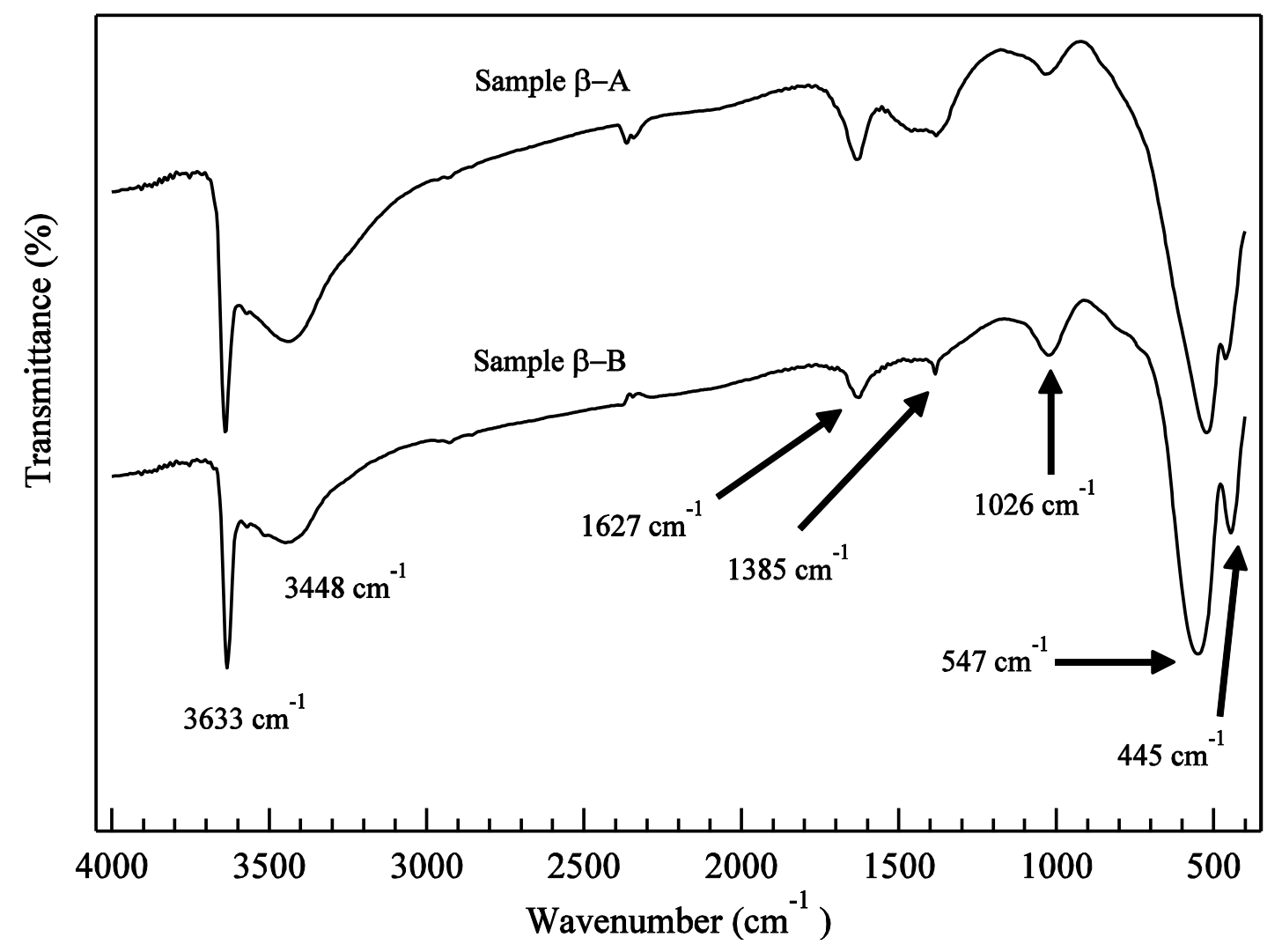

Figure 2.10: FTIR spectra of sample $\beta$-A and sample $\beta$-B in the KBr pellet form. See text above for IR band descriptions. 


\subsubsection{Sample Morphology and Particle Size}

The analysis given above provided both the phase and purity of the samples. However, full characterization of the samples includes shape (morphology) and size. This is usually done with two techniques: XRD pattern and TEM/SEM. The XRD pattern can determine the average size and suggest a possible morphology. The XRD pattern shown in Fig. 2.8 suggests a morphology of a platelet due to the non-uniform broadening between the $(00 \ell)$ and the (k00) lines. Since the (00€) lines are broader than the (k00) lines, it suggests the nanoplates are more wide than thick. The non-uniform broadening of the (100) line is due to the hexagonal layered structure and the stacking faults associated with the crystal structure. The average size can usually be obtained through the Williamson-Hall relation, Eq. (2.3), of more than 4 lines in the XRD pattern. However, for our XRD pattern we are unable to get the average size due to the lack

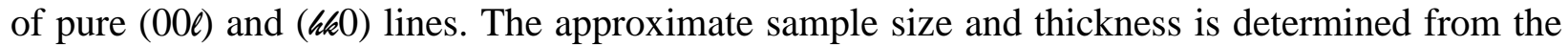
(100) and (001) line, respectively using only the first term in Eq. (2.3) viz. the Scherrer relation: $\mathrm{L}_{h\lfloor\ell}={ }^{\mathrm{K}_{O} \lambda} / \beta \cos \theta$. With hexagonal platelets, $\mathrm{K}_{\mathrm{o}}=0.90$ for the thickness of the nanoplates and $\mathrm{K}_{\mathrm{o}}=1.84$ for the diameter of the nanoplates [Klug \& Alexander, 1954 p. 690]. Table 2.1 summarizes the results of both samples $\beta-\mathrm{A}$ and $\beta-\mathrm{B}$.

\begin{tabular}{|l|l|l|l|l|l|}
\hline & $(001) \beta\left(^{\circ}\right)$ & $(100) \beta\left(^{\circ}\right)$ & $\begin{array}{l}\text { Instrumental } \\
\text { Broadening }\left(^{\circ}\right)\end{array}$ & $\begin{array}{l}\text { Thickness }(\mathrm{nm}) \\
\mathrm{L}=\end{array}$ & $\begin{array}{l}\text { Diameter }(\mathrm{nm}) \\
\mathrm{D} \simeq\end{array}$ \\
\hline Sample $\beta$-A & 1.84 & 0.502 & 0.177 & 4.4 & 36 \\
\hline Sample $\beta$-B & 0.390 & 0.332 & 0.177 & 24 & 72 \\
\hline
\end{tabular}


TEM was also used in order to more accurately determine the size and morphology of sample $\beta$-A through direct imaging. Fig. 2.11 shows the TEM images obtained with two differing magnifications. At higher magnifications, it is evident that sample $\beta$-A is in the form of hexagons (Fig. 2.11(a)) with a very thin thickness (Fig. 2.11(b)). The hexagons range between 30 $-50 \mathrm{~nm}$ with thicknesses between $2-4 \mathrm{~nm}$. These results are similar to the XRD estimates of sample $\beta$-A in Table 2.1. Although we are able to get a rough estimate of the sizes, an exact histogram of particle size distribution is unattainable due to the increase overlap of the individual nanoplates. From the c-axis size of $0.467 \mathrm{~nm}$ and the thickness of $2-4 \mathrm{~nm}$, the average number of layers contained in each nanoplate varies between 5 - 9 layers.

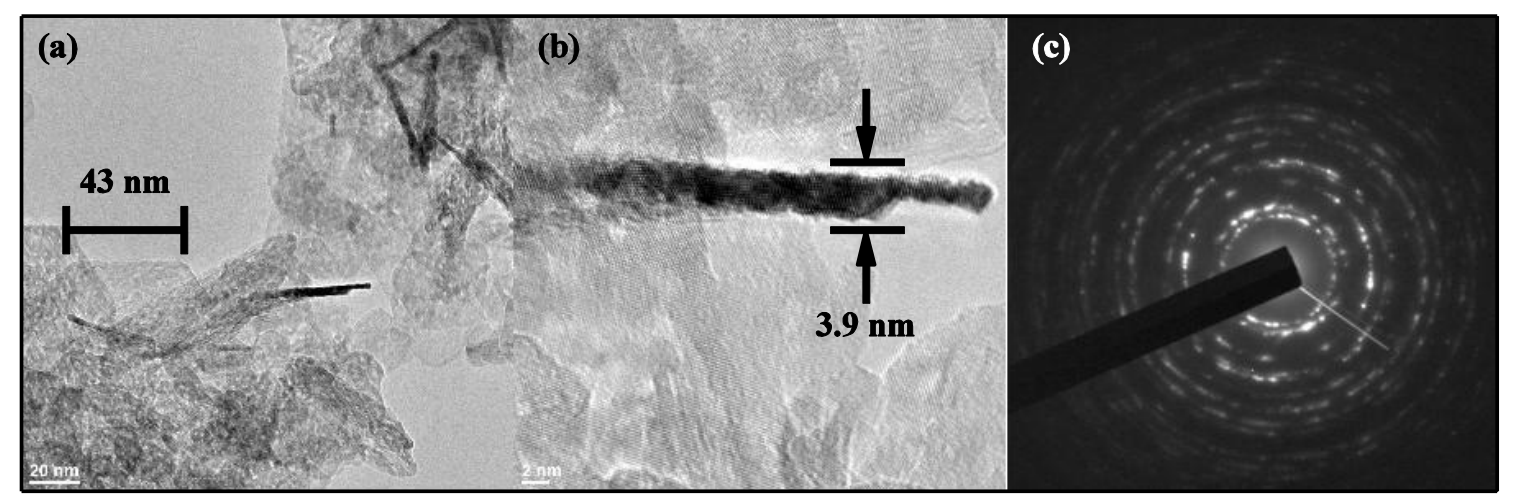

Figure 2.11: TEM images of sample $\beta$-A at magnifications (a) $100 \mathrm{kx}$, (b) $600 \mathrm{kx}$, and (c) SAED $300 \mathrm{kx}$.

\subsection{Synthesis and Characterization of $\alpha-\mathrm{Ni}(\mathrm{OH})_{2}$}

\subsubsection{Synthesis}

Synthesis of $\alpha-\mathrm{Ni}(\mathrm{OH})_{2}$ was done hydrothermally both with a vacuum oven (sample $\alpha-\mathrm{A}$ ) and with the stainless steel autoclave (sample $\alpha$-B) similar to the procedure described by Yang et al. [2007]. The samples were obtained by adding nickel acetate to heated ethylene glycol solvent. 


$$
\mathrm{Ni}\left(\mathrm{OOCCH}_{3}\right)_{2}+\mathrm{C}_{2} \mathrm{H}_{4}(\mathrm{OH})_{2} \rightleftharpoons \mathrm{Ni}(\mathrm{OH})_{2}+\mathrm{C}_{2} \mathrm{H}_{4}\left(\mathrm{OOCCH}_{3}\right)_{2}
$$

The homogeneous solution was then heated through the method outlined below. The green precipitate was centrifuged from the liquid, twice washed with deionized water, washed once with ethanol, and dried at room temperature overnight. Sample $\alpha$-A was heated in a vacuum oven until the lime green precipitate formed near $\mathrm{T} \sim 180{ }^{\circ} \mathrm{C}$. The precipitate and solution was then cooled to room temperature. Sample $\alpha-\mathrm{B}$ was heated in a $300 \mathrm{ml}$ capacity stainless steel autoclave by Parr Instruments to $\mathrm{T} \sim 170-190{ }^{\circ} \mathrm{C}$ for three hours. The autoclave was then cooled naturally to room temperature. Fig. 2.12 shows the summary of $\alpha-\mathrm{Ni}(\mathrm{OH})_{2}$ synthesis of sample $\alpha$-A and sample $\alpha$-B.

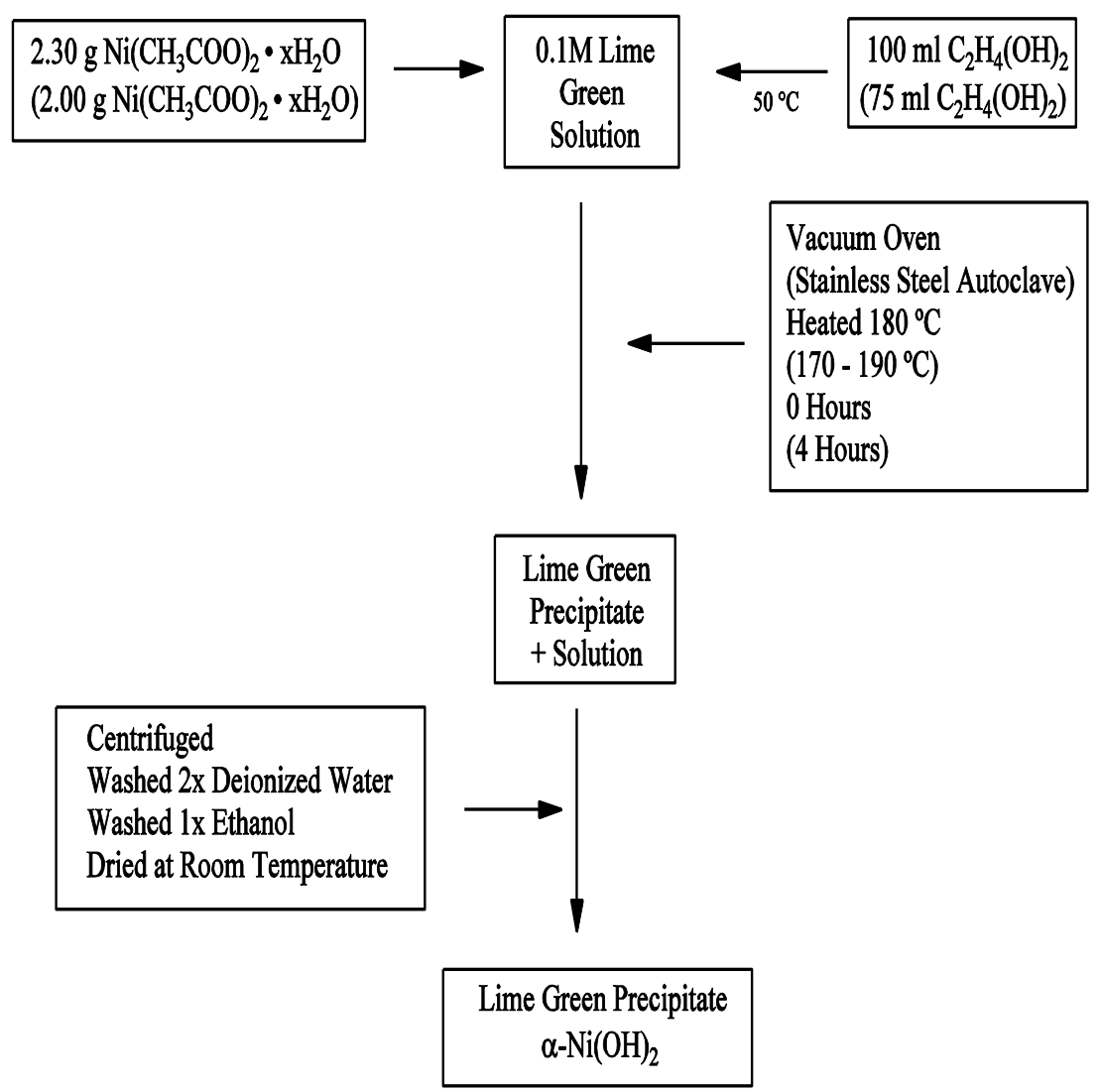

Figure 2.12: Synthesis procedure of $\alpha-\mathrm{Ni}(\mathrm{OH})_{2}$ for sample $\alpha$-A (sample $\alpha-\mathrm{B}$ ). 
Although the final heating temperatures and times are given, changing the conditions used in the synthesis gives interesting insight to the chemical route. Fig. 2.13 shows the progression while the sample was in the vacuum oven. EG2 was held at $200{ }^{\circ} \mathrm{C}$ for 1.5 hours. Although it shows the

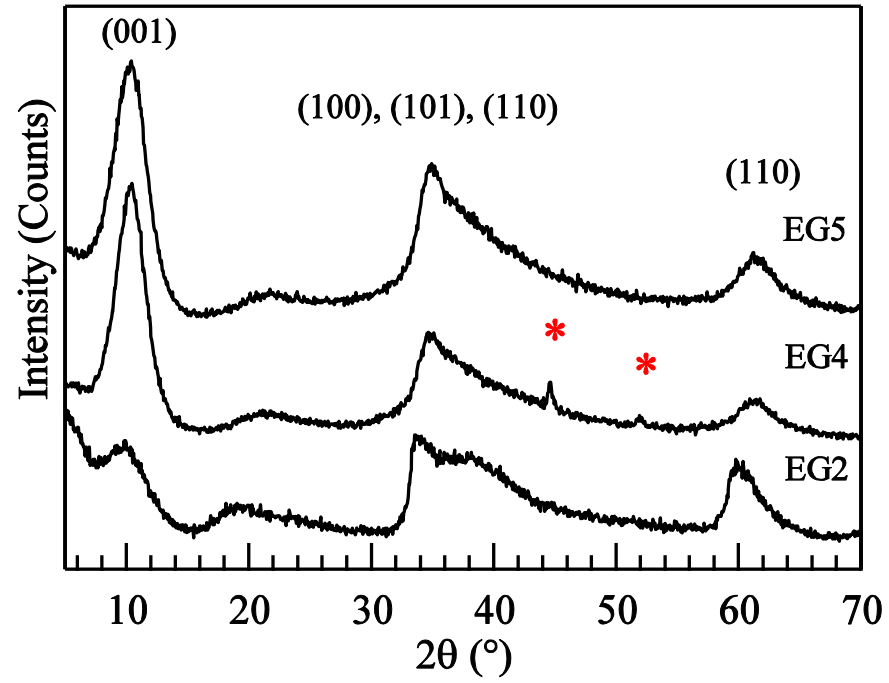
presence of $\alpha-\mathrm{Ni}(\mathrm{OH})_{2}$, the sample does not seem to be well structured because of Figure 2.13: Sample development while using the vacuum oven. See text for differing conditions.

the weak (001) line around $10^{\circ}$. EG4 was heated to $185{ }^{\circ} \mathrm{C}$ for 15 minutes and then cooled to room temperature. It indicates a slight presence of nickel at $44^{\circ}$ and $52^{\circ}$ marked with an asterisk (*). The final sample EG5 was prepared by heating the sample up until the precipitate forms then

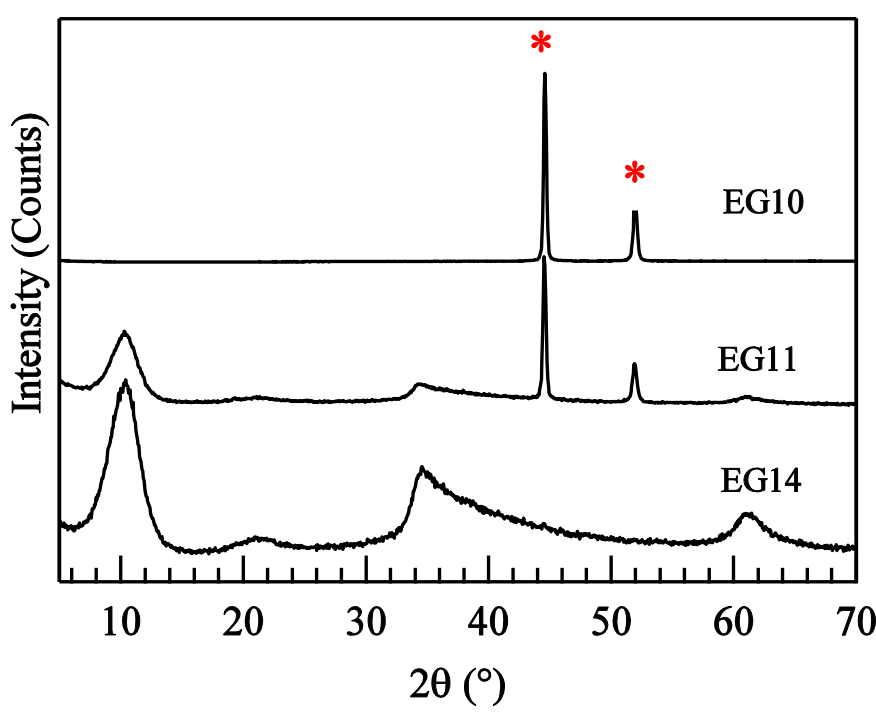

Figure 2.14: Sample progression using the stainless steel autoclave. See text for the different conditions. cooling to room temperature immediately and it shows a wellstructured sample with no nickel content.

The second batch of $\alpha-\mathrm{Ni}(\mathrm{OH})_{2}$ made was synthesized using the $300 \mathrm{ml}$ autoclave with a more accurate temperature gauge and pressure seal than the vacuum oven. The three samples shown in Fig. 2.14 were 
prepared under differing conditions, viz. time and temperature. EG10 was heated to $210{ }^{\circ} \mathrm{C}$ and held there for 2 hours, and it indicates the pure bulk-like form of nickel (*). EG11 was also heated at $200{ }^{\circ} \mathrm{C}$, but it was immediately cooled to room temperature after reading this temperature. The XRD pattern of EG11 shows the intermediate step of having both the nickel(II) hydroxide and nickel present. The final version, EG14, was heated in the range of $170-190{ }^{\circ} \mathrm{C}$ for 2 hours. The XRD pattern shows no indication of either pure nickel or the $\beta$-phase. Note should be taken that these trials indicate an unusual route to synthesizing pure nickel without the common intermediate of $\mathrm{NiO}$, which could create different morphology than the typical routes. Similar indications are made through the temperature programmed reduction of $\beta-\mathrm{Ni}(\mathrm{OH})_{2}$ (see appendix A).

\subsubsection{Lattice and Crystal Structure}

The two final samples used are EG5 (sample $\alpha$-A) and EG14 (sample $\alpha$-B). Fig. 2.15 shows the XRD patterns of these two samples. The main feature of these samples is the (001) and (002) lines near $10^{\circ}$ and $20^{\circ}$ respectively. Using Bragg's equation and the $(001) /(002)$ line position, the distance between the nickel atoms along the z-direction can be determined to equal $\mathrm{c}=8.6 \AA$, and $8.5 \AA$ for sample $\alpha$ - $\mathrm{A}$ and sample $\alpha-B$, respectively. The assignment of the (001) and (002) lines here are not the typical labels of (003) and (006) often found in the literature. There have been studies on sulfur infused $\alpha-\mathrm{Ni}(\mathrm{OH})_{2}$ which truly have $(003) /(006)$ lines around $10^{\circ}$ and $20^{\circ}$. These studies also provides low angle Bragg lines with indices (001), (002), (003), (004), (005), and

\begin{tabular}{|l|l|}
\hline Line & $2 \theta$ \\
\hline$(001)$ & 10.4 \\
\hline$(002)$ & 20.9 \\
\hline$(003)$ & 31.6 \\
\hline$(100)$ & 34.1 \\
\hline$(101)$ & 35.7 \\
\hline$(102)$ & 40.3 \\
\hline$(004)$ & 42.6 \\
\hline$(103)$ & 47.1 \\
\hline$(110)$ & 61.0 \\
\hline$(111)$ & 62.0 \\
\hline$(112)$ & 65.19 \\
\hline Table 2.2: & Theoretical \\
line positions.
\end{tabular}


(006) between $3^{\circ}-25^{\circ}$ [Cheng \& Hwang, 2009]. We do not see any of these lines either for low angles (Fig. 2.16) or in the regular XRD. Therefore our conclusion is that these lines should be labeled as (001) and (002). Using the only other semi-pure line of (110) to approximate the nickel spacing within the sheets, $\mathrm{a}=3.01 \AA$, and $3.03 \AA$ for sample $\alpha$-A and sample $\alpha$-B respectively, is obtained. Given the parameters a and c for the hexagonal lattice, all the position of the lines can be determined (Table 2.2). These theoretical values for line positions partly show the reason for the unusual behavior around $34^{\circ}$. This line is composed of several different lines of the (10€) family. The other nature of the broadened backside of the (100) and (110) lines are due to the random orientation between one sheet of nickel and the other sheet of nickel (known as turbostraticity) [Babu \& Seehra, 1996; Seehra \& Pavlovic, 1993].

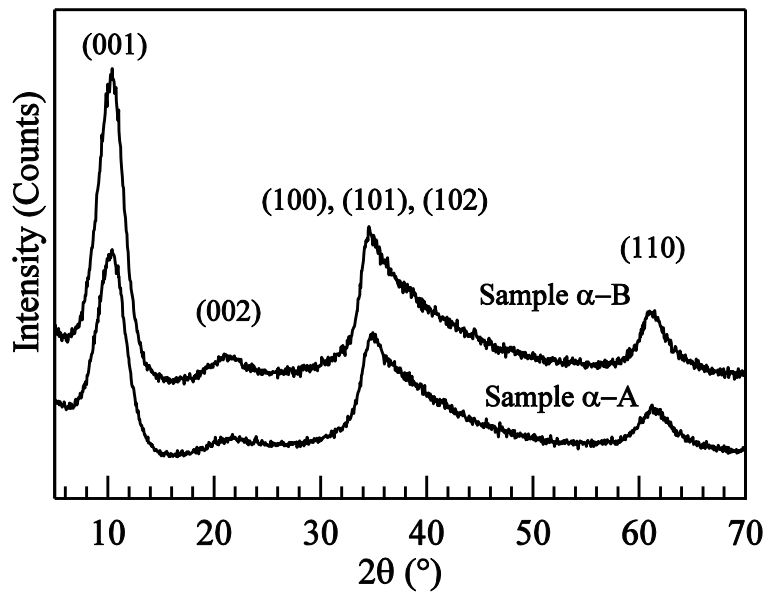

Figure 2.15: XRD pattern of sample $\alpha-A$ (EG5) and sample $\alpha-B$ (EG14).

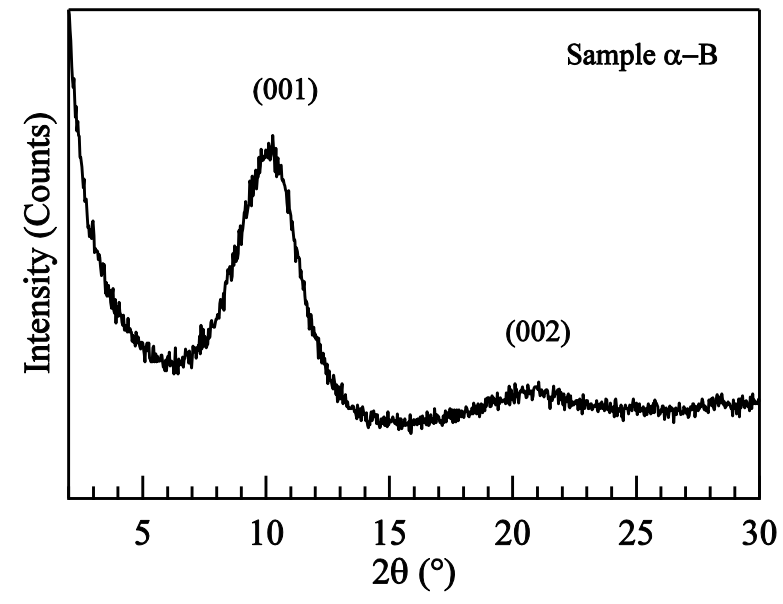

Figure 2.16: Low angle XRD pattern of sample $\alpha$-B.

The major difference between the two phases of $\mathrm{Ni}(\mathrm{OH})_{2}$ viz. $\beta-\mathrm{Ni}(\mathrm{OH})_{2}$ and $\alpha-\mathrm{Ni}(\mathrm{OH})_{2}$ is the difference in the c-axis due to the intercalation of ionic species in between the nickel layers. The intercalation usually takes place during synthesis of the samples. In our case, the 
synthesis consisted of nickel acetate as the starting material; therefore, one would assume to see acetate anions in the sample. Fig. 2.17 shows the transmittance FTIR spectra of the samples. The synthesis with nickel acetate has been widely used and documented [Taibi et al., 2002]. The typical bands for $\mathrm{OH}$ and $\mathrm{H}_{2} \mathrm{O}$ bonds are present and incorporated into the band around $3400 \mathrm{~cm}^{-1}\left(\delta_{\mathrm{H}_{2} \mathrm{O}}\right)$. The doublet seen at $2800 \mathrm{~cm}^{-1}\left(v_{\mathrm{C}-\mathrm{O}}\right)$ along with the triplet around $1400 \mathrm{~cm}^{-1}$ are known to be from the acetate anions present in the samples. The $\mathrm{OH}$ and $\mathrm{NiO}$ bond bending and stretching are seen at higher energies of $650 \mathrm{~cm}^{-1}$ and $450 \mathrm{~cm}^{-1}$ respectively. The doublet around $1100 \mathrm{~cm}^{-1}$ has been attributed to the presence of adsorbed ethylene glycol on the surface of the samples [Li et al., 2008]. Through FTIR data, the two samples have a formula of the form $\mathrm{Ni}(\mathrm{OH})_{2-x}\left(\mathrm{CH}_{3} \mathrm{COO}^{-}\right)_{x} \bullet n \mathrm{H}_{2} \mathrm{O}$, neglecting the surface ethylene glycol.

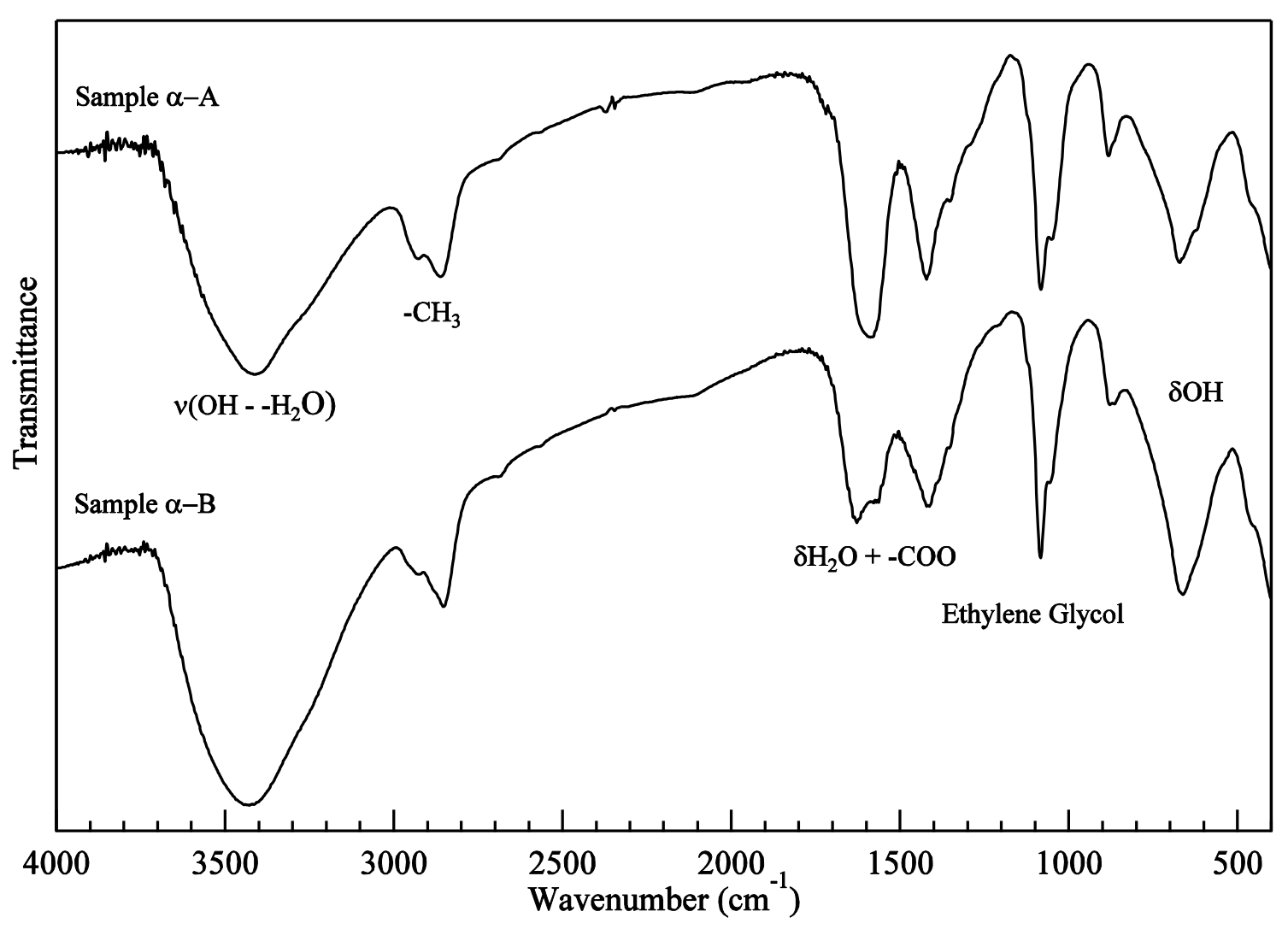

Figure 2.17: FTIR of sample $\alpha$-A and sample $\alpha$-B for $\alpha-\mathrm{Ni}(\mathrm{OH})_{2}$. 
Although the FTIR spectrum gives the composition of the samples, it does not provide information on the amount of each species in the sample which is usually done through TGA. The TGA curve, obtained with a heating rate of $3{ }^{\circ} \mathrm{C} / \mathrm{min}$, of sample $\alpha$-A and sample $\alpha$-B are shown in Fig. 2.18(a) and 2.18(b), respectively. The respective XRD and FTIR data are shown below the TGA in Fig. 2.18(c)/(d) and 2.18(e)/(f). Both samples show a prominent two step decomposition. The first step around $100{ }^{\circ} \mathrm{C}$ is attributed to burning off the water from the sample both within and on the surface of the sample. The second step around $260{ }^{\circ} \mathrm{C}$ is attributed to both burning of the acetate ions and decomposition to $\mathrm{NiO}$ [De Jesus, González, Quevedo, \& Puerta, 2005].

The XRD of the TGA sample byproducts show pure $\mathrm{NiO}$ without any indication of nickel hydroxide present. Note: the peak denoted with the asterick $(*)$ is due to the silica sample holder. The FTIR data of both samples are nearly identical showing an adsorbed water molecules on the surface around $3450 \mathrm{~cm}^{-1}$, a carbonate signature around $1600 \mathrm{~cm}^{-1}$ and $1024 \mathrm{~cm}^{-1}$, and the $\mathrm{Ni}-\mathrm{O}$ stretching at $450 \mathrm{~cm}^{-1}$. The adsorbed water could be due to the air moisture between the acquisition of the TGA data and the start of the FTIR data ( 3 days). The carbonate indication is also believed to be on the surface of the sample. However the adsorbed carbonate is believed to occur directly while the samples are being heated, resulting in a continual loss of weight in the sample above $275{ }^{\circ} \mathrm{C}$. It is important to note the lack of any indication of acetate in the samples after performing TGA on them. The molecular formula can be determined directly from the TGA data (appendix A). The molecular formula of the samples are determined to be $\mathrm{Ni}(\mathrm{OH})_{2-x}\left(\mathrm{CH}_{3} \mathrm{COO}^{-}\right)_{x} \bullet n \mathrm{H}_{2} \mathrm{O}$ with $\mathrm{x}=0.77(0.61)$ and $\mathrm{n}=1.41(1.23)$ for sample $\alpha$-A (sample $\alpha-B)$. 


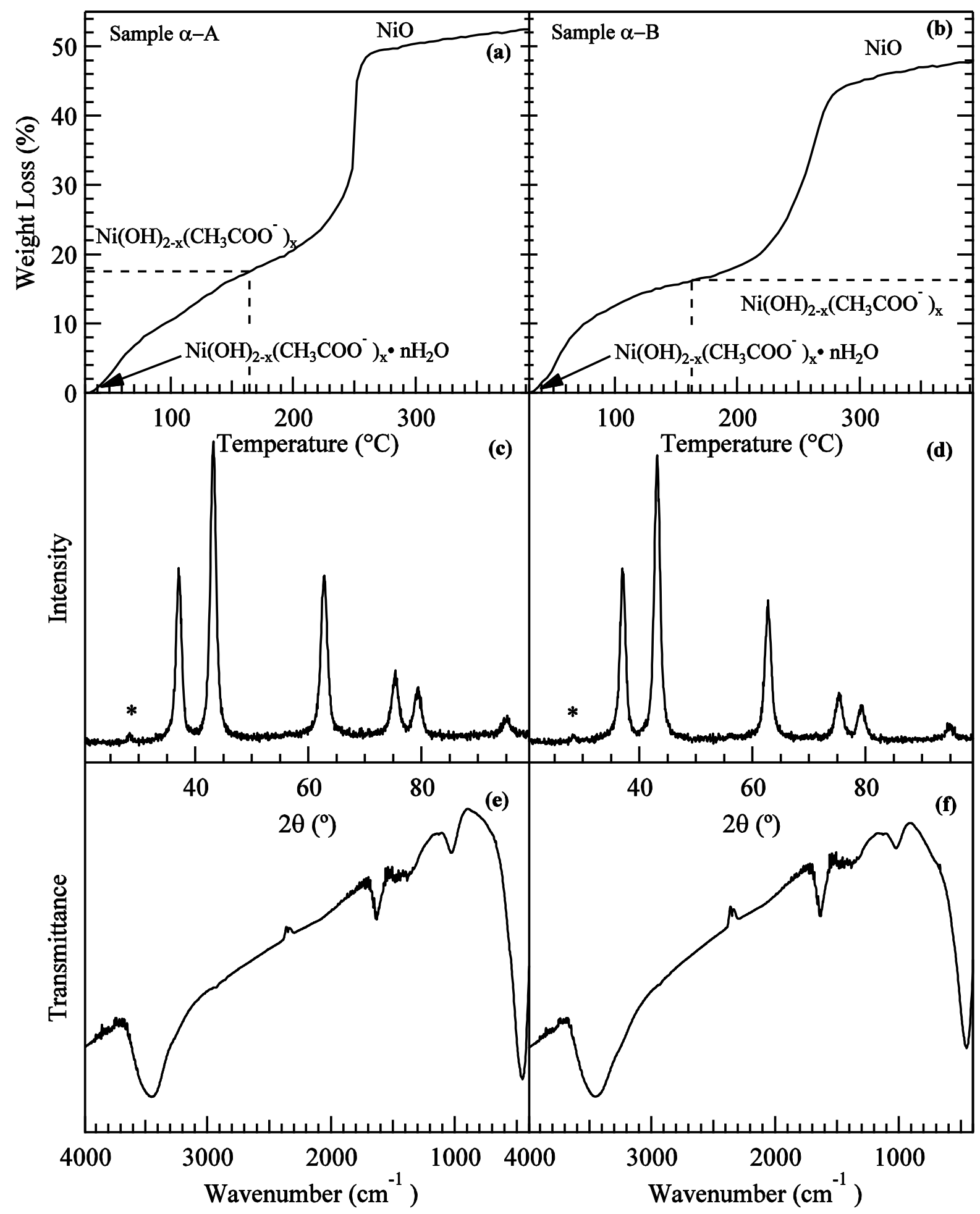

Figure 2.18: TGA of (a) Sample $\alpha$-A and (b) sample $\alpha$-B; XRD of (c) sample $\alpha$-A and (d) sample $\alpha$-B after TGA; FTIR of (e) sample $\alpha$-A and (f) sample $\alpha$-B after TGA. 


\subsubsection{Morphology and Size}

The XRD patterns shown in Fig. 2.15 give little indication of the particle morphology and size due to the merging of lines and non-uniform broadening of the (101) line. However assuming spherical morphology and using the pure (001) and semi-pure (110) lines, the sizes are estimated to be $3.0(3.2) \mathrm{nm}$ along the c-axis and $3.3(3.0) \mathrm{nm}$ along the layers for sample $\alpha$-A (sample $\alpha-B$ ).

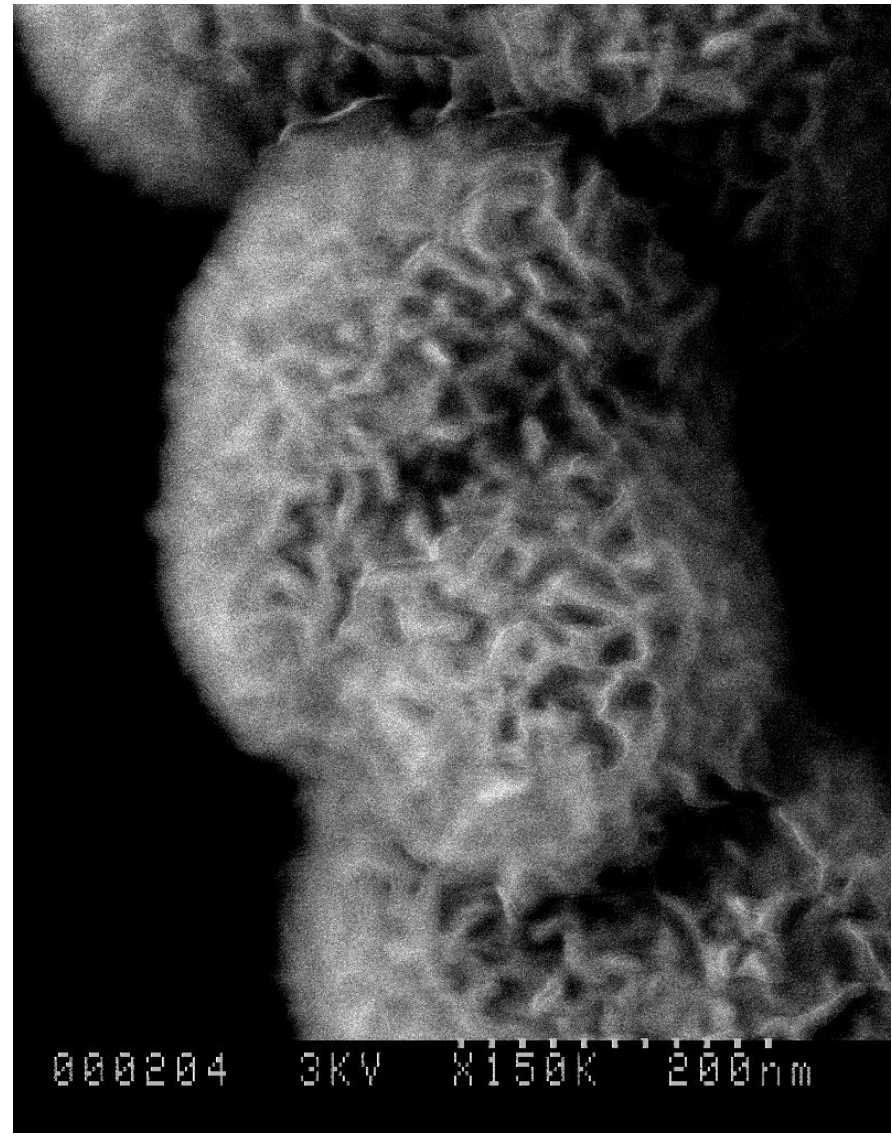

Figure 2.19: SEM image of sample $\alpha$-A.
The $\alpha-\mathrm{Ni}(\mathrm{OH})_{2}$ sample has a higher density due to particle-particle interactions resulting in a lack of transmission light when using the TEM. As a result, the morphology and sizes are estimated through the use of SEM. The particle morphology (Fig. 2.19) shows a clear petal structure clumped around a center. However, the SEM images do not provide evidence whether the center of these particles are core $\alpha-\mathrm{Ni}(\mathrm{OH})_{2}$ similar to a flower or the sheets of petals are continuous throughout the particle similar to crumpled paper. The particles are approximately $300-500 \mathrm{~nm}$ while the petal thicknesses are $\sim 10 \mathrm{~nm}$. The thicknesses using a SEM are not as accurate as TEM. Therefore it is difficult to say for certain the number of layers of Ni sheets in each petal. 


\section{CHAPTER III \\ Magnetic Properties of $\beta-\mathrm{Ni}(\mathrm{OH})_{2}$}

\subsection{Introduction}

The magnetic properties of $\beta-\mathrm{Ni}(\mathrm{OH})_{2}$ was first reported in 1966 by Takada et al. [1966]. They concluded bulk nickel(II) hydroxide to be antiferromagnetic ( $\mathrm{T}_{\mathrm{N}} \sim 30 \mathrm{~K}$ ) with spins aligning along the c-axis, dominant intra-planar ferromagnetism and weakly coupled interplanar antiferromagnetism. This conclusion was based on the positive Weiss constant $(\theta \sim 35 \mathrm{~K})$ and the metamagnetic behavior in $\mathrm{M}$ vs. $\mathrm{H}$ around $55 \mathrm{kOe}$. These findings and additional details were investigated by Miyamoto [1966]. The nature of spin order was further studied and confirmed directly with neutron scattering by Szytula et al. [1971]. Analysis of the magnetic measurements quantified the in-plane ferromagnetic and interplanar antiferromagnetic interactions as $J_{1} / k_{\mathrm{B}} \sim 2.7 \mathrm{~K}$, and $J_{2} / k_{\mathrm{B}} \sim-0.28 \mathrm{~K}$ respectively [Enoki \& Tsujikawa, 1975]. Analysis of the magnetic specific heat data by Enoki and Tsujikawa [1978] revealed a temperature dependent two step transition from low temperature antiferromagnetism to in-plane ferromagnetism and finally from ferromagnetism to paramagnetism with increase in temperature. Miyamoto also continued his study of nickel(II) hydroxide by changing particle size from 15 x $2.5 \mathrm{~nm}$ platelets to bulk samples. The size dependence changed some of the magnetic properties $\left(\mathrm{T}_{\mathrm{N}}, \theta\right.$, etc.) but the main difference occurred in the appearance of a second transition before the spin-flip transition [Miyamoto, 1976]. 


\subsection{Magnetic Measurements}

Magnetic measurements of sample $\beta$-A and sample $\beta$-B were performed with an in-house, referenced as WVU, SQUID (Superconducting Quantum Interference Device) magnetometer system with the RSO and AC susceptibility technique. Magnetization of sample $\beta$-A was also measured at the NHMFL (National High Magnetic Field Laboratory) in Tallahassee, FL with applied magnetic fields up to $180 \mathrm{kOe}$. The NHMFL measurements were taken using the AC susceptibility technique. The zero field cooled (ZFC) data shown here was taken by cooling the sample in the absence of a magnetic field to $2 \mathrm{~K}$. At $2 \mathrm{~K}$, a measuring magnetic field $(\mathrm{H})$ is applied and the measurements of $\mathrm{M}$ vs. $\mathrm{T}$ are taken by increasing the temperature from $2 \mathrm{~K}$ to $350 \mathrm{~K}$ while stabilizing the system at select temperatures. After reaching $350 \mathrm{~K}$, the field cooled $(\mathrm{FC})$ data is acquired similar to the $\mathrm{ZFC}$ data by cooling the sample in the measuring magnetic field $(\mathrm{H})$ to $2 \mathrm{~K}$. The magnetic field variation of magnetization is measured by cooling the sample in the absence of a field (ZFC) or in a magnetic field $(\mathrm{FC}(\mathrm{H}))$ to a temperature $(\mathrm{T})$ from $300 \mathrm{~K}$. At T, the applied magnetic field is increased from 0 to $65 \mathrm{kOe}$ (WVU) or $180 \mathrm{kOe}(\mathrm{NHMFL})$ at select magnetic fields for the former and a "continuous" data set for the latter. It should be noted that the "stabilization" of the NHMFL data since the magnetic field was increased from 0 to $180 \mathrm{kOe}$ in 30 minutes. The WVU magnetization data are

corrected for the small temperature-independent diamagnetic susceptibility $\left(=-2.3 \times 10^{-8} \mathrm{emu} / \mathrm{Oe}\right)$ of the sample holder. 


\subsubsection{Temperature Dependence}

Temperature dependent magnetic susceptibility $\chi(=\mathrm{M} / \mathrm{H})$ for the ZFC $(\mathrm{H}=100 \mathrm{Oe})$ and $\mathrm{FC}(\mathrm{H}=100 \mathrm{Oe})$ cases for nanoplate sample $\beta$-A (bulk sample $\beta$-B) in Fig. 3.1 shows $\chi(\mathrm{ZFC})$ peaks at $\mathrm{T}_{\mathrm{p}}=24.5 \mathrm{~K}(26.5 \mathrm{~K})$ and $\chi(\mathrm{FC})>\chi(\mathrm{ZFC})$ below $\mathrm{T}_{\mathrm{p}}$. Although $\chi(\mathrm{ZFC})$ and $\chi(\mathrm{FC})$ bifurcates at $\mathrm{T}_{\mathrm{p}}$ for sample $\beta$-B, $\chi(\mathrm{ZFC})$ and $\chi(\mathrm{FC})$ in sample $\beta$-A begins to bifurcate at a slightly higher temperature than $T_{p}$. The magnetic susceptibility at the peak temperature, $\chi\left(T_{p}\right)$, is equivalent between samples $\beta$-A and $\beta$-B indicating a similar long range order between the bulk and nanoparticle samples (inset of Fig. 3.1). However, the $\chi(\mathrm{FC})$ data for samples $\beta$-A and $\beta$-B show distinctly different behavior below $\mathrm{T}_{\mathrm{p}}$. In fact $\chi(\mathrm{FC})$ for sample $\beta$-B has a peak indicative of antiferromagnetism while $\chi(\mathrm{FC})$ for sample $\beta$-A shows a ferromagnetic-like behavior.

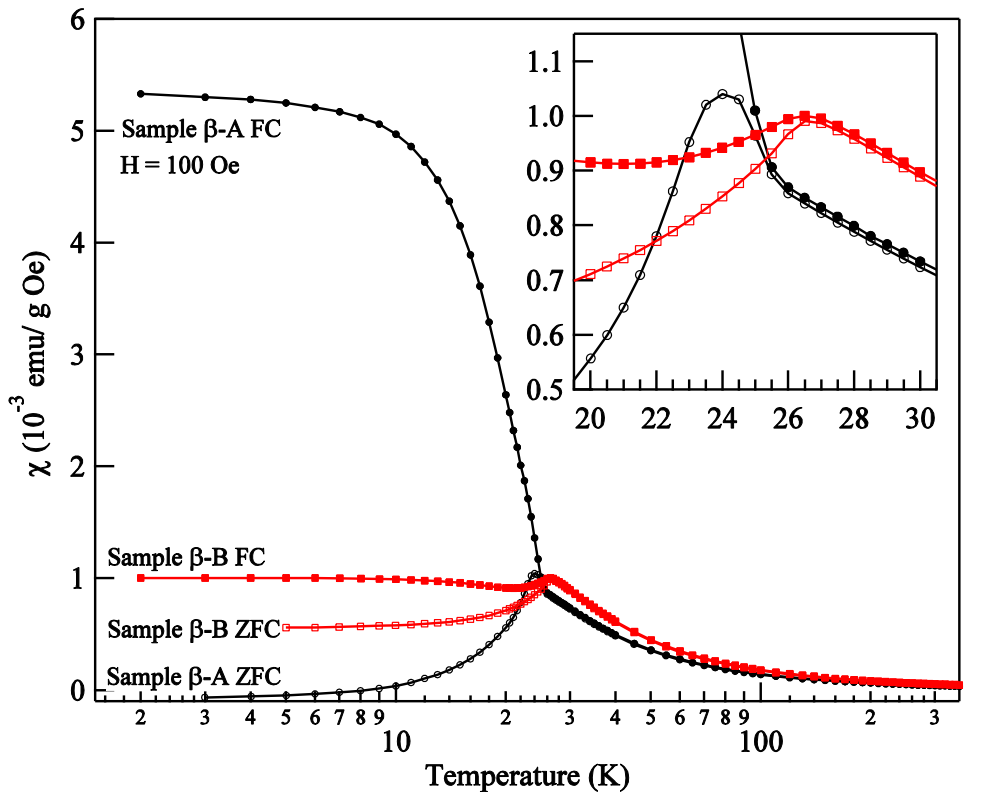

Figure 3.1: Temperature variation of magnetization of samples $\beta$-A and $\beta$-B for $\mathrm{H}=100$ Oe. 
The magnetization data above $T_{p}$ is identical for $\mathrm{ZFC}$ and $\mathrm{FC}$ cases for both sample $\beta$-A and bulk sample $\beta$-B. Magnetization data above $50 \mathrm{~K}$ is fitted to the Curie-Weiss law, $\chi=C /(\mathrm{T}-\theta)$, with the plot of $\chi^{-1}$ vs. T shown in Fig. 3.2. The observed linear relationship $\left(\chi^{-1}=\frac{\mathrm{T}}{C}-\frac{\theta}{C}\right)$ yields $\theta=20.5 \mathrm{~K}(16 \mathrm{~K})$ and $C=112 \times 10^{-4} \mathrm{emu} /\left(\mathrm{g}\right.$ Oe) $\left(149 \times 10^{-4} \mathrm{emu} /(\mathrm{g}\right.$ Oe) $)$ for sample $\beta$-A (sample $\beta$-B). Using $C=\mathrm{N}^{2} / 3 k_{B}$ and $\mu^{2}=g^{2} \mu_{\mathrm{B}}^{2} \mathrm{~S}(\mathrm{~S}+1)$ with $\mathrm{g}=2.2$ for $\mathrm{Ni}^{2+}$ yields $\mu=2.92 \mu_{\mathrm{B}}\left(3.33 \mu_{\mathrm{B}}\right)$ and $\mathrm{S}=0.92(1.09)$ for sample $\beta$-A (sample $\beta$-B). The slight departure from the expected $\mathrm{S}=1$ for $\mathrm{Ni}^{2+}$ for sample $\beta$-A is likely due to the zero-point spin deviation which has also been observed in bulk NiO system [Srinivon \& Seehra, 1984]. The magnitude of $\mu\left(2.92 \mu_{\mathrm{B}}, 3.33 \mu_{\mathrm{B}}\right)$ is similar to those reported by others [Enoki \& Tsujikawa, 1975; Tiwari \& Rajeev, 2008]. Although the sign of $\theta$ usually references the magnetism of the system, the

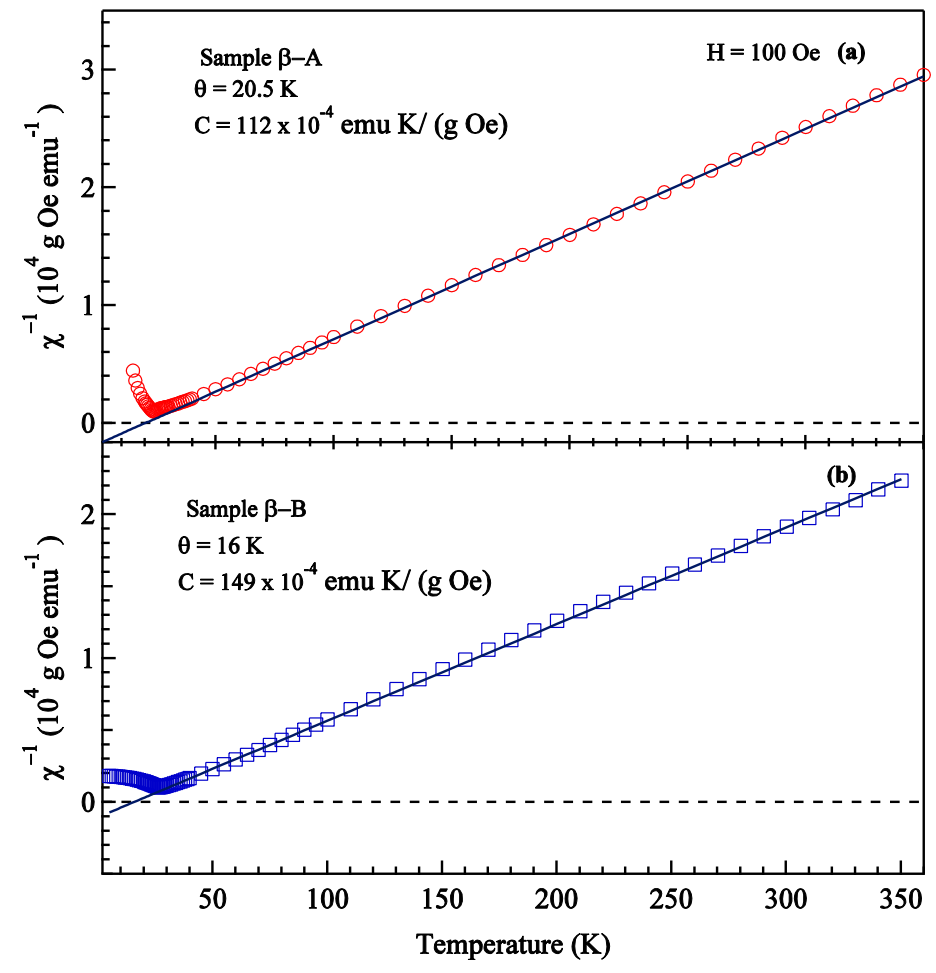

Figure 3.2: Plots of inverse susceptibility vs. temperature for (a) sample $\beta$-A and (b) sample $\beta$-B. positive $\theta$ observed here and in other references indicate a dominant intra-planar ferromagnetic interaction due to the $\mathrm{Ni}^{2+}$ layers while having an overall antiferromagnetic arrangement between the ferromagnetic layers, which has also been verified using neutron diffraction [Szytula et al., 1971]. 
The $\mathrm{M}$ vs. $\mathrm{T}$ data for three measuring magnetic fields for sample $\beta$-B are shown in Fig. 3.3. The peak temperature $\left(T_{p}\right)$ does not change with the applied magnetic field between 30 Oe and 500 Oe. Therefore, the peak is not associated with a blocking temperature [Tiwari \& Rajeev, 2008], but the peak temperature is related to a magnetic transition. It is well known that the Néel temperature $\left(\mathrm{T}_{\mathrm{N}}\right)$ for an antiferromagnet does not coincide with the peak temperature, but instead is given by the maximum of $\frac{\partial(\chi \mathrm{T})}{\partial \mathrm{T}}$ [Fisher, 1962]. For bulk sample $\beta$-B, the plots of $\chi \mathrm{T}$ vs $\mathrm{T}$ and $\frac{\partial(\chi \mathrm{T})}{\partial \mathrm{T}}$ vs. T have nearly identical curves for differing magnetic fields (Fig. 3.4). The Néel temperature does not vary with applied magnetic field. In fact there seems to be no measurable change in $\frac{\partial(\chi \mathrm{T})}{\partial \mathrm{T}}$ between $\mathrm{H}=30 \mathrm{Oe}$ and $\mathrm{H}=500$ Oe. The broad minimum due to ferromagnetism in Fig. 3.4(b) is discussed below in terms of the Curie-Weiss law.

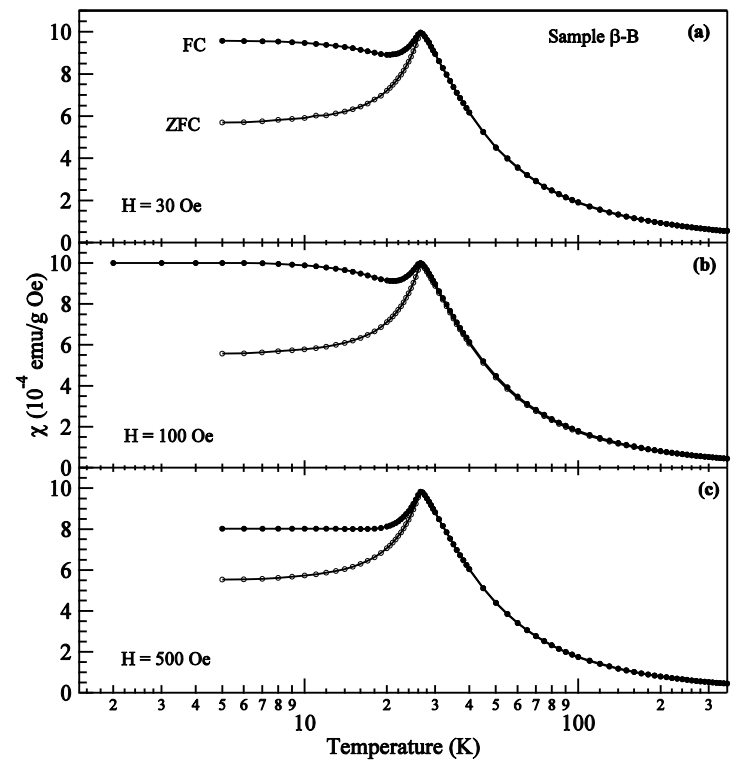

Figure 3.3: $\mathrm{M}(\mathrm{T})$ for sample $\beta-\mathrm{B}$ with $\mathrm{H}=$ (a) 30, (b) 100, (c) 500 Oe.

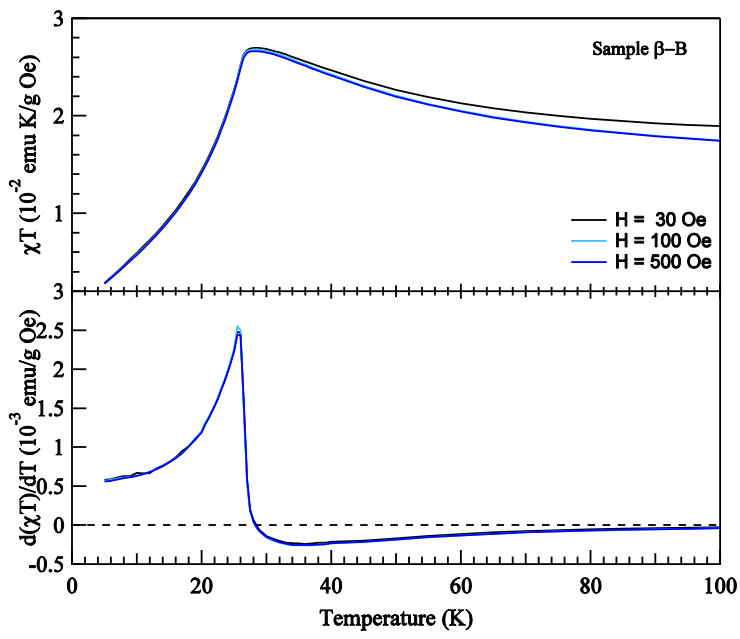

Figure 3.4: Temperature variation of (a) $\chi \mathrm{T}$ and (b) $\frac{\partial(\chi \mathrm{T})}{\partial \mathrm{T}}$ for the data in Fig. 3.3. 
Twelve applied magnetic fields were used to measure $M$ vs. T for sample $\beta$-A for the ZFC data between $5 \mathrm{~K}$ and $50 \mathrm{~K}$ (Fig. 3.5(a)). Statistically $\mathrm{T}_{\mathrm{p}}=24.5 \mathrm{~K}$ is observed for all magnetic fields between 50 Oe and 2000 Oe. There is a slight decrease in $\mathrm{T}_{\mathrm{p}}$ as $\mathrm{H}$ is increased to $30 \mathrm{kOe}$, but this is attributed to the large magnetic field rather than a characteristic of the magnetic ordering. The plots of $\chi \mathrm{T}$ vs. $\mathrm{T}$ in Fig. 3.5(b) indicate an unusual form considering typical antiferromagnets in which $\chi \mathrm{T}$ does not have a maximum value. In order to determine the nature of the magnetic transitions, $\frac{\partial(\chi \mathrm{T})}{\partial \mathrm{T}}$ vs. $\mathrm{T}$ is computed from the data and plotted in Fig. 3.6(a). The $\frac{\partial(\chi \mathrm{T})}{\partial \mathrm{T}}$ vs. $\mathrm{T}$ data shows two extrema, a maximum peak $\left(\mathrm{T}_{2}\right)$ lower than $\mathrm{T}_{\mathrm{p}}$ and a

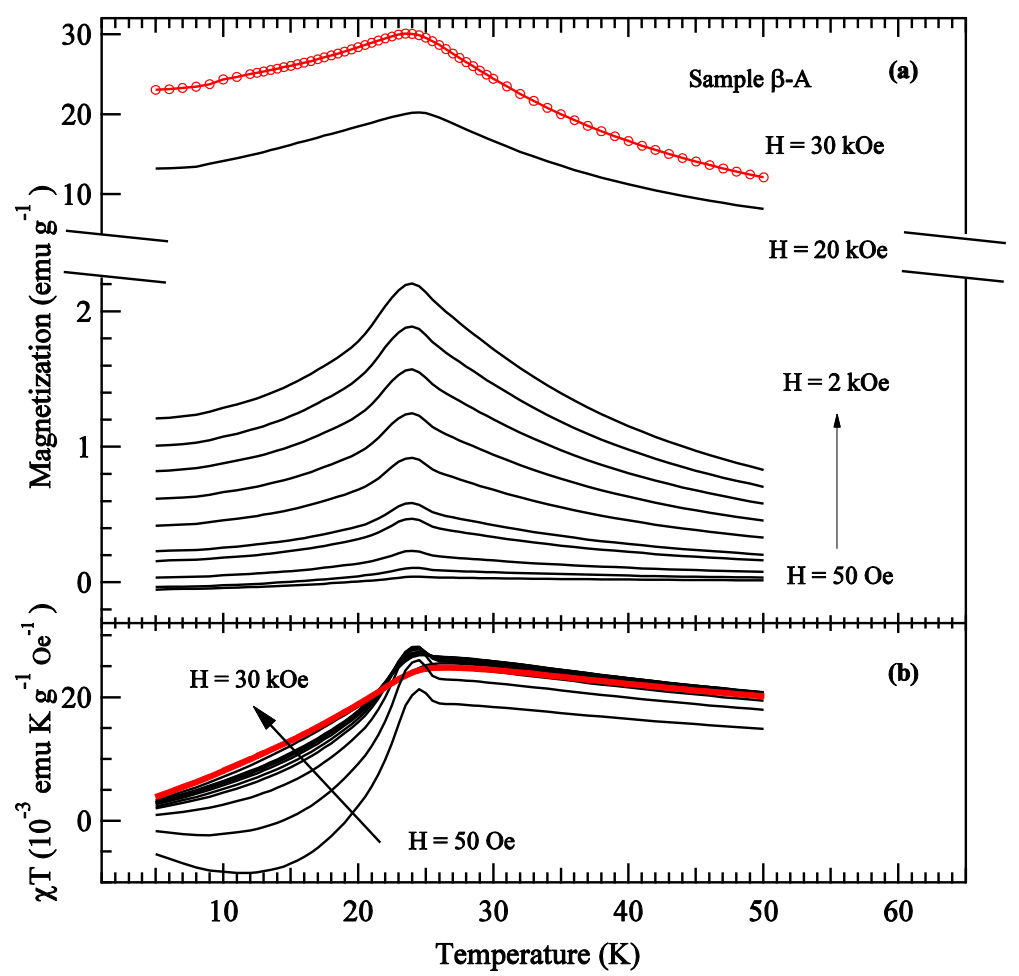

Figure 3.5: Temperature variation of (a) magnetization and (b) $\chi \mathrm{T}$ of sample $\beta$-A for $\mathrm{H}=50,100,200,400,500,800,1100,1400$, $1700,2000,20000$, and 30000 Oe. minimum $\left(\mathrm{T}_{1}\right)$ above $\mathrm{T}_{\mathrm{p}}$. These two extrema are unusual for antiferromagnets where only the maximum is observed and $\frac{\partial(\chi \mathrm{T})}{\partial \mathrm{T}}>0$ for all temperatures. This unusual behavior is interpreted as follows. For $\mathrm{T}>\mathrm{T}_{\mathrm{N}}$, $\chi=\mathrm{C} /(\mathrm{T}-\theta)$ is observed with a positive $\theta$ as a result of the dominant FM interaction as shown earlier, which is attributed to the unusual nature of this antiferromagnetic system. 
The Curie-Weiss law leads to

$$
\frac{\partial(\chi \mathrm{T})}{\partial \mathrm{T}}=-\frac{\mathrm{C} \theta}{(\mathrm{T}-\theta)^{2}}
$$

For $\theta>0$ as in ferromagnets, $\frac{\partial(\chi \mathrm{T})}{\partial \mathrm{T}}<0$ and a negative minimum occurs at $\mathrm{T}=\theta$. For $\theta<0$ as in typical antiferromagnets with dominant antiferromagnetic exchange interaction, $\frac{\partial(\chi \mathrm{T})}{\partial \mathrm{T}}>0$ and a positive maxima occurs at $\mathrm{T}=\theta$ as observed experimentally in a number of antiferromagnets [Bragg \& Seehra, 1973; Wolf \& Wyatt, 1964; Skalyo, Cohen, Friedberg, \& Griffiths, 1967]. Given the maxima and minimum observed in $\beta-\mathrm{Ni}(\mathrm{OH})_{2}$ with the layered structure leads to the conclusion that the system is characterized by a $2 \mathrm{D}$ ferromagnetic order of the $\mathrm{Ni}^{2+}$ moments in the $(00 \ell)$ sheets at $\mathrm{T}_{1}$ and a long range $3 \mathrm{D}$ antiferromagnetic order between the $\mathrm{Ni}^{2+}$ sheets at the lower temperature $T_{2}$. The variation of $T_{1}$ and $T_{2}$ with applied magnetic field is shown in Fig. 3.6(b). The 2D ferromagnetic order is field independent, whereas $\mathrm{T}_{2}$ has a slight magnetic field dependence. The 3D antiferromagnetic ordering temperature generally decreases with applied field as seen in Fig. 3.6(b) [Morrish, $2001 \mathrm{p}$ 458]. However, the magnetic field dependence of the Néel temperature usually follows $\mathrm{H}^{2}$ and the dependence on $\mathrm{H}^{1 / 2}$ is still unknown. This two-step transition from paramagnetic to antiferromagnetic is not uncommon to occur in layered systems [de Jongh, 1990]. As noted earlier, the data of specific heat vs. temperature in micron size plates of $\beta-\mathrm{Ni}(\mathrm{OH})_{2}$ was also interpreted by Enoki and Tsujikawa [1975] as a transition from 2D ordering at higher temperatures followed by transition to 3D ordering at a lower temperature. Thus analysis of the magnetic susceptibility data reported here confirms the two-step ordering directly from magnetic measurements with the added knowledge that $2 \mathrm{D}$ ordering is ferromagnetic, followed by 3D antiferromagnetic ordering at the lower 
temperature. These results have been published in our recent papers [Rall, Seehra, Shah, \& Huffman, 2010(b); Rall, Seehra, \& Choi, 2010(a)].
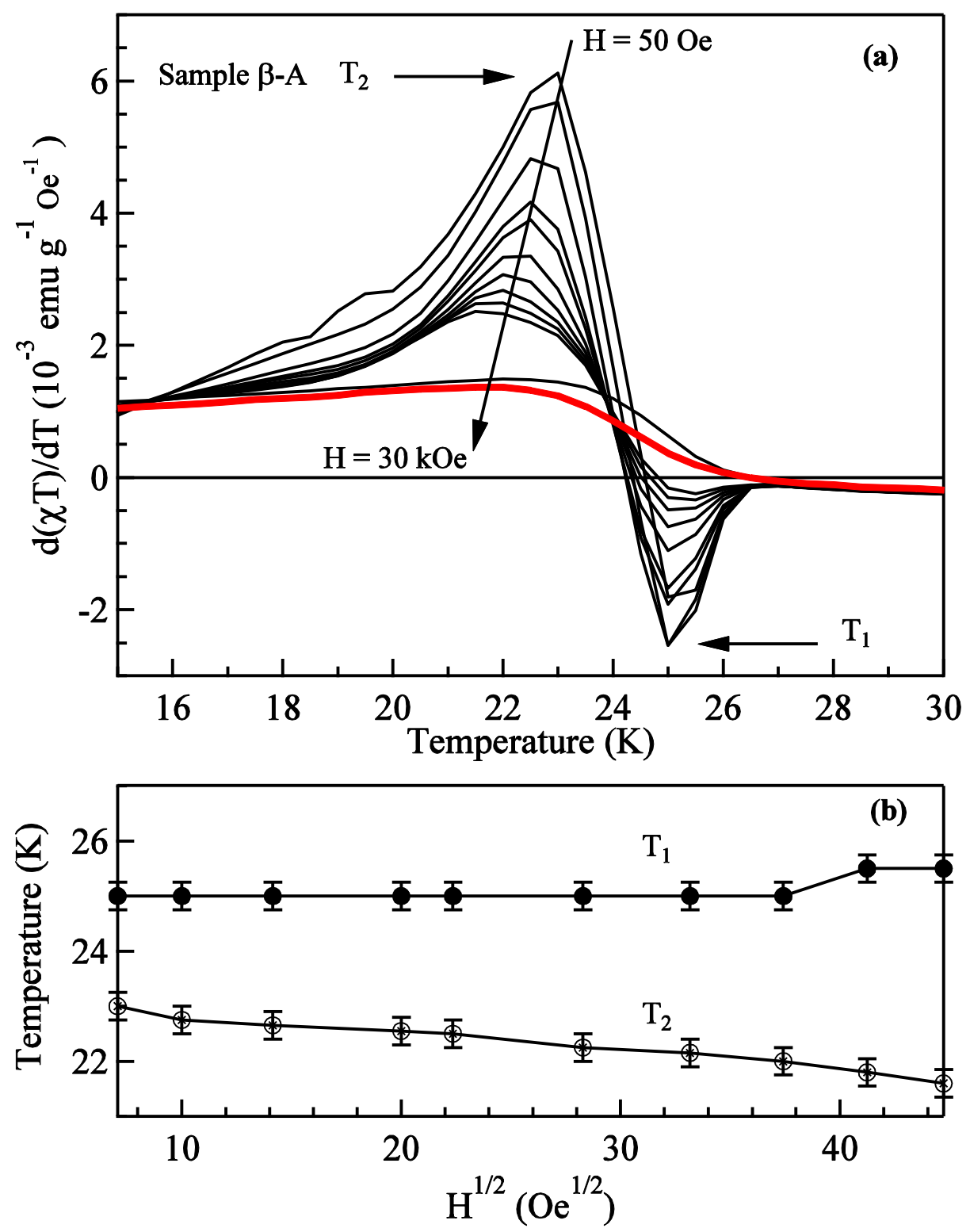

Figure 3.6: (a) Plots of the computed $\frac{\partial(\chi \mathrm{T})}{\partial \mathrm{T}}$ using the data in Fig. 3.5 at different magnetic fields to determine $\mathrm{T}_{1}$ and $\mathrm{T}_{2} ;$ (b) applied magnetic field dependence of $\mathrm{T}_{1}$ and $\mathrm{T}_{2}$. 


\subsubsection{AC Susceptibility}

Investigations by ac susceptibility were also performed to verify magnetic transitions in this system. These measurements were done using the WVU SQUID system for frequencies $\mathrm{f}$ varying between $0.1 \mathrm{~Hz}$ to $1000 \mathrm{~Hz}, \mathrm{H}_{\mathrm{ac}}=6.8 \mathrm{Oe}$ and $\mathrm{H}_{\mathrm{DC}}=0$ Oe and 500 Oe. Because $\mathrm{H}_{\mathrm{ac}}$ is time-varying, $\chi_{a c}=\chi^{\prime}-i \chi^{\prime \prime}$ is complex and so plots of $\chi^{\prime}$ vs. T and $\chi^{\prime \prime}$ vs. T for different frequencies are shown in Fig. 3.7. There is no frequency dependence of $T_{p}$ consistent with a magnetic transition in a concentrated bulk magnetic system. $\chi^{\prime}$ and $\chi^{\prime \prime}$ were also measured in a DC field $\mathrm{H}_{\mathrm{DC}}=500$ Oe. $\mathrm{T}_{\mathrm{p}}$ increased slightly to $24.5 \mathrm{~K}$ but still has no significant frequency dependence. AC measurements all correspond with the system undergoing a magnetic transition around $\mathrm{T}_{\mathrm{p}}$ rather than a blocking temperature, the later being strongly frequency dependent in non-interacting nanoparticles [Singh, Seehra, \& Bonevich, 2009]. The magnitude of $\chi^{\prime \prime}$ is weaker by a factor of about 50 as compared to that of $\chi^{\prime}$ and is at the bottom of the detection limit available for the SQUID. The relation of peak position of $\chi^{\prime \prime}$ coinciding with the position of peak in $\frac{\partial\left(\chi^{\prime} \mathrm{T}\right)}{\partial \mathrm{T}}$ appears to be valid here also [Singh et al., 2009]. 


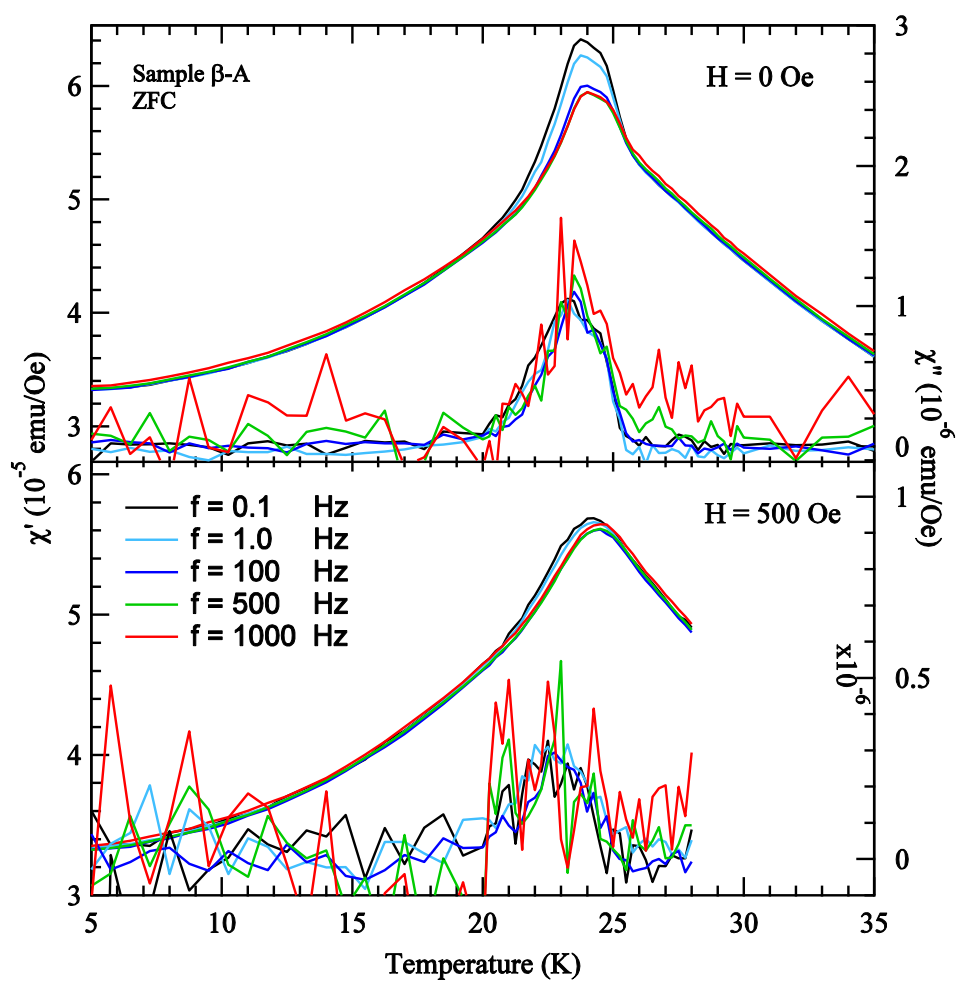

Figure 3.7: AC susceptibility measurements for sample $\beta$-A (a) without an applied DC field and (b) with a DC field of $\mathrm{H}_{\mathrm{DC}}=500$ Oe.

\subsubsection{Magnetic Field Dependence of Magnetization}

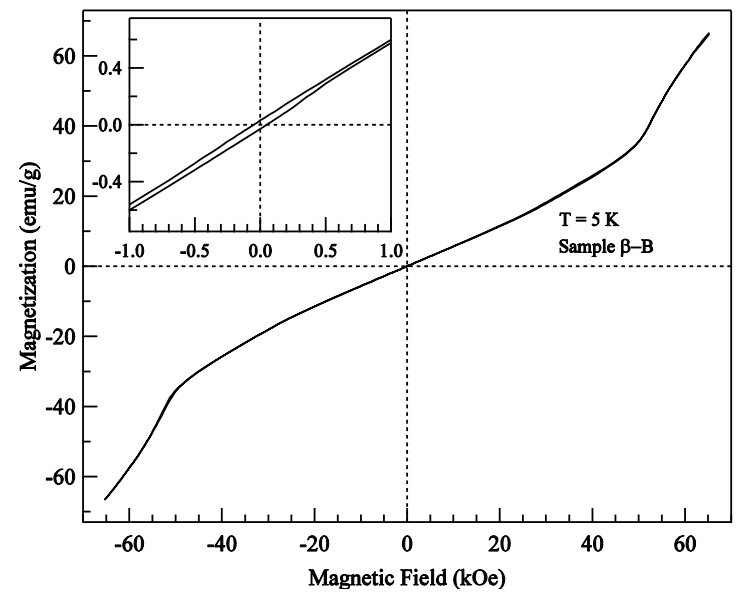

Figure 3.8: ZFC hysteresis loop at $\mathrm{T}=5 \mathrm{~K}$ for sample $\beta$-B
Hysteresis loop measurements of $\mathrm{M}$ vs. $\mathrm{H}$ were done for both samples; however for sample $\beta$ - $\mathrm{B}$, the data were taken only at $5 \mathrm{~K}$ due to the lack of hysteresis (Fig. 3.8). The inset of Fig. 3.8 shows only a minor coercivity $\left(\mathrm{H}_{\mathrm{c}}=40 \mathrm{Oe}\right)$ which is typical for bulk antiferromagnets. On the other hand, for sample $\beta$-A with nanoplate dimensions, hysteresis loops were measured at select

temperatures between $2 \mathrm{~K}$ and $34 \mathrm{~K}$ for the ZFC case (Fig. 3.9, 3.10, 3.11). The low field region 
(insets) shows significant coercivity $\mathrm{H}_{\mathrm{c}}=400$ Oe and a magnetic remanence $\mathrm{M}_{\mathrm{r}}$. The hysteresis loops were also measured after cooling the sample in a magnetic field $\mathrm{H}=25 \mathrm{kOe}$. These M vs. H loops (Fig. 3.12 and 3.13) give similar results as the ZFC data sets except some difference in $\mathrm{H}_{\mathrm{c}}$ and loop shift or exchange bias $\mathrm{H}_{\mathrm{eb}}$ are observed. The appearance of coercivity, remanence, and exchange bias in the nanoparticle sample indicates the importance of the uncompensated surface spin on the magnetization measurements. This reasoning will be further discussed in section 3.3.

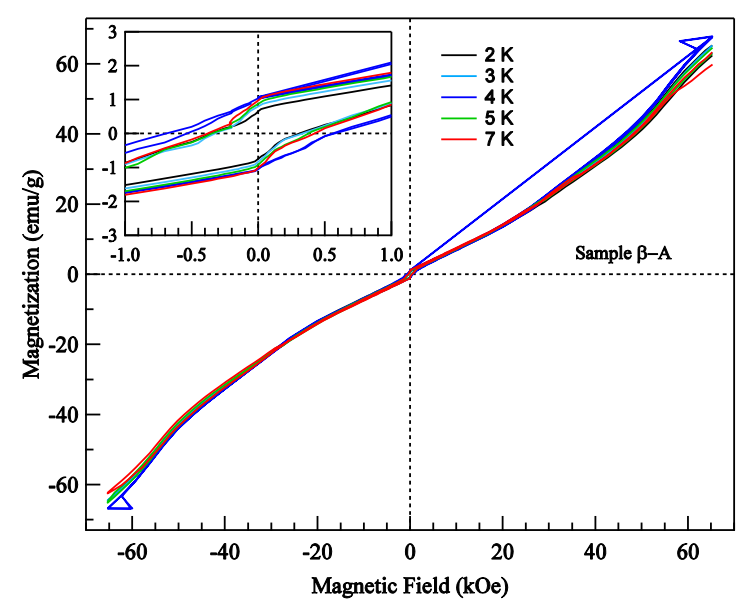

Figure 3.9: ZFC hysteresis loops at $\mathrm{T}=2,3,4,5$, and 7 $\mathrm{K}$ for sample $\beta$-A.

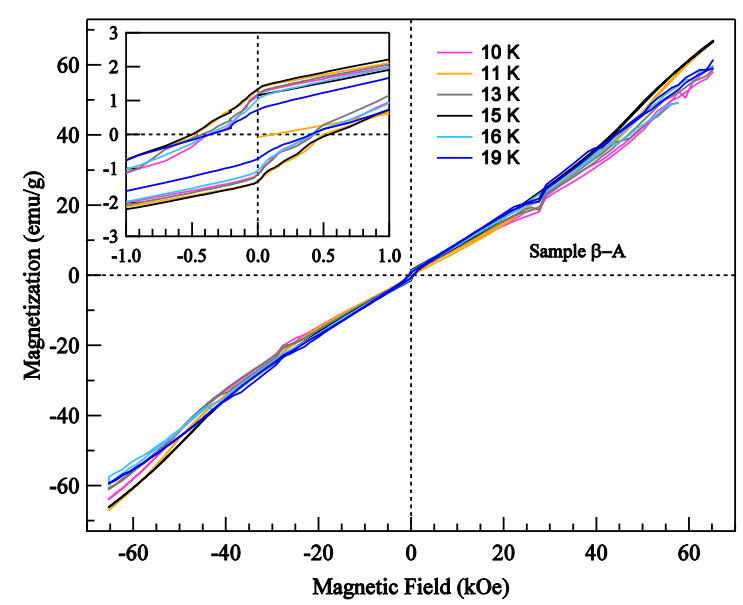

Figure 3.10: ZFC hysteresis loops at $\mathrm{T}=10,11,13,15$, 16 , and $19 \mathrm{~K}$ for sample $\beta$-A. 


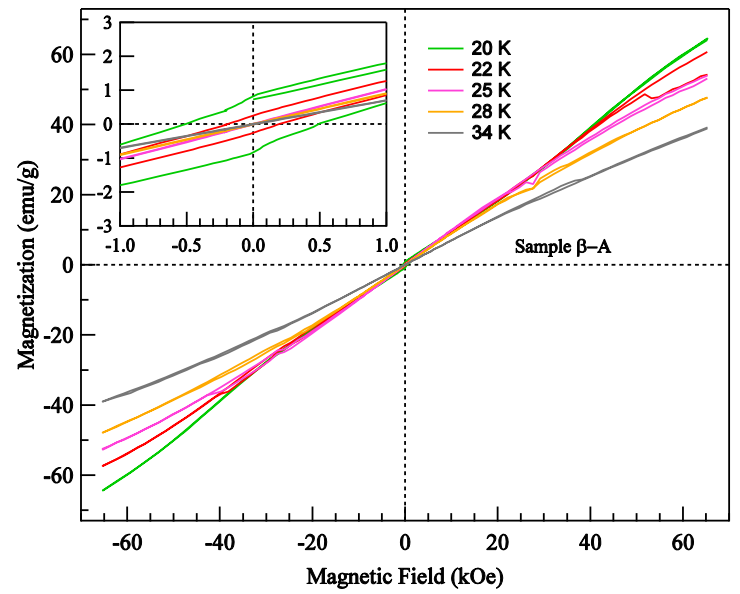

Figure 3.11: ZFC hysteresis loops at $\mathrm{T}=20,22,25$, 28 , and $34 \mathrm{~K}$ for sample $\beta$-A.

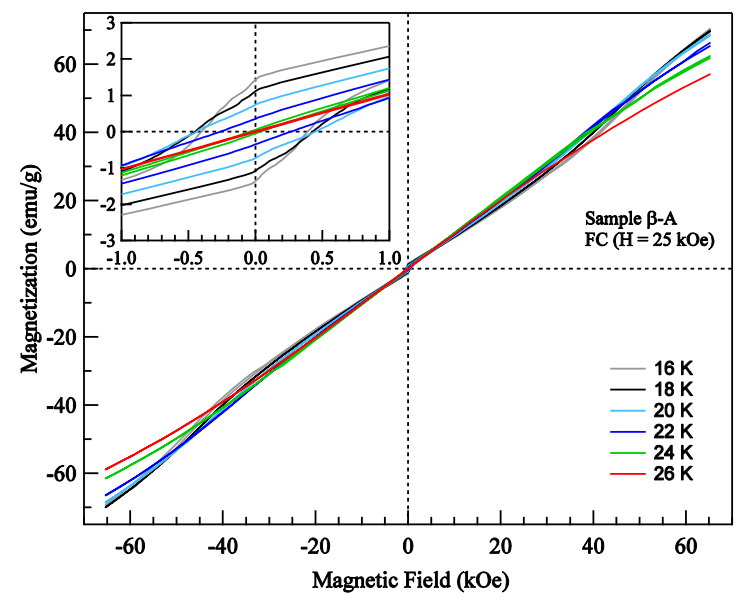

Figure 3.13: $\mathrm{FC}(\mathrm{H}=25 \mathrm{kOe})$ hysteresis loops at $\mathrm{T}=$ $16,18,20,22,24$, and $26 \mathrm{~K}$ for sample $\beta-\mathrm{A}$.

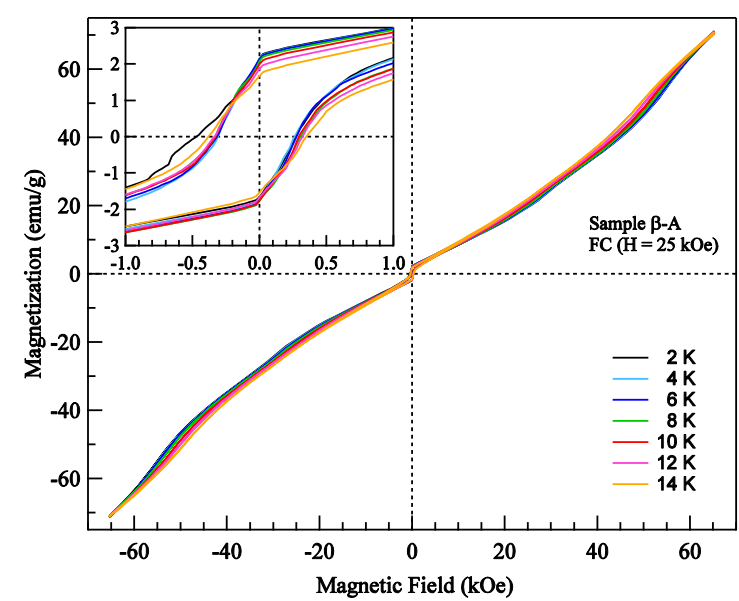

Figure 3.12: $\mathrm{FC}(\mathrm{H}=25 \mathrm{kOe})$ hysteresis loops at $\mathrm{T}=2,4,6,8$, 10,12 , and $14 \mathrm{~K}$ for sample $\beta$-A.

The temperature dependence of the coercivity $\left(\mathrm{H}_{\mathrm{c}}\right)$ and exchange bias (loop shift, $\mathrm{H}_{\mathrm{eb}}$ ) for sample $\beta$-A (Fig. 3.14) was determined from the hysteresis loops for $\mathrm{ZFC}$ and $\mathrm{FC}(\mathrm{H}=25 \mathrm{kOe})$ cases. As $\mathrm{T}$ is lowered below $\mathrm{T}_{\mathrm{N}}, \mathrm{H}_{\mathrm{c}}$ increases rapidly to maximum of $\mathrm{H}_{\mathrm{c}, \max }=470$ Oe at $\mathrm{T}=20 \mathrm{~K}$. Below $20 \mathrm{~K}$ there is little change of $\mathrm{H}_{\mathrm{c}}$ while $\mathrm{H}_{\mathrm{c}}(\mathrm{ZFC})>\mathrm{H}_{c}(\mathrm{FC}) \quad$ generally. The constant coercivity below $20 \mathrm{~K}$ indicates that the

mechanism creating the coercivity occurs near the antiferromagnetic ordering temperature. The small exchange bias of ZFC and FC does not have a great significance since measuring and setting the magnetic field in the SQUID is comparable to $\mathrm{H}_{\mathrm{eb}}$. Note that $\mathrm{H}_{\mathrm{c}}$ and $\mathrm{H}_{\mathrm{eb}}$ are calculated from the measured positions with zero magnetization. If $\mathrm{H}_{1}$ and $\mathrm{H}_{2}$ represent the position of 
$\mathbf{M}=0$ for the right and left side of the loop, then $\mathrm{H}_{e b}={ }^{\left(H_{1}+H_{2}\right)} / 2$ and $\mathrm{H}_{\mathrm{c}}={ }^{\left(H_{1}-H_{2}\right) / 2}$. For a symmetric loop, $\mathrm{H}_{1}=-\mathrm{H}_{2}$, leading to $\mathrm{H}_{e b}=0$ and $\mathrm{H}_{\mathrm{c}}=\left|H_{1}\right|=\left|H_{2}\right|$.

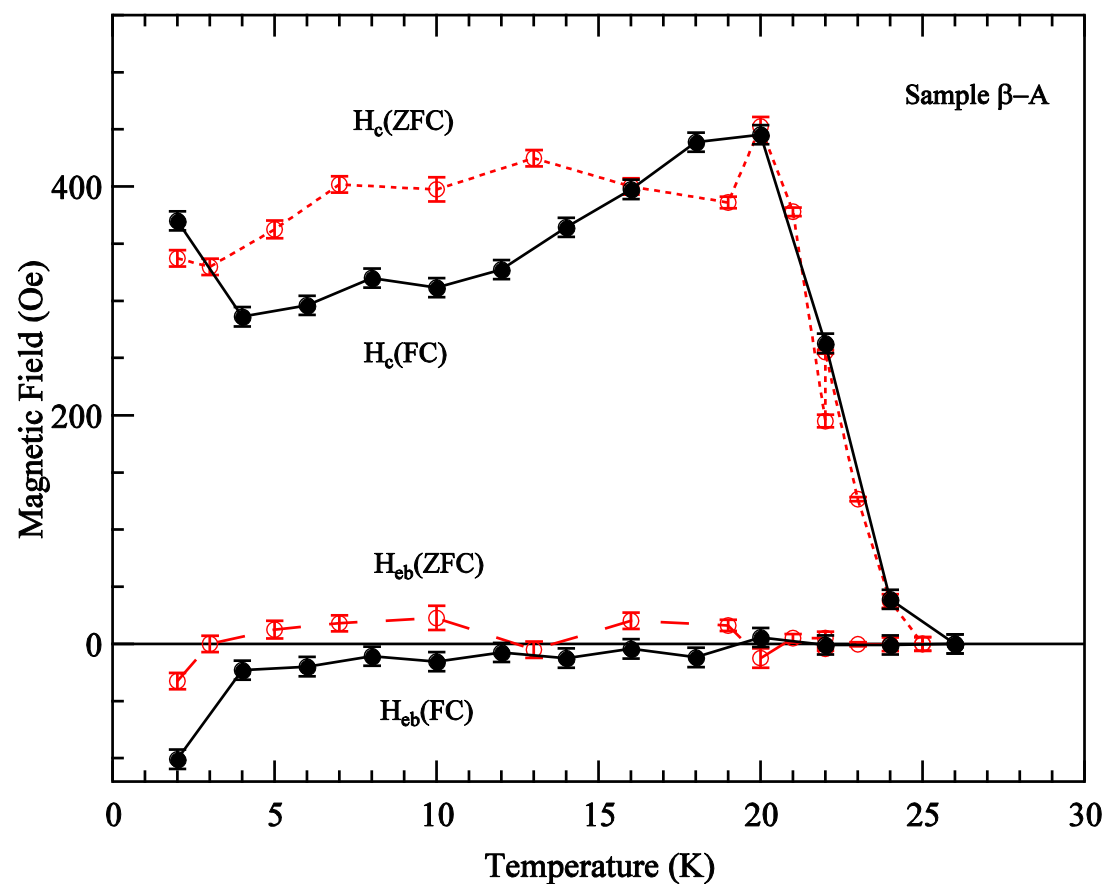

Figure 3.14: Temperature dependence of the coercivity and exchange bias for sample $\beta$-A while cooling it in $\mathrm{H}=0 \mathrm{Oe}(\mathrm{ZFC})$ and in $\mathrm{H}=25 \mathrm{kOe}(\mathrm{FC})$.

The

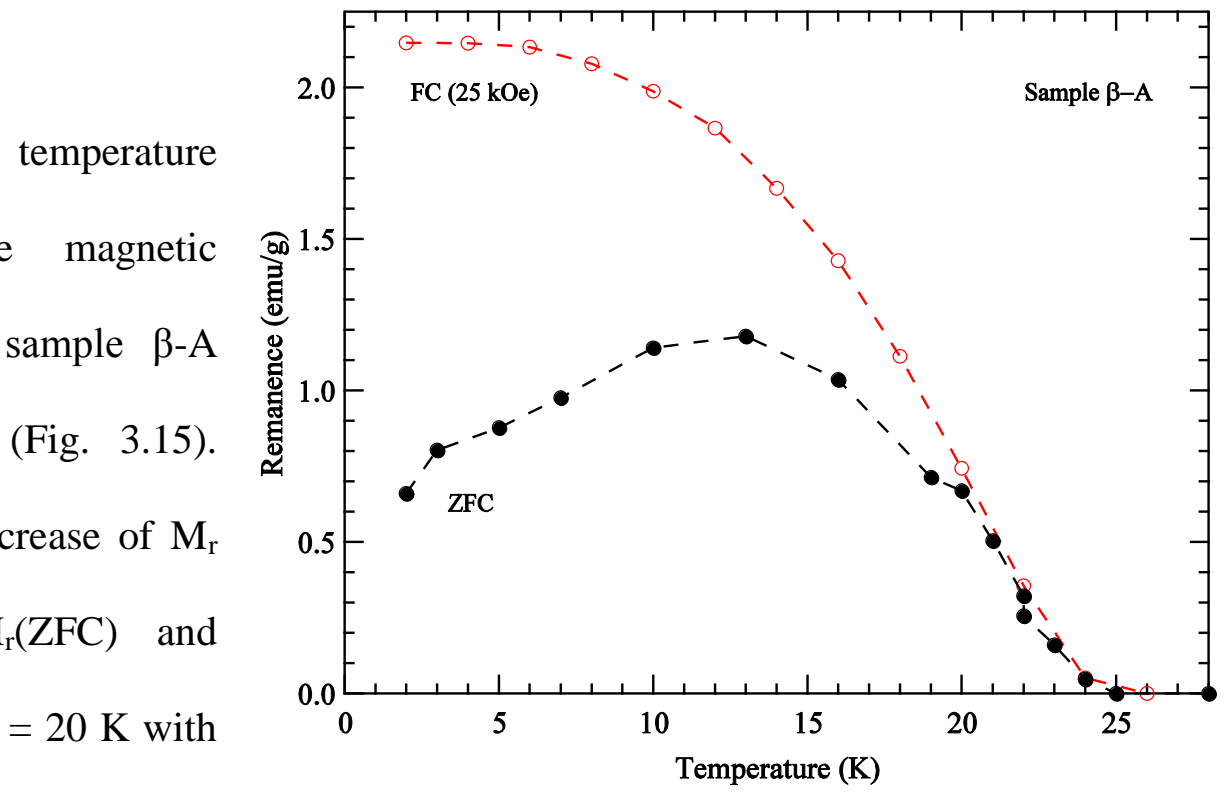

$\mathrm{M}_{\mathrm{r}}(\mathrm{FC})>\mathrm{M}_{\mathrm{r}}(\mathrm{ZFC}) . \quad \mathrm{M}_{\mathrm{r}}(\mathrm{FC})$

Figure 3.15: Temperature variation of the remanence $\mathrm{M}_{\mathrm{r}}$ measured from the hysteresis loops of Fig. $3.9-3.13$. 
continues to increase as $\mathrm{T} \rightarrow 0 \mathrm{~K}$ with $\mathrm{M}_{\mathrm{r}}(\mathrm{FC}, \mathrm{T}=0 \mathrm{~K})=2.15 \mathrm{emu} / \mathrm{g}$ obtained by extrapolation. $\mathrm{M}_{\mathrm{r}}(\mathrm{ZFC})$ shows a different variation with $\mathrm{M}_{\mathrm{r}}(\mathrm{ZFC})$ increasing below $\mathrm{T}_{\mathrm{N}}$ to a maximum at $\mathrm{T}_{\max }=13 \mathrm{~K}$. Below $\mathrm{T}_{\max }, \mathrm{M}_{\mathrm{r}}(\mathrm{ZFC})$ decreases without evidence of $\mathrm{M}_{\mathrm{r}}(\mathrm{ZFC})$ going to zero as $\mathrm{T} \rightarrow 0 \mathrm{~K}$. The remanence of the $\mathrm{FC}$ data at $\mathrm{T}=2 \mathrm{~K}$ is consistent with the alignment of all uncompensated surface spins as shown in section 3.3. However, the origin of this maximum in $\mathrm{M}_{\mathrm{r}}(\mathrm{ZFC})$ is not yet understood.

Magnetic field dependence of magnetization was measured for both sample $\beta$-A (Fig. 3.16) and sample $\beta$-B (Fig. 3.17). For sample $\beta$-A, M vs. $H$ was taken at temperatures between $2 \mathrm{~K}$ and $24 \mathrm{~K}$ using the WVU SQUID magnetometer. The derived magnetic susceptibility $\left(\chi=\frac{\partial \mathrm{M}}{\partial \mathrm{H}}\right)$ is also shown. For nanoplatelet sample $\beta$-A there are two distinct transitions, $\mathrm{H}_{\mathrm{C} 1}=28 \mathrm{kOe}$ and $\mathrm{H}_{\mathrm{C} 2}=55 \mathrm{kOe}$. However, bulk sample $\beta$-B only shows a single transition at $\mathrm{H}_{\mathrm{C} 2}=55 \mathrm{kOe}$. Both samples have their peaks in $\frac{\partial M}{\partial H}$ decrease as $\mathrm{T}$ increases toward $\mathrm{T}_{\mathrm{N}}$. In earlier studies on bulk $\beta-\mathrm{Ni}(\mathrm{OH})_{2}$, the transition near $55 \mathrm{kOe}$ was attributed to a

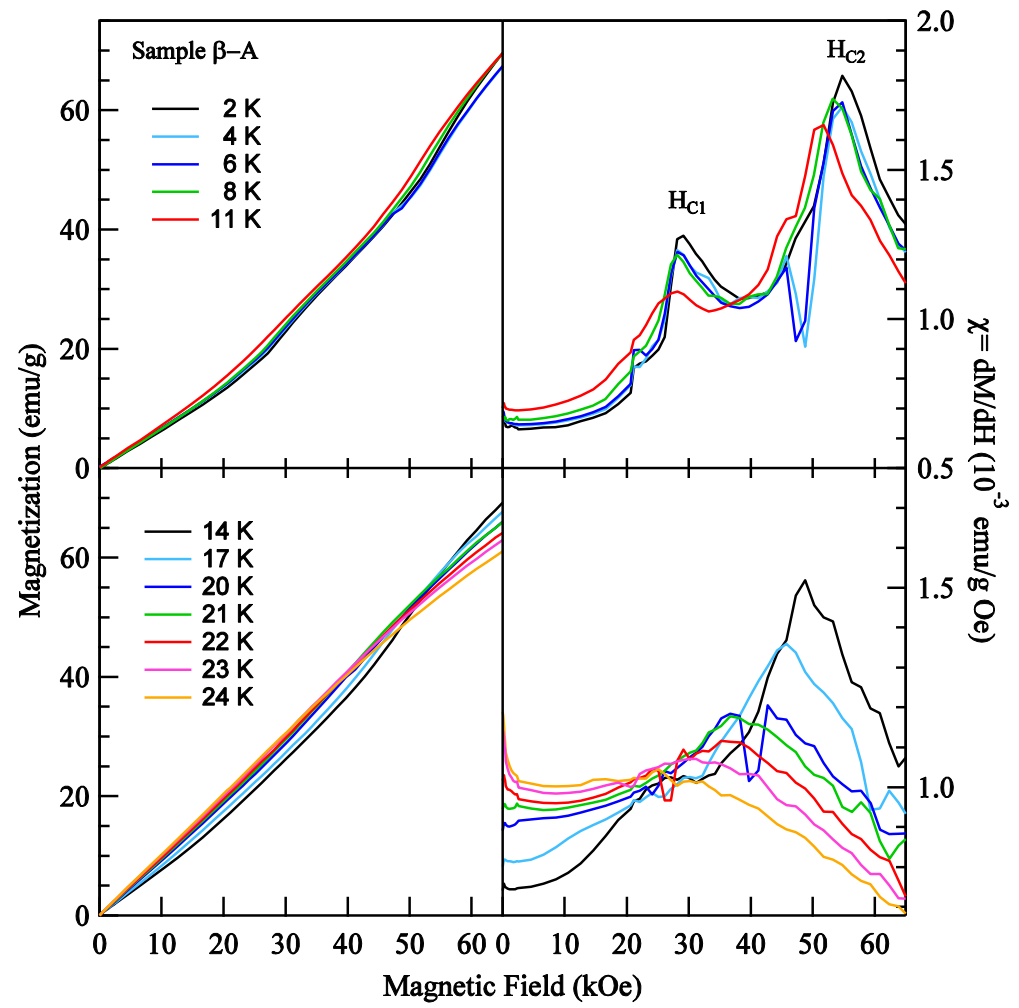
for sample $\beta$-A acquired at WVU and taken at temperatures T $=2,4,6,8,11,14,17,20,21,22,23$, and $24 \mathrm{~K}$. 
metamagnetic (spin-flip) transition from antiferromagnetic ordering to ferromagnetic ordering for $\mathrm{H}>\mathrm{H}_{\mathrm{C} 2}=55 \mathrm{kOe}$ [Takada et al., 1966]. The first transition in the nanoparticle sample is attributed to the spin-flipping of the surface spins parallel to the z-axis. The relation of $\mathrm{H}_{\mathrm{C} 1} \simeq \mathrm{H}_{\mathrm{C} 2} / 2$ will be thoroughly justified using the theoretical model in section 3.3.

From the SQUID magnetometer data of $\mathrm{M}$ vs. $\mathrm{H}$, the magnetization is not saturated at $\mathrm{H}=65 \mathrm{kOe}$, the maximum field available in the SQUID. Therefore the NHMFL facilities were employed to measure the magnetic susceptibility $(\chi)$ up to $180 \mathrm{kOe}$. For measuring $\chi$, the $\mathrm{AC}$ method was used while sweeping the

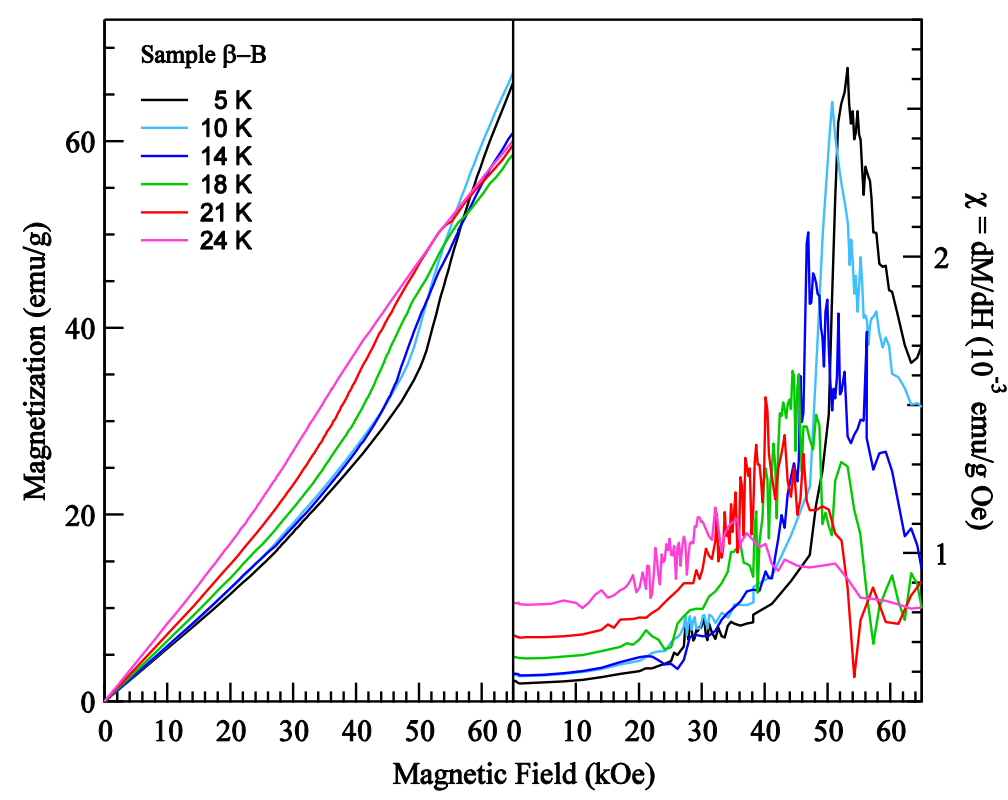
magnetic field from 0 to $180 \mathrm{kOe}$ Figure 3.17: $\mathrm{M}(\mathrm{H})$ and $\chi(\mathrm{H})$ for sample $\beta$-B obtained at WVU and taken at temperatures $\mathrm{T}=5,10,14,18,21$, and $24 \mathrm{~K}$.

in 30 minutes. These data sets of $\chi$ vs. $\mathrm{H}$ are shown in Fig. 3.18. The system has an internal noise resonance near $25 \mathrm{kOe}$ making determination of $\mathrm{H}_{\mathrm{C} 1}$ impossible above $\mathrm{T}=14 \mathrm{~K}$. Through integration of $\chi$ vs. $\mathrm{H}$ data the magnetization of sample $\beta$-A was determined (Fig. 3.19). The NHMFL magnetization data for $\mathrm{T}=2 \mathrm{~K}$ is normalized to $\mathrm{WVU}$ data at $\mathrm{T}=2 \mathrm{~K}$ and $\mathrm{H}=65 \mathrm{kOe}$. Above $\mathrm{H}=150 \mathrm{kOe}, \mathrm{M}$ is saturated with a saturation magnetization value $\mathrm{M}_{\mathrm{s}}=118 \mathrm{emu} / \mathrm{g}$. Due to the sample being polycrystalline $\mathrm{M}$ is not saturated at $\mathrm{H}=\mathrm{H}_{\mathrm{C} 2}$ and an interpretation of this is presented later. 


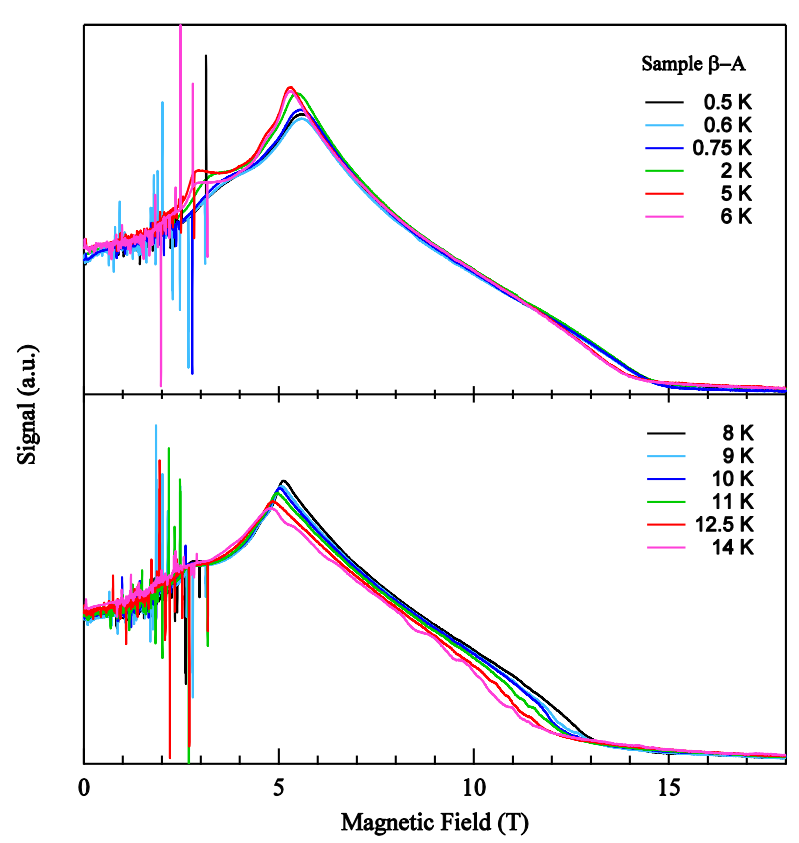

Figure 3.18: $\chi(\mathrm{H})$ for sample $\beta$-A acquired at NHMFL from 0 to $180 \mathrm{kOe}$ at temperatures $\mathrm{T}=$ $0.5,0.6,0.75,2,5,6,8,9,10,11,12.5$, and $14 \mathrm{~K}$.

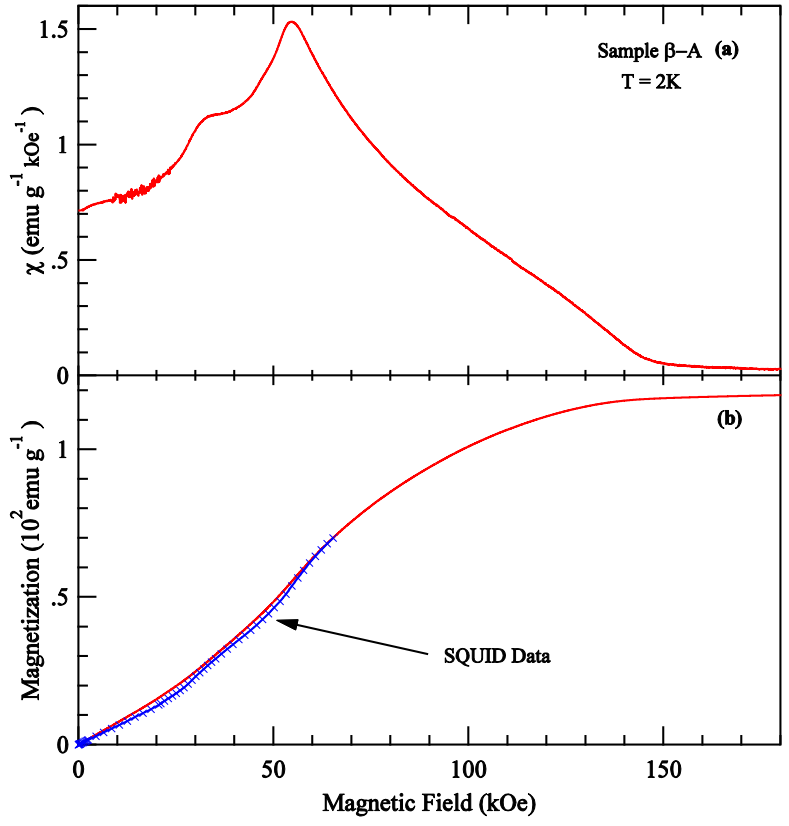

Figure 3.19: The NHMFL data at $\mathrm{T}=2 \mathrm{~K}$ after cleaning the noise in (a) $\chi(\mathrm{H})$ and (b) $\mathrm{M}(\mathrm{H})$. The WVU data is shown for the normalization of the NHMFL magnetization.

\subsubsection{Temperature Dependence of the Critical Fields}

The WVU and NHMFL data of M vs. $\mathrm{H}$ are compiled together to determine the phase diagram of the two transitions given by $\mathrm{H}_{\mathrm{C} 1}$ and $\mathrm{H}_{\mathrm{C} 2}$ (Fig. 3.20). The absence of $\mathrm{H}_{\mathrm{C} 1}$ from the bulk sample $\beta$-B is again noted. For $\mathrm{H}_{\mathrm{C} 2}$ in sample $\beta$-A, it can be inferred that the magnitude goes to zero as $T$ approaches $T_{N}$ from the low temperature side. Similar results of the temperature variation of $\mathrm{H}_{\mathrm{C} 2}$ are observed for sample $\beta$-B. The solid curve is the calculated Brillouin function variation for spin $\mathrm{S}=1$ of $\mathrm{Ni}^{2+}$ following the magnitudes of the Brillouin function as a function of $\mathrm{T} / \mathrm{T}_{\mathrm{N}}$ calculated by Darby [1967]. It is noted that in Fig. 3.20(b) both $\mathrm{H}_{\mathrm{C} 1}$ and $\mathrm{H}_{\mathrm{C} 2}$ are normalized to $\mathrm{H}_{\mathrm{C} 2}(0)=54.5 \mathrm{kOe}$, whereas in Fig. 3.20(a) $\mathrm{H}_{\mathrm{C} 2}$ is normalized to $\mathrm{H}_{\mathrm{C} 2}(0)=53.5 \mathrm{kOe}$, to plot the critical fields in reduced scales. 


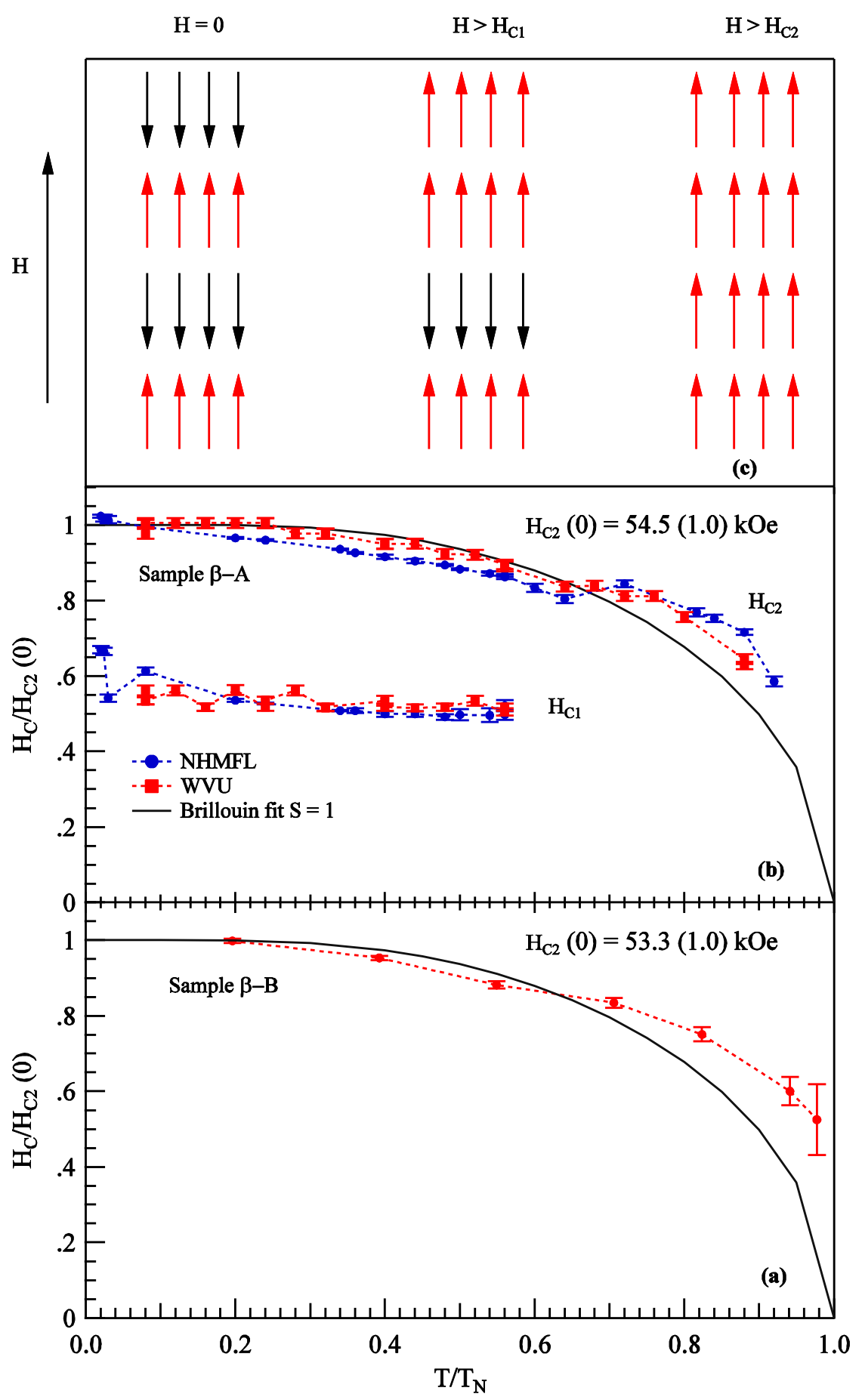

Figure 3.20: Normalized critical magnetic fields for (a) sample $\beta$-B and (b) sample $\beta$-A. (c) Schematic representation of the evolution of the system from antiferromagnetic to ferromagnetic with an applied magnetic field. 


\subsection{Discussion and Interpretation}

For a ferromagnet in the limit $\mathrm{T} \rightarrow 0 \mathrm{~K}, \mathrm{M}_{\mathrm{S}}=\mathrm{Ng} \mu_{\mathrm{B}}\langle S\rangle$. For sample $\beta$-A $\left(\beta-\mathrm{Ni}(\mathrm{OH})_{2} \bullet 0.15 \mathrm{H}_{2} \mathrm{O}\right)$, using $\mathrm{g}=2.2$ and $\mathrm{S}=0.92$ yields the calculated $\mathrm{M}_{\mathrm{S}}=118.5 \mathrm{emu} / \mathrm{g}$ in excellent agreement with the experimental $\mathrm{M}_{\mathrm{S}}=118 \mathrm{emu} / \mathrm{g}$ determined above in Fig. 3.19 for $\mathrm{H}>145 \mathrm{kOe}$. Thus it is inferred from above that for $\mathrm{H}>145 \mathrm{kOe}$, the system is in the ferromagnetic state. Why saturation of magnetization is not observed just above $\mathrm{H}_{\mathrm{c}}=55 \mathrm{kOe}$ is discussed later. We next address the origin for $\mathrm{H}_{\mathrm{C} 2}$ and the equality $\mathrm{H}_{\mathrm{C} 1} \simeq \mathrm{H}_{\mathrm{C} 2} / 2$ by deriving expressions for $\mathrm{H}_{\mathrm{C} 2}$ and $\mathrm{H}_{\mathrm{C} 1}$ using a molecular field approach.

As noted earlier, the $\mathrm{Ni}^{2+}$ spins in $\beta-\mathrm{Ni}(\mathrm{OH})_{2}$ in the antiferromagnetic state are parallel along the c-axis within each c-plane, with the alternate c-planes aligned antiferromagnetically. The model is based on a two-sublattice model, the standard procedures for the molecular-field model [Morrish, 2001], and the Hamiltonian

$$
\mathscr{H}=-2 \sum_{i, j} J_{i j} \overrightarrow{S_{i}} \cdot \overrightarrow{S_{j}}-\mathrm{g} \mu_{\mathrm{B}} \vec{H} \cdot \sum_{i} \overrightarrow{S_{i}}
$$

Assuming Ising-like ordering, $\overrightarrow{\mathrm{H}} \|$ to the $\mathrm{c}$-axis, and the three exchange interactions $\mathbf{J}_{1}, \mathrm{~J}_{2}$, and $\mathbf{J}_{3}$ (seen in Fig. 2.1), the following equations for $\theta$ and $\mathrm{T}_{\mathrm{N}}$ are obtained:

$$
\begin{gathered}
3 k_{\mathrm{B}} \theta=2 \mathrm{~S}(\mathrm{~S}+1)\left[\mathrm{J}_{1} \mathrm{Z}_{1}+\left(\mathrm{J}_{2} \mathrm{Z}_{2}+\mathrm{J}_{3} \mathrm{Z}_{3}\right)\right] \\
3 k_{\mathrm{B}} \mathrm{T}_{\mathrm{N}}=2 \mathrm{~S}(\mathrm{~S}+1)\left[\mathrm{J}_{1} \mathrm{Z}_{1}-\left(\mathrm{J}_{2} \mathrm{Z}_{2}+\mathrm{J}_{3} \mathrm{Z}_{3}\right)\right]
\end{gathered}
$$


where $k_{\mathrm{B}}$ is the Boltzmann constant and $\mathrm{Z}_{1}=6, \mathrm{Z}_{2}=2$, and $\mathrm{Z}_{3}=12$ are the appropriate number of neighbors involved in the exchange constants $J_{1}, J_{2}$, and $J_{3}$ respectively for the hexagonal lattice. To obtain an equation for $\mathrm{H}_{\mathrm{C} 2}$ for the transition from the antiferromagnetic state in $\mathrm{H}=0$ to the ferromagnetic state for $\mathrm{H} \geq \mathrm{H}_{\mathrm{C} 2}$ applied along the c-axis, we compare the energies of the two states using the Hamiltonian in Eq. (3.2):

$$
\begin{gathered}
\mathrm{E}_{\uparrow \downarrow}=-2 \mathrm{NS}^{2}\left[\mathrm{~J}_{1} \mathrm{Z}_{1}-\left(\mathrm{J}_{2} \mathrm{Z}_{2}+\mathrm{J}_{3} \mathrm{Z}_{3}\right)\right] \\
\mathrm{E}_{\uparrow \uparrow}=-2 \mathrm{NS}^{2}\left[\mathrm{~J}_{1} \mathrm{Z}_{1}+\left(\mathrm{J}_{2} \mathrm{Z}_{2}+\mathrm{J}_{3} \mathrm{Z}_{3}\right)\right]-\mathrm{Ng} \mu_{\mathrm{B}} \mathrm{SH}
\end{gathered}
$$

For $\mathrm{E}_{\uparrow \downarrow}=\mathrm{E}_{\uparrow \uparrow}$ at $\mathrm{H}=\mathrm{H}_{\mathrm{C} 2}$ yields

$$
\mathrm{H}_{\mathrm{C} 2}=-4 \mathrm{~S}\left(\mathrm{~J}_{2} \mathrm{Z}_{2}+\mathrm{J}_{3} \mathrm{Z}_{3}\right) /\left(\mathrm{g} \mu_{\mathrm{B}}\right)
$$

The signs and magnitudes of $\mathrm{J}_{1}, \mathrm{~J}_{2}, \mathrm{~J}_{3}$, and $\mathrm{H}_{\mathrm{C} 2}$ are now calculated using the above derived equations for $\theta, \mathrm{T}_{\mathrm{N}}$, and $\mathrm{H}_{\mathrm{C} 2}$. For sample $\beta-\mathrm{A}, \theta=20.5 \mathrm{~K}$ and we take $\mathrm{T}_{\mathrm{N}}=25 \mathrm{~K}$ (the temperature at which $2 \mathrm{D}$ ordering sets in). Use of these magnitudes of $\theta$ and $\mathrm{T}_{\mathrm{N}}$ with $\mathrm{g}=2.2$ and $\mathrm{S}=0.92$ in Eqs. (3.3) and (3.4) leads to $J_{1} / k_{B}=3.25 \mathrm{~K}$, and $\left(J_{2} \mathrm{Z}_{2}+J_{3} \mathrm{Z}_{3}\right) / k_{B}=-1.91 \mathrm{~K}$. Following the arguments by Enoki and Tsujikawa [1975], $\mathrm{J}_{2}=3 \mathrm{~J}_{3}$ is assumed leading to $J_{2} / k_{\mathrm{B}}=-0.32 \mathrm{~K}$ and $J_{3} / k_{\mathrm{B}}=-0.11 \mathrm{~K}$. The signs and magnitudes of the exchange constants $\mathrm{J}_{1}, \mathrm{~J}_{2}$, and $\mathrm{J}_{3}$ determined above implies that the dominant intra-planar exchange $\left(\mathrm{J}_{1}\right)$ is ferromagnetic, and it is an order of magnitude larger than the interplanar antiferromagnetic exchange constants $\left(\mathbf{J}_{2}\right.$ and $\left.\mathbf{J}_{3}\right)$. Similar analysis for sample $\beta$-B with $\theta=19.8 \mathrm{~K}$ and $\mathrm{T}_{\mathrm{N}}=25.5 \mathrm{~K}$ (Fig. 3.2(b) and Fig. 3.4(b)) yields $\mu=3.3 \mu_{\mathrm{B}} / \mathrm{Ni}^{2+}$ ion, $J_{1} / k_{\mathrm{B}}=2.67 \mathrm{~K}$ and $J_{2} / k_{\mathrm{B}}=3 J_{3} / k_{\mathrm{B}}=-0.315 \mathrm{~K}$. In the earlier studies of bulk-like 
$\beta-\mathrm{Ni}(\mathrm{OH})_{2}\left[\right.$ Enoki \& Tsujikawa, 1975] $J_{1} / k_{\mathrm{B}}=2.70 \mathrm{~K}, J_{2} / k_{\mathrm{B}}=-0.28 \mathrm{~K}$, and $J_{3} / k_{\mathrm{B}}=-0.09 \mathrm{~K}$ were determined. So the signs and magnitudes of the exchange constants determined here for our sample $\beta$-B and those determined by Enoki and Tsujikawa for bulk-like $\beta-\mathrm{Ni}(\mathrm{OH})_{2}$ are nearly the same.

Next, Eq. (3.7) and the exchange constants determined above are used to determine the magnitude of $\mathrm{H}_{\mathrm{C} 2}$ for the two cases discussed above. For $\mathrm{S}=0.92$ as in sample $\beta$-A, $\mathrm{H}_{\mathrm{C} 2}=47.6 \mathrm{kOe}$ is calculated using Eq. (3.7), whereas for the $\mathrm{S}=0.97$ case, $\mathrm{H}_{\mathrm{C} 2}=51.8 \mathrm{kOe}$ is determined. These magnitudes are in good agreement with the experimental value of $\mathrm{H}_{\mathrm{C} 2} \simeq 55 \mathrm{kOe}$ considering that the calculations of $\mathrm{H}_{\mathrm{C} 2}$ were determined using parameters determined from the data for $\mathrm{T}>\mathrm{T}_{\mathrm{N}}$, whereas the experimental value of $55 \mathrm{kOe}$ is measured at $2 \mathrm{~K}$. According to Eq. (3.7), the temperature dependence of $\mathrm{H}_{\mathrm{C} 2}$ should be governed by the temperature dependence of $\langle\vec{S}\rangle$, which reflects the order parameter. The solid line in Fig. 3.20 is the Brillouin function variation for $S=1$ [Darby, 1967] showing agreement with the temperature variation of the data for $\mathrm{H}_{\mathrm{C} 2}$ for our samples except for the region close to $\mathrm{T}_{\mathrm{N}}$ where experimental values of $\mathrm{H}_{\mathrm{C} 2}$ are consistently higher for both samples. Some comments on this disagreement are made later. Furthermore, this analysis shows that for the metamagnetic transition to ferromagnetic order, the required magnetic field needs to overcome the interplanar antiferromagnetic coupling only (Eq. (3.7)). Since our measurements have been carried out on polycrystalline samples, the observed transition at $\mathrm{H}_{\mathrm{C} 2}$ is somewhat smeared because only a fraction of the crystallites are oriented with $\overrightarrow{\mathrm{H}} \| \mathrm{c}$-axis.

For $\mathrm{Ni}^{2+}$ spins on the surface layer of a $(00 \ell)$ oriented nanoplate of $\beta-\mathrm{Ni}(\mathrm{OH})_{2}$, the number of next-nearest-neighbors $\left(Z_{2}=1\right.$ and $\left.Z_{3}=6\right)$ are just half the number for spins than that for a 
layer deep inside the nanoplate. Although $Z_{1}=6$ is unchanged for the surface layer, Eq. (3.7) does not depend on $Z_{1}$. Therefore, the magnetic field required to switch the moments of a surface layer is just half of $\mathrm{H}_{\mathrm{C} 2}$. This field is associated with $\mathrm{H}_{\mathrm{C} 1}$ observed here following the suggestion of Miyamoto [1966]. Although Miyamoto did not carry out any calculations for $\mathrm{H}_{\mathrm{C} 1}$ or $\mathrm{H}_{\mathrm{C} 2}$, the gradual weakening of the peak associated with $\mathrm{H}_{\mathrm{Cl}}$ was reported as the particle size increased. Thus $\mathrm{H}_{\mathrm{C} 1}=\mathrm{H}_{\mathrm{C} 2} / 2$ represents the switching of the moments on the surface layer from the antiparallel to a direction parallel to the applied magnetic field (Fig. 3.20(c)). The peak associated with $\mathrm{H}_{\mathrm{C} 1}$ weakens with increase in particle size because the fraction of spins on the surface to the total number of spins in the sample decreases with increase in size. Thus the absence of a peak related to $\mathrm{H}_{\mathrm{Cl}}$ in bulk-like sample $\beta$-B can be understood.

The magnetic field $\mathrm{H}_{\mathrm{S}} \simeq 150 \mathrm{kOe}$ required to saturate the magnetization (Fig. 3.19) is much larger than the field $\mathrm{H}_{\mathrm{C} 2} \simeq 55 \mathrm{kOe}$ needed for metamagnetic transition. This apparent anomaly results from the fact that in a powder sample on average, $\chi_{\mathrm{p}}=\left(\chi_{\|}+2 \chi_{\perp}\right) / 3$ is the measured susceptibility where $\chi_{\|}\left(\chi_{\perp}\right)$ is the susceptibility for $\overrightarrow{\mathrm{H}} \|(\perp)$ to the c-axis. Whereas $\mathrm{H}_{\mathrm{C} 2}$ corresponds to metamagetism for $\vec{H} \| \mathrm{c}$-axis, $\mathrm{H}_{\mathrm{S}}$ is interpreted to be the magnetic field required to saturate $\chi_{\perp}$ when $\mathrm{M}_{\perp}=\mathrm{M}_{\|}$. Using $\chi_{\perp}=7.71 \times 10^{-4} \mathrm{emu} /(\mathrm{g} \mathrm{Oe})$ reported by Takada et al. [1966] $\mathrm{H}_{\mathrm{S}}=\mathrm{M}_{S} / \chi_{\perp}=153 \mathrm{kOe}$ is calculated for $\mathrm{M}_{\mathrm{S}}=118 \mathrm{emu} / \mathrm{g}$. This is in good agreement with $\mathrm{H}_{\mathrm{S}} \simeq 150 \mathrm{kOe}$ evident in the data of Fig. 3.19.

The magnetic remanence $\left(\mathrm{M}_{\mathrm{r}}\right)$ and its temperature dependence is likely associated with the particle size effect also since studies by Miyamoto [Miyamoto, 1966] on four different particle sizes of $\beta-\mathrm{Ni}(\mathrm{OH})_{2}$ showed $\mathrm{M}_{\mathrm{r}}$ to increase with decrease in particle size. An explanation 
for this effect is as follows. For even number of (00€) layers in nanoplates, the moments are compensated for $\mathrm{H}=0$ and $\mathrm{T} \rightarrow 0 \mathrm{~K}$, leading to antiferromagnetic order and zero $\mathrm{M}_{\mathrm{r}}$. However, for odd number of layers, there are uncompensated spin moments yielding $\mathrm{M}_{\mathrm{r}}$. Based on the statistical orientation of a polycrystalline sample, on average only $1 / 3$ of the particles will be oriented with $\vec{H} \| \mathrm{c}$-axis, and the number of crystallites with odd number of layers on average equal about half of the total number. The number of uncompensated surface layers depends on the total $(2 m+1)$ odd number of layers. These factors lead to $M_{r}=\frac{M_{s}}{6(2 m+1)}$ with $m=4$ for our sample with plate thickness $d=4.3 \mathrm{~nm}$ using $\mathrm{c}=0.467 \mathrm{~nm}$. This yields $\mathrm{M}_{\mathrm{r}} \simeq 2.2 \mathrm{emu} / \mathrm{g}$, in close agreement with the measured value for the $\mathrm{FC}$ case at $2 \mathrm{~K}$ (Fig. 3.15). The temperature dependence of $M_{r}$ for the FC case closely follows the Brillouin function variation for $S=1$ as expected. The peak in $\mathrm{M}_{\mathrm{r}}(\mathrm{ZFC}$ ) near $15 \mathrm{~K}$ (Fig. 3.15) is not yet understood.

The sharp rise of $\chi(\mathrm{FC})$ in Fig. 3.1 for $\mathrm{T}<\mathrm{T}_{\mathrm{p}}$ is observed only in sample $\beta$-A but not in bulk-like sample $\beta$-B. A similar rise for $\chi(\mathrm{FC})$ in the $8 \mathrm{~nm}$ sample of Tiwari et al. [2008] was also reported. Therefore, it is inferred that this effect is present only in nanoparticles. It is very likely that this effect is due to the uncompensated spins of the odd number of layers and the fact that $\mathrm{H}_{\mathrm{C} 1}$ is also likely zero at $\mathrm{T}_{\mathrm{N}}$. Thus nanoplates of $\beta-\mathrm{Ni}(\mathrm{OH})_{2}$ display the unique characteristics of both ferromagnetic and antiferromagnetic order depending on whether the sample is cooled to $\mathrm{T}<\mathrm{T}_{\mathrm{N}}$ in a magnetic field or in zero field.

In Fig. 3.20 it is evident that in the temperature variation of $\mathrm{H}_{\mathrm{C} 2}$ on approach to $\mathrm{T}_{\mathrm{N}}$, the observed magnitudes of $\mathrm{H}_{\mathrm{C} 2}$ are higher than the predicted Brillouin function variation for $\mathrm{S}=1$ based on the molecular field approximation. Theoretically, Fox and Guttmann [1973] have examined the low temperature critical behavior of the Ising model for $S=1$ and $S=3 / 2$ using the 
low temperature series expansions. Their results for the triangular and BCC lattices on the variation of $\langle S\rangle$ against $\mathrm{T} / \mathrm{T}_{\mathrm{C}}$ show that on approach to $\mathrm{T}_{\mathrm{C}}$, the calculated magnitude of $\langle S\rangle$ for a given $\mathrm{T} / \mathrm{T}_{\mathrm{C}}$ is larger than that predicted by the molecular field theory. This is qualitatively similar to our observation in Fig. 3.20 for both samples $\beta$-A and $\beta$-B. However a quantitative test is not possible because of the dependence of the calculations on the lattice type and size dependence is not addressed by Fox and Guttmann.

Our final comment is on the observed magnetic field variation of $\mathrm{T}_{1}$ and $\mathrm{T}_{2}$ in Fig. 3.6(b). Whereas $T_{1}$ associated with $2 \mathrm{D}$ ferromagnetic ordering is essentially independent of $H, T_{2}$ associated with 3D antiferromagnetic ordering varies nearly as $\mathrm{H}^{\frac{1}{2}}$. Bienenstock [1966] has calculated the variation of $\mathrm{T}_{\mathrm{N}}$ in Ising antiferromagnets with $\mathrm{H}$ using high temperature series expansion, yielding $\mathrm{T}_{\mathrm{C}}(\mathrm{H}) / \mathrm{T}_{\mathrm{C}}(0)=\left[1-\left(\mathrm{H} / \mathrm{H}_{\mathrm{K}}\right)^{2}\right]^{\xi}$ with $\xi=0.87,0.35$, and 0.36 for square, SC, and BCC lattices. The importance of these predictions is that for $3 \mathrm{D}$ ordering, change in $\mathrm{T}_{\mathrm{C}}(\mathrm{H})$ with $\mathrm{H}$ is much weaker than the $\mathrm{H}^{2}$ dependence, as observed here for $\mathrm{T}_{2}$ in $\beta-\mathrm{Ni}(\mathrm{OH})_{2}$. However, without an accurate knowledge of $\mathrm{H}_{\mathrm{K}}$, a more quantitative comparison is not possible.

\subsection{Concluding Remarks:}

Detailed measurements of the magnetic properties of the layered antiferromagnet $\beta-\mathrm{Ni}(\mathrm{OH})_{2}$ have been compared for two samples viz. sample $\beta$-A with nanoplate morphology and bulk-like sample $\beta-\mathrm{B}$, along with theoretical interpretation of the results using a molecular field approach. These investigations have clearly established this material to be a metamagnet with a critical field $\mathrm{H}_{\mathrm{C} 2} \simeq 55 \mathrm{kOe}$ associated with the transition from antiferromagnetism for 
$\mathrm{H}<\mathrm{H}_{\mathrm{C} 2}$ to ferromagnetism for $\mathrm{H}>\mathrm{H}_{\mathrm{C} 2}$ for $\vec{H} \| \mathrm{c}$-axis. Moreover, the observed $\mathrm{H}_{\mathrm{C} 1} \simeq 28 \mathrm{kOe}$ in sample $\beta$-A only is associated with the magnetic field-induced flipping of the $\mathrm{Ni}^{2+}$ moments on the surface layers whose relative fraction increases with decrease in the thickness of the nanoplates. Therefore the observation of $\mathrm{H}_{\mathrm{C} 1}$ being a size-dependent effect is understood. Similarly the observed remanence and coercivity in sample $\beta$-A for $T<T_{N}$ is also a nanosize effect related to uncompensated surface layers. In contrast, in bulk-like sample $\beta-\mathrm{B} \mathrm{H}_{\mathrm{C} 1}$ is not observed, while its remanence and coercivity for $\mathrm{T}<\mathrm{T}_{\mathrm{N}}$ are negligible. Because the in-plane exchange coupling is ferromagnetic and it is also an order of magnitude larger than the antiferromagnetic interplane coupling, it leads to the observed two-step magnetic ordering on lowering the temperature: ferromangetic ordering of the $\mathrm{Ni}^{2+}$ moments in the $(00 \ell)$ layers at a higher temperature $T_{1}$ followed by long-range antiferromagnetic ordering at a lower temperature $\mathrm{T}_{2}$. The appearance of this two-step transition has been previously observed using specific heat measurements, but this study is the first to show these transitions using magnetic measurements directly. Using a molecular field approach, expressions for $\mathrm{H}_{\mathrm{C} 1}$ and $\mathrm{H}_{\mathrm{C} 2}$ are derived in terms of the exchange constants and the theoretical estimates of $\mathrm{H}_{\mathrm{C} 1}$ and $\mathrm{H}_{\mathrm{C} 2}$ are in good agreement with the observed values. Similarly, the observed magnitude of remanence is satisfactorily explained. Finally, the observed temperature dependence of $\mathrm{H}_{\mathrm{C} 2}$ in samples $\beta-\mathrm{A}$ and $\beta-\mathrm{B}$ are compared with the Brillouin function variation for $S=1$; the observed disagreements on approach to $T_{N}$ are discussed in terms of the breakdown of the molecular field approximation near $\mathrm{T}_{\mathrm{N}}$. 


\section{CHAPTER IV \\ Magnetic properties of $\alpha-\mathrm{Ni}(\mathrm{OH})_{2}$}

\subsection{Experimental Procedure for Measurements}

All magnetic measurements on the two samples of $\alpha-\mathrm{Ni}(\mathrm{OH})_{2}$ viz. sample $\alpha-\mathrm{A}$ and sample $\alpha$-B described in this chapter were carried out with our in-house SQUID magnetometer. The magnetization was measured up to $\pm 65 \mathrm{kOe}$ while changing magnetic field (isotherms) and by changing temperature at a fixed magnetic fields (isofields) from $2 \mathrm{~K}$ to $300 \mathrm{~K}$, independently. These magnetization measurements were carried out using the Reciprocating Sample Option (RSO), while ac susceptibility was measured with an oscillatory magnetic field $\mathrm{H}_{\mathrm{ac}}=7$ Oe between $2 \mathrm{~K}$ and $36 \mathrm{~K}$ for frequencies from $0.1 \mathrm{~Hz}$ to $1000 \mathrm{~Hz}$. Additional ac susceptibility measurements were performed with a DC applied magnetic field up to $2 \mathrm{kOe}$ for insight into the thermal phase transitions. Zero field cooled (ZFC) data were taken by reducing the sample temperature from room temperature to $2 \mathrm{~K}$ without an applied magnetic field, then turning on the magnetic field $\mathrm{H}$ while increasing temperature and taking magnetization measurements at select temperature up to $300 \mathrm{~K}$. The field cooled (FC) magnetization data was taken directly after ZFC data by decreasing the temperature from $300 \mathrm{~K}$ to $2 \mathrm{~K}$ in the applied magnetic field $\mathrm{H}$ from $\mathrm{ZFC}$ data. Magnetic field dependent magnetization was performed by lowering the temperature from $300 \mathrm{~K}$ to the select temperature in zero magnetic field (ZFC) and an applied magnetic field of $5 \mathrm{kOe}(\mathrm{FC}(\mathrm{H}=5 \mathrm{kOe}))$. The temperature was raised to $300 \mathrm{~K}$ between each $\mathrm{M}$ vs. $\mathrm{H}$ data and hysteresis loop measurements. 


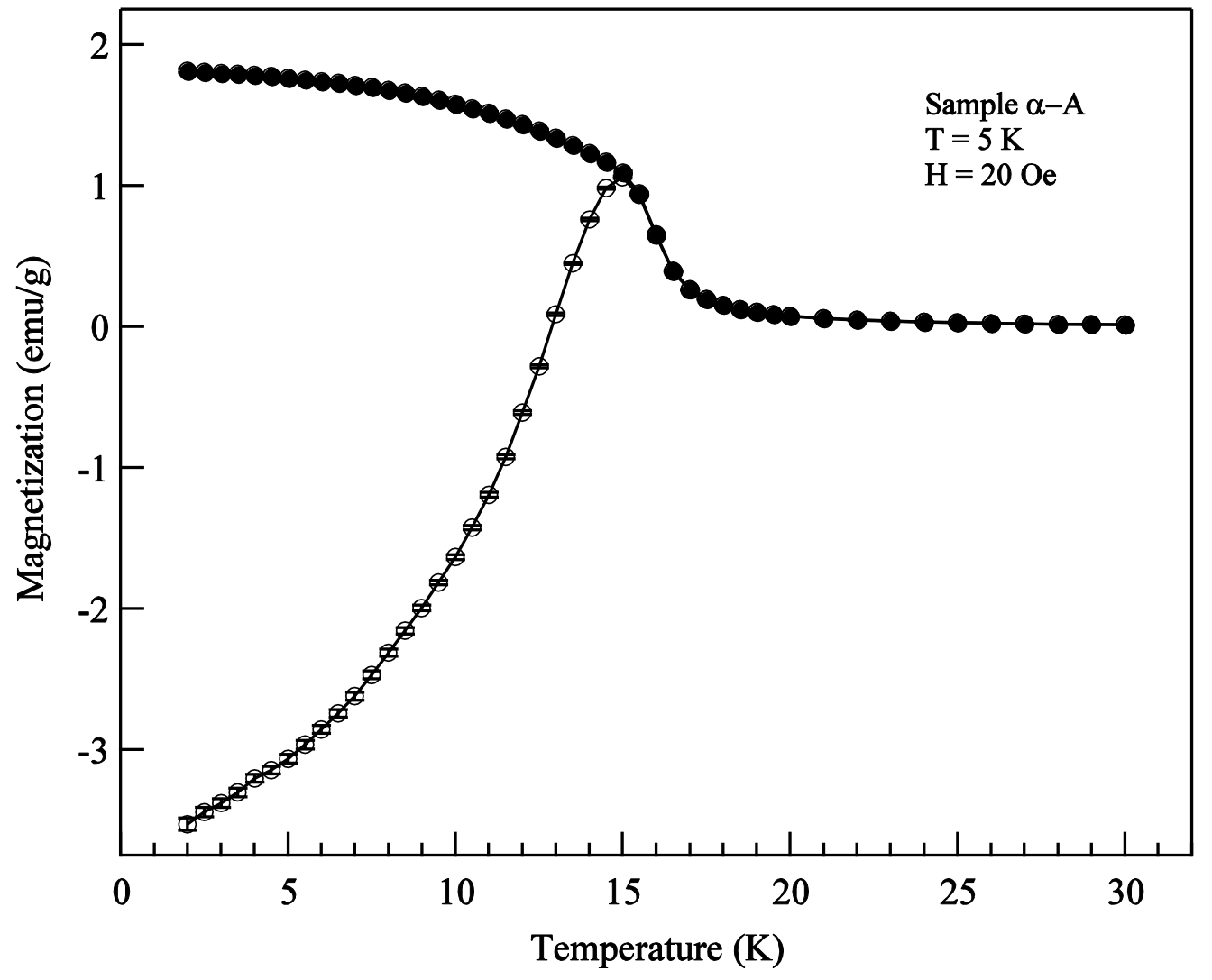

Figure 4.1: Preliminary temperature dependent magnetization data for sample $\alpha$-A.

\subsection{Preliminary Results}

Fig. 4.1 shows the initial measurements of $\alpha-\mathrm{Ni}(\mathrm{OH})_{2}$ sample $\alpha$-A for the ZFC-FC mode in $\mathrm{H}=20$ Oe. From these measurements, a transition near $\mathrm{T}_{\mathrm{p}}=15 \mathrm{~K}$ is apparent. The unusual negative magnetization in $\mathrm{M}$ vs. $\mathrm{T}$ data below $15 \mathrm{~K}$ is due to a remanent magnetic field in the system indicating that the field has to be reset to zero between each run. Therefore, after each data set (i.e. ZFC-FC, $\mathrm{H}=20 \mathrm{Oe}$ ) the system was heated up to $300 \mathrm{~K}$, and the magnetic field was reset to zero by quenching any remanent magnetic field. The SQUID system has a set procedure to accomplish this task. All the measurements reported next were done after the zero-field reset procedure. 


\subsection{Temperature Dependence of Magnetization}

The ZFC-FC data were taken at several applied magnetic fields viz. $\mathrm{H}=50,100,300$, $800,1000,2500,3000$, and 3500 Oe for sample $\alpha-A$ and $H=50$ and 500 Oe for sample $\alpha-B$ (Fig. 4.2 and 4.3). Both samples show similar characteristics in the ZFC-FC data and in the effect of an applied magnetic field on the ZFC-FC curves. For $\mathrm{H}=50 \mathrm{Oe}$, maximum in $\mathrm{M}(\mathrm{ZFC})$ is observed at $T_{p}=13 \mathrm{~K}$ and $16 \mathrm{~K}$ for sample $\alpha$-A and sample $\alpha-B$, respectively. Although the peak seems to broaden with applied magnetic field, the decrease in the magnetization from its peak

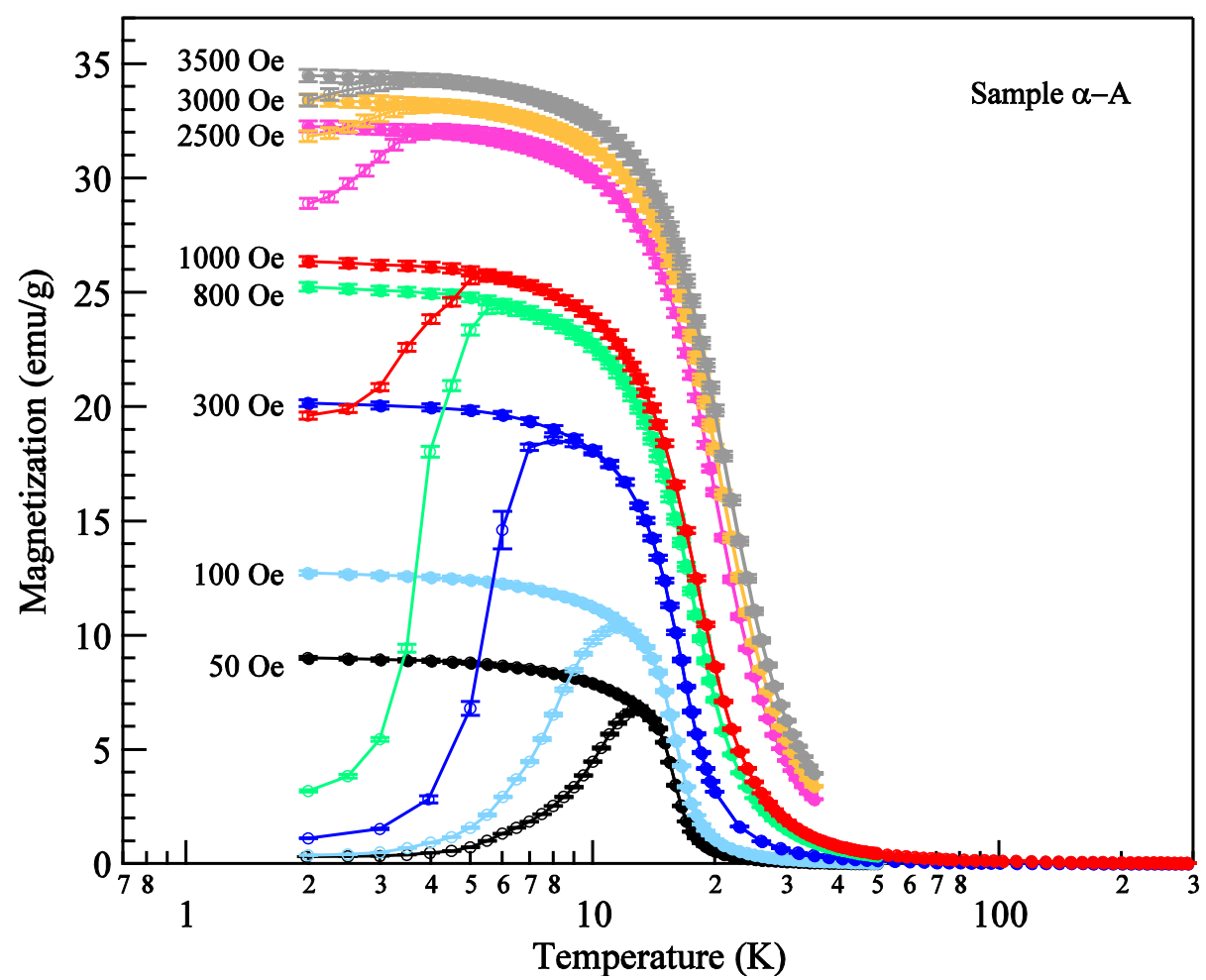

Figure 4.2: Thermal variation of magnetization for sample $\alpha$-A.

value at $\mathrm{T}_{\mathrm{p}}$ for the $\mathrm{ZFC}$ case is observed for all magnetic fields. The $\mathrm{M}(\mathrm{ZFC})$ and $\mathrm{M}$ (FC) data are nearly identical above $T_{p}$ for each applied magnetic field and they bifurcate below $T_{p}$. Although $\mathrm{H}$ does not appear to affect the characteristics of $\mathrm{M}(\mathrm{FC})$, it does have an affect on $\mathrm{M}(\mathrm{ZFC})$ and the approach to maximum. It is noted that this bifurcation still occurs at magnetic 
field of $\mathrm{H}=3500 \mathrm{kOe}$. The non-uniform broadening of the peak in $\mathrm{M}$ vs. $\mathrm{T}$ with applied magnetic field $\mathrm{H}$ is due to the peak being a composition of three thermal transitions. These transitions become more evident in the ac susceptibility measurements (section 4.7). Interpretations of these transitions are given in section 4.9.

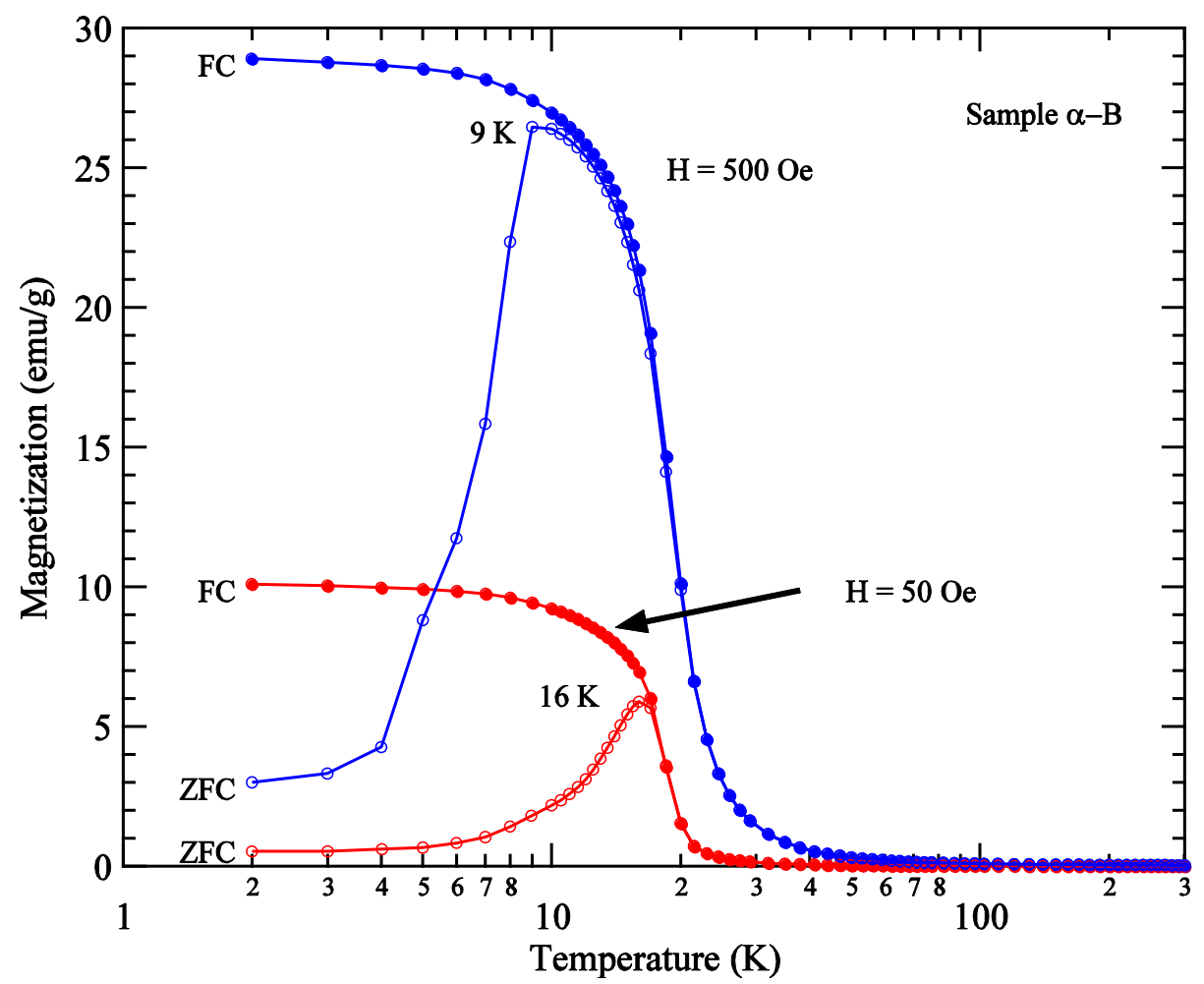

Figure 4.3: Thermal variation of magnetization for sample $\alpha-B$.

Due to the unusual broadening of the peak in M(ZFC) data with applied magnetic field, Fig. 4.4 shows a more thorough study of $\mathrm{M}(\mathrm{T})$ for the ZFC case at larger number of magnetic fields up to $\mathrm{H}=1800$ Oe. The inset shows the magnetic field dependence of $T_{p}$. As noted in chapter III, the transition temperature of an antiferromagnet is not associated with the peak temperature, but corresponds to the maximum temperature of $\left(\frac{\partial(\chi \mathrm{T})}{\partial \mathrm{T}}\right)$ [Fisher, 1962]. Using the Curie-Weiss variation leads to $\frac{\partial(\chi \mathrm{T})}{\partial \mathrm{T}}=-\frac{\mathrm{C} \theta}{(\mathrm{T}-\theta)^{2}}$ and maximum corresponding to negative $\theta$ 
(i.e. antiferromagnetic) while positive is associated with ferromagnetism and minimum of $\left(\frac{\partial(\chi \mathrm{T})}{\partial \mathrm{T}}\right)$. A similar analysis was presented for $\beta-\mathrm{Ni}(\mathrm{OH})_{2}$ in the previous chapter and in our published paper on $\beta-\mathrm{Ni}(\mathrm{OH})_{2}$ [Rall et al., 2010(a)]. Fig. 4.5 shows both $\chi \mathrm{T}$ and $\left(\frac{\partial(\chi \mathrm{T})}{\partial \mathrm{T}}\right)$ vs. $\mathrm{T}$ plots for $\mathrm{M}(\mathrm{ZFC})$ data of Fig. 4.4. $\mathrm{T}_{1}$ represents a $2 \mathrm{D}$ ferromagnetic transition similar to the results seen in $\beta-\mathrm{Ni}(\mathrm{OH})_{2}$ while $\mathrm{T}_{2}$ does not represent a magnetic transition due to the large dependence on magnetic field. The slight increase of $T_{1}$ due to an applied field in Fig. 4.6 is consistent with a $2 \mathrm{D}$ Curie temperature for a ferromagnet. The magnetic field dependence of $\mathrm{T}_{2}$ is used as evidence of a blocking temperature in the system due to nanoparticle sizes and is more thoroughly discussed in section 4.9 .

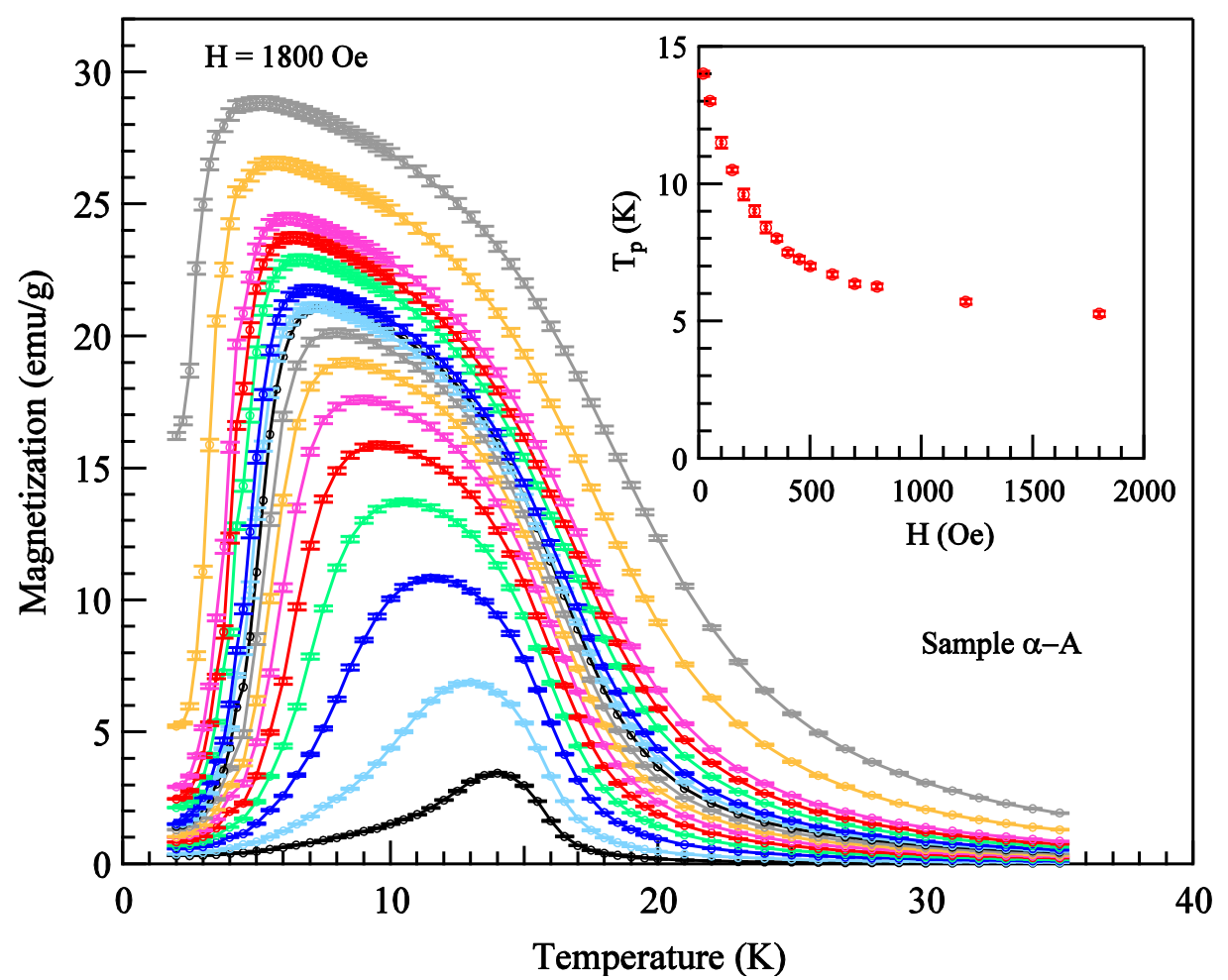

Figure 4.4: Temperature dependence of $\mathrm{M}(\mathrm{ZFC})$ in different applied magnetic fields: $H=20,50,100,150,200,250,300$, $350,400,450,500,600,700,800,1200$, and 1800 Oe. The inset shows the H dependence of $\mathrm{T}_{\mathrm{p}}$. 


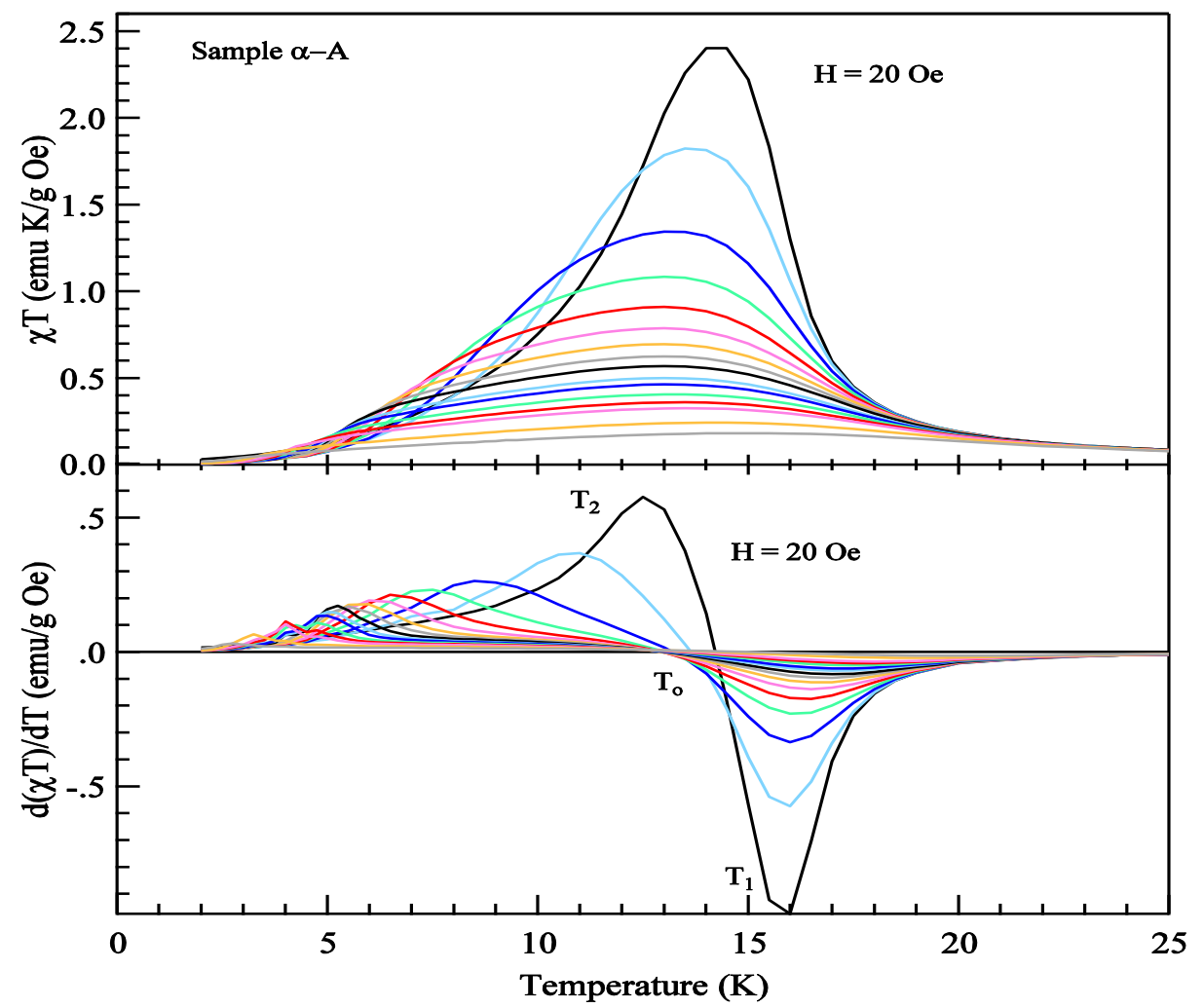

Figure 4.5: Temperature dependence of $\chi \mathrm{T}$ and $\partial(\chi \mathrm{T}) / \partial \mathrm{T}$ for different $\mathrm{H}$ using the data of Fig. 4.4.

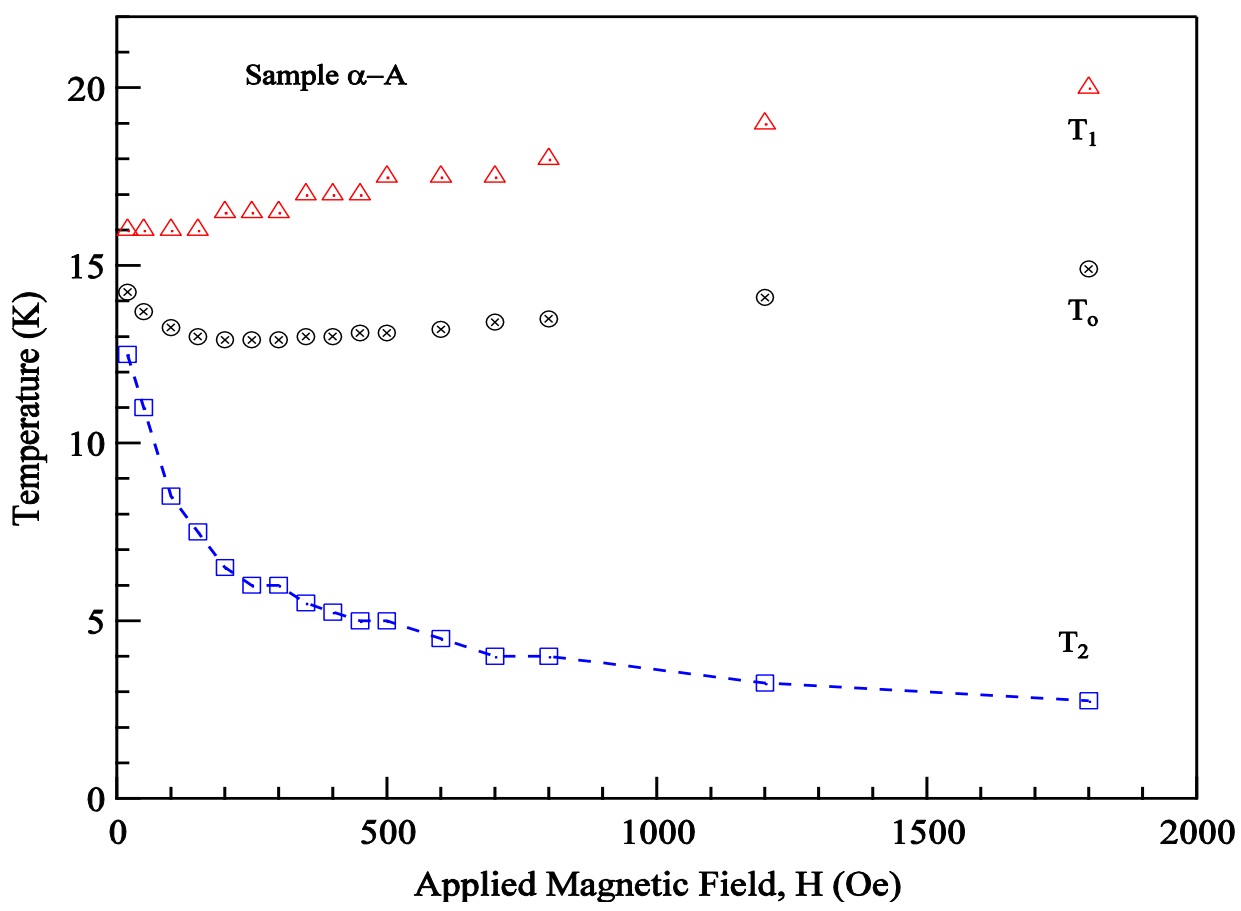

Figure 4.6: Magnetic field dependence of the three characteristic temperature of $\mathrm{T}_{1}, \mathrm{~T}_{\mathrm{o}}$, and $\mathrm{T}_{2}$, defined in Fig. 4.5. 


\subsection{Magnetic Field Dependence}

The $\mathrm{M}$ vs. $\mathrm{H}$ plots for sample $\alpha$-A in Fig. 4.7 at $\mathrm{T}=2,10,15,120,220$, and $320 \mathrm{~K}$ indicate the presence of three distinct temperature regions. At $\mathrm{T}=2 \mathrm{~K} \mathrm{M}$ vs. $\mathrm{H}$ shows an approximate $\mathrm{S}$ shaped curve similar to metamagnetism transition with $\mathrm{H}_{\mathrm{C}} \simeq 1150 \mathrm{Oe}$. This is significantly lower than $\mathrm{H}_{\mathrm{C}} \simeq 55 \mathrm{kOe}$ for $\beta-\mathrm{Ni}(\mathrm{OH})_{2}$ [Rall et al., 2010(a)]. At $\mathrm{T}=2 \mathrm{~K}$, even the magnetization is almost saturated at $\mathrm{H}=65 \mathrm{kOe}$. The $\mathrm{M}(\mathrm{H})$ curve at $10 \mathrm{~K}$ and $15 \mathrm{~K}$ shows more of a ferromagnetic behavior. At $\mathrm{T}=120 \mathrm{~K}, 220 \mathrm{~K}$, and $320 \mathrm{~K}$ (well above $\mathrm{T}_{\mathrm{p}}$ ), the $\mathrm{M}$ vs. $\mathrm{H}$ curves are linear, typical of paramagnetism. Sample $\alpha-B$ shows similar qualitative results for $\mathrm{M}(\mathrm{H})$ between 2 and $18 \mathrm{~K}$ (Fig. 4.8). A plot of $\mathrm{M}$ vs. $1 / \mathrm{H}$ for the $\mathrm{T}=2 \mathrm{~K}$ data yields $\mathrm{M}_{\mathrm{S}}=71 \mathrm{emu} / \mathrm{g}$ as the saturation magnetization in the limit of $\mathrm{H} \rightarrow \infty$, Fig. 4.9. This magnitude is considerably smaller than $\mathrm{M}_{\mathrm{S}}=118 \mathrm{emu} / \mathrm{g}$ observed for $\beta-\mathrm{Ni}(\mathrm{OH})_{2}$. The difference of the saturation magnetization is mainly attributed to the difference in density from the incorporation of anions and expansion of the unit cell.

\subsection{Temperature Dependence of the Critical Field for Metamagnetism}

The critical field $\mathrm{H}_{\mathrm{C}}$ above which the magnetization is almost saturated is determined from the maximum in $\chi=\frac{\partial \mathrm{M}}{\partial \mathrm{H}}$ using the data for $\mathbf{M}$ vs. $\mathrm{H}$ variation. This analysis is shown in Fig. 4.8(c) for sample $\alpha$-B and in Fig. 4.11 for sample $\alpha$-A. For a clearer view of this transition, $\mathrm{M}$ vs. $\mathrm{H}$ up to $\mathrm{H}=5 \mathrm{kOe}$ was taken at $1 \mathrm{~K}$ steps between 4 and $10 \mathrm{~K}$, followed by the data at $\mathrm{T}=12,14$, and $16 \mathrm{~K}$ (Fig. 4.10). To determine the magnetic field transition, $\chi=\frac{\partial \mathrm{M}}{\partial \mathrm{H}}$ (Fig. 4.11) was calculated from the data shown in Fig. 4.10 and the $2 \mathrm{~K}$ data in Fig. 4.8. The inset of Fig. 4.11 shows the temperature dependence of $\mathrm{H}_{\mathrm{C}} \cdot \mathrm{H}_{\mathrm{C}}$ approaches zero around $\mathrm{T}=10 \mathrm{~K}$, 
significantly lower than the transition temperature $\mathrm{T}_{1} \simeq 16 \mathrm{~K}$. In sample $\alpha-\mathrm{A}$ and $\alpha-\mathrm{B}, \chi=\frac{\partial \mathrm{M}}{\partial \mathrm{H}}$ shows only one transitional magnetic field. Given the results in the previous chapter (chapter III) and elsewhere [Rall et al., 2010(a)] about the particle size effects, there should be two magnetic field transitions since $\mathrm{c}=0.85 \mathrm{~nm}$ and the layer thickness of $\sim 10 \mathrm{~nm}$ gives $\sim 12$ layers. The lack of the second transition contradicts the typical two-sublattice model for antiferromagnetism established here for $\beta-\mathrm{Ni}(\mathrm{OH})_{2}$. The critical field $\mathrm{H}_{\mathrm{C}}$ is the result of domain-like structure embedded in the morphology of the particles. Further discussion is presented in section 4.9.

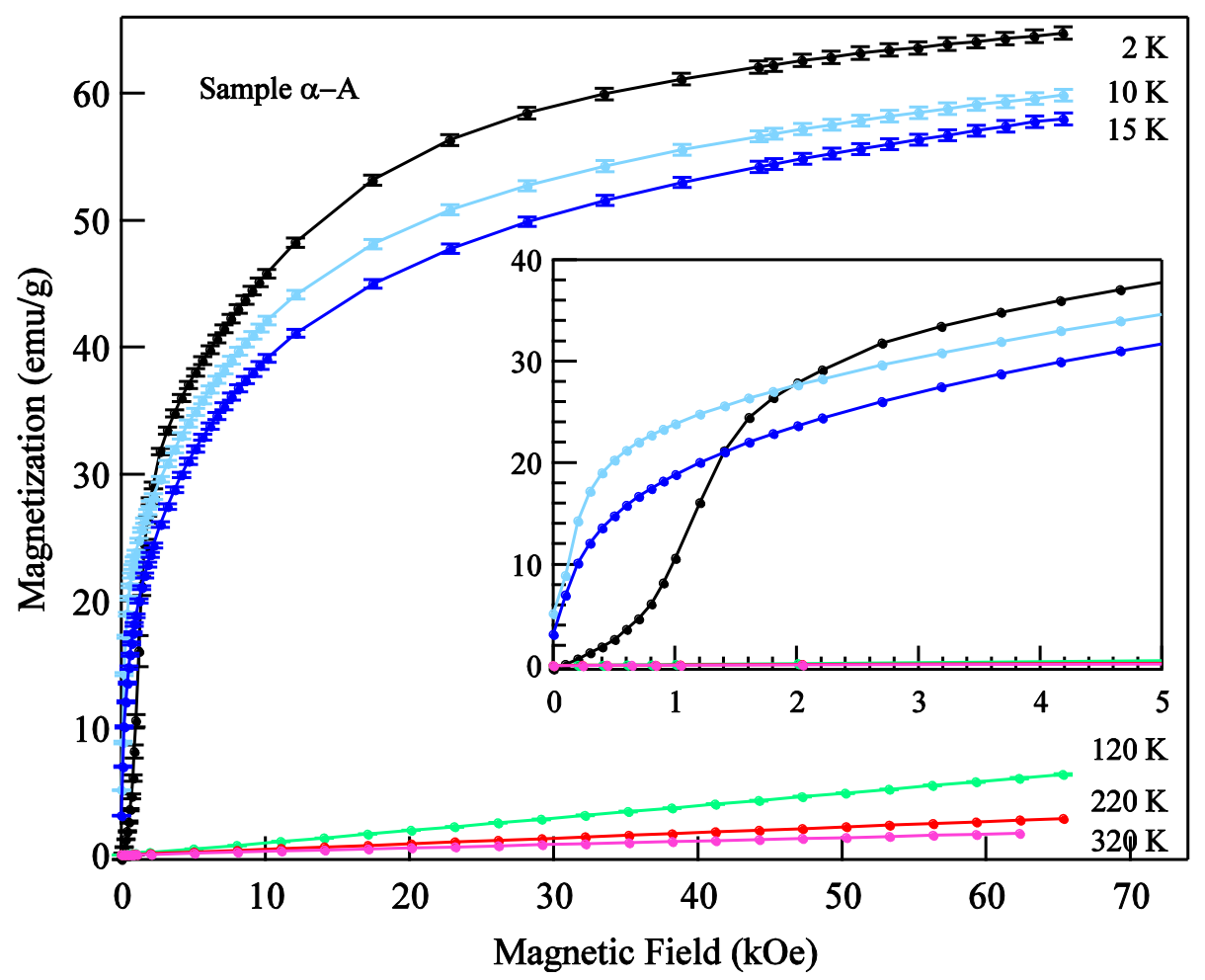

Figure 4.7: Magnetic field variation of magnetization at differing temperature of $\mathrm{T}=2,10,15,120,220$, and $320 \mathrm{~K}$. 


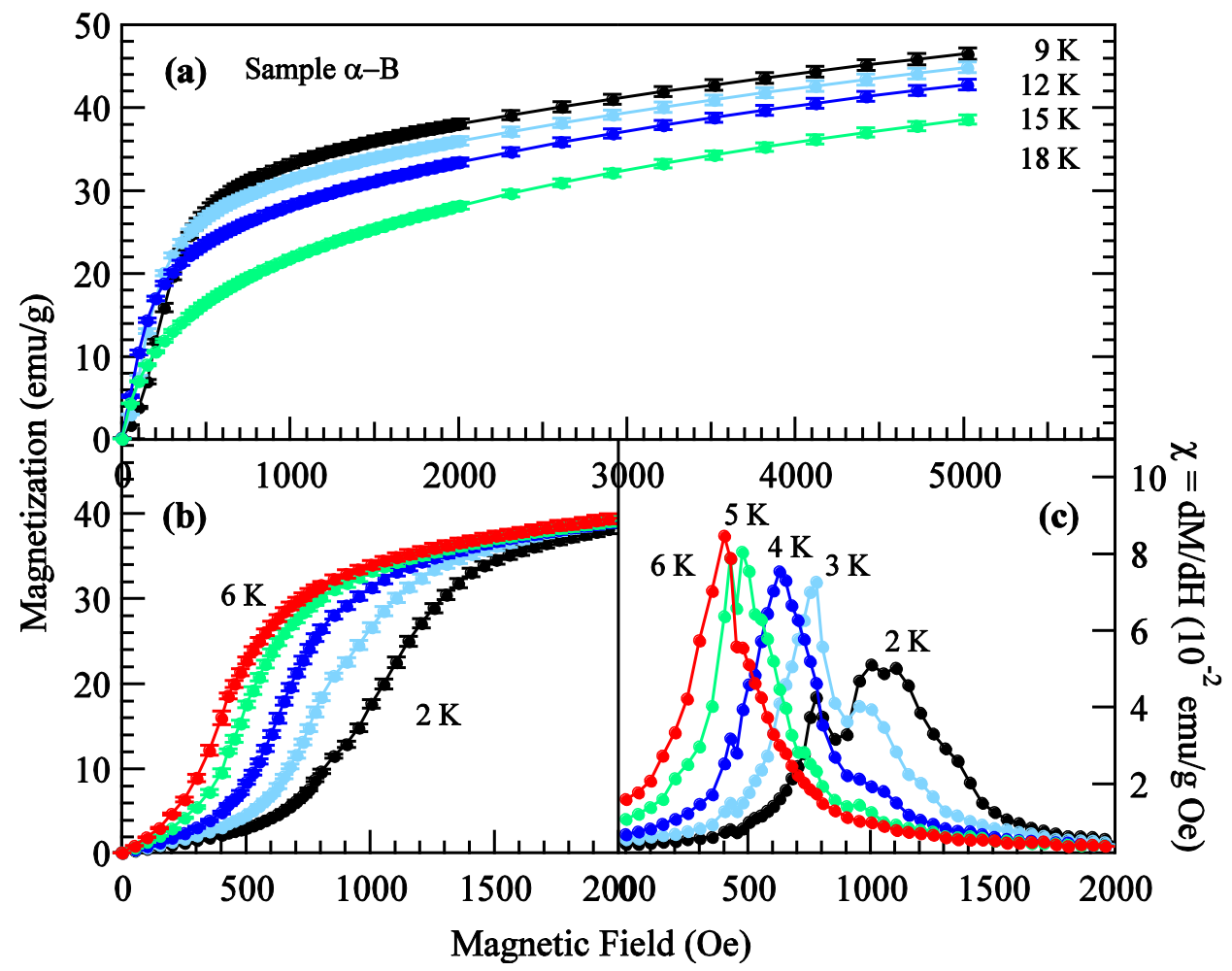

Figure 4.8: Magnetic field variation for sample $\alpha$-B of magnetization at $\mathrm{T}=$ (b) 2, 3, 4, 5, 6, (a) 9, 12, 15, and $18 \mathrm{~K}$ and (c) magnetic susceptibility at $\mathrm{T}=2,3,4,5$, and $6 \mathrm{~K}$.

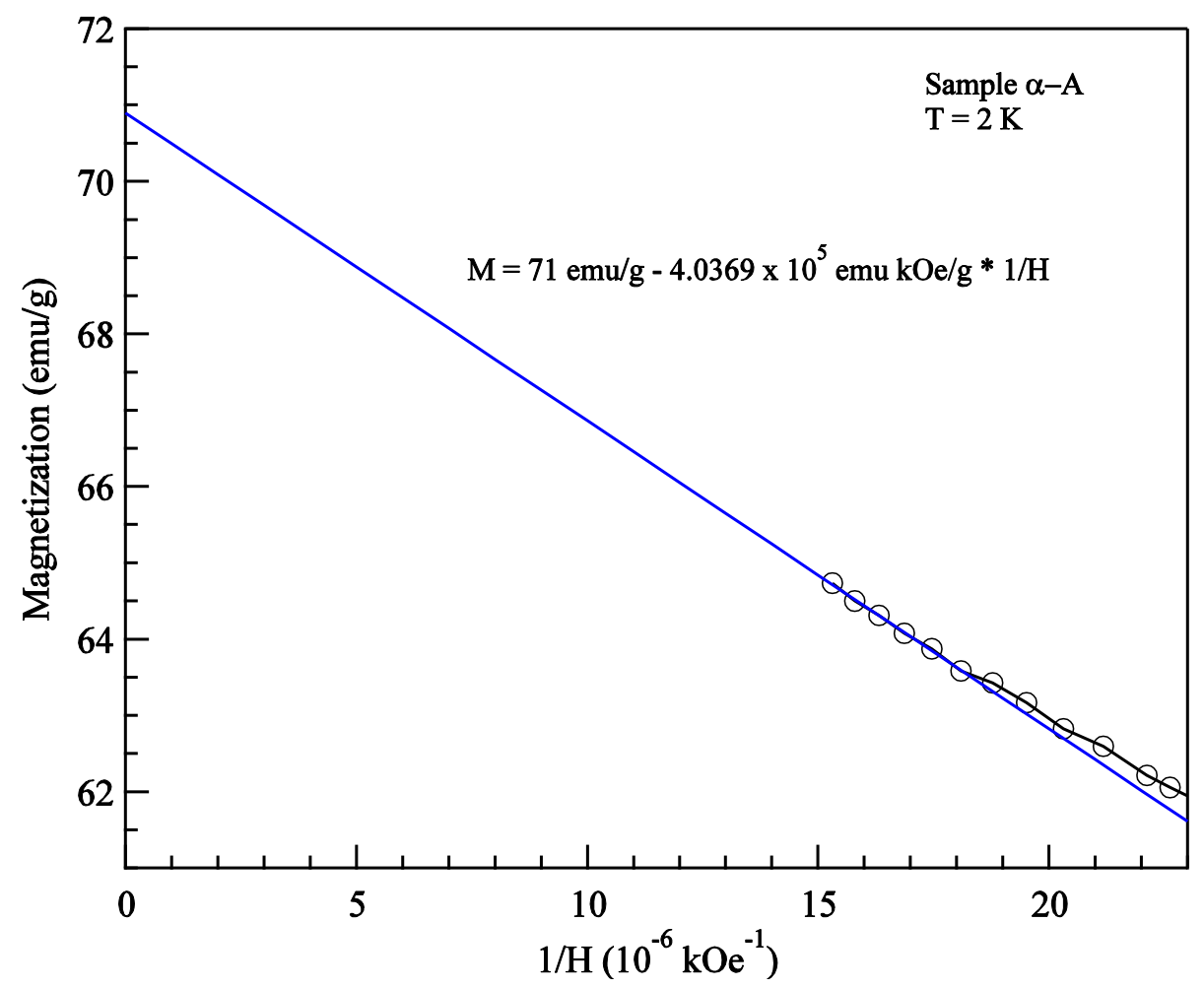

Figure 4.9: $1 / \mathrm{H}$ vs. $\mathrm{T}$ for sample $\alpha-\mathrm{A}$ at $\mathrm{T}=2 \mathrm{~K} . \mathrm{M}_{\mathrm{S}}$ is determined when $1 / \mathrm{H} \rightarrow 0$. 


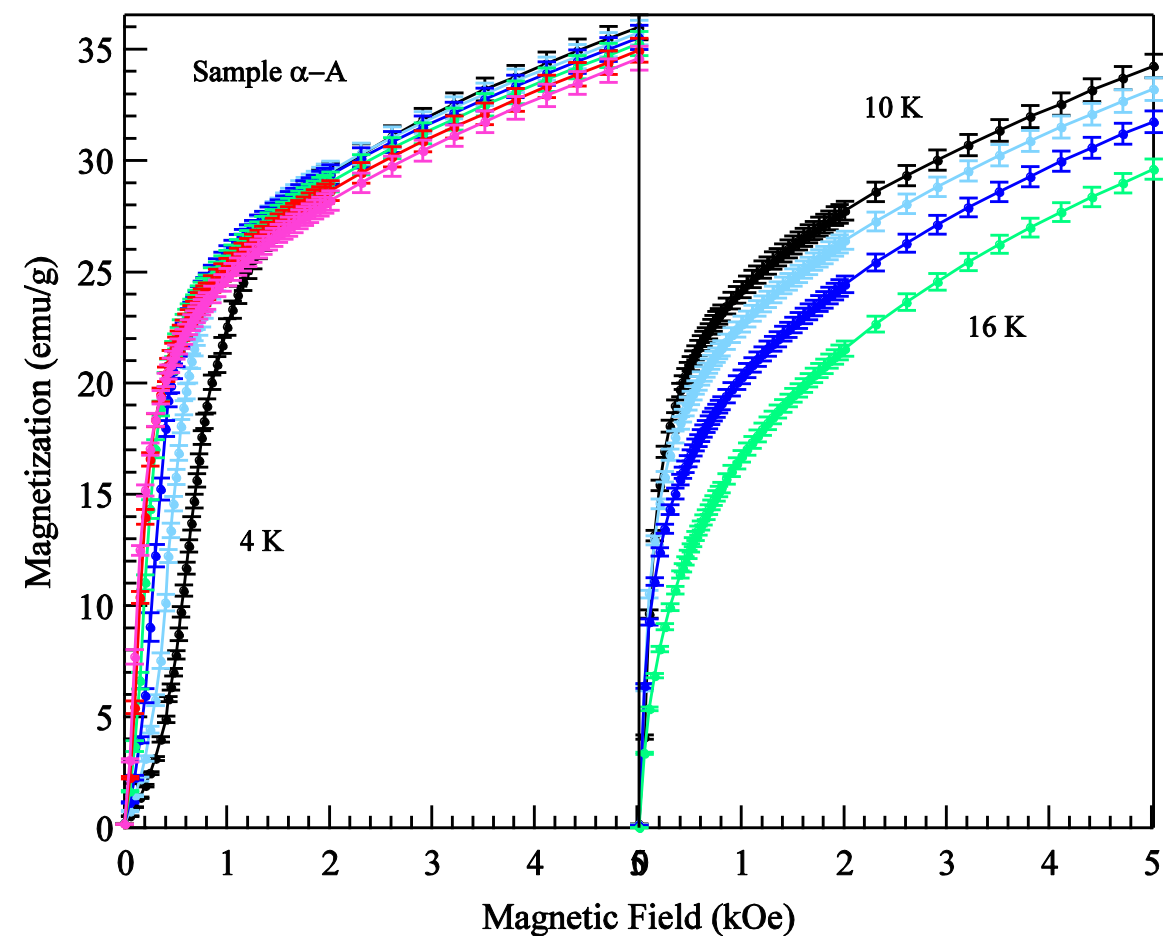

Figure 4.10: Low magnetic field variation of magnetization at $\mathrm{T}=4,5,6,7,8,9,10,12,14$, and $16 \mathrm{~K}$.

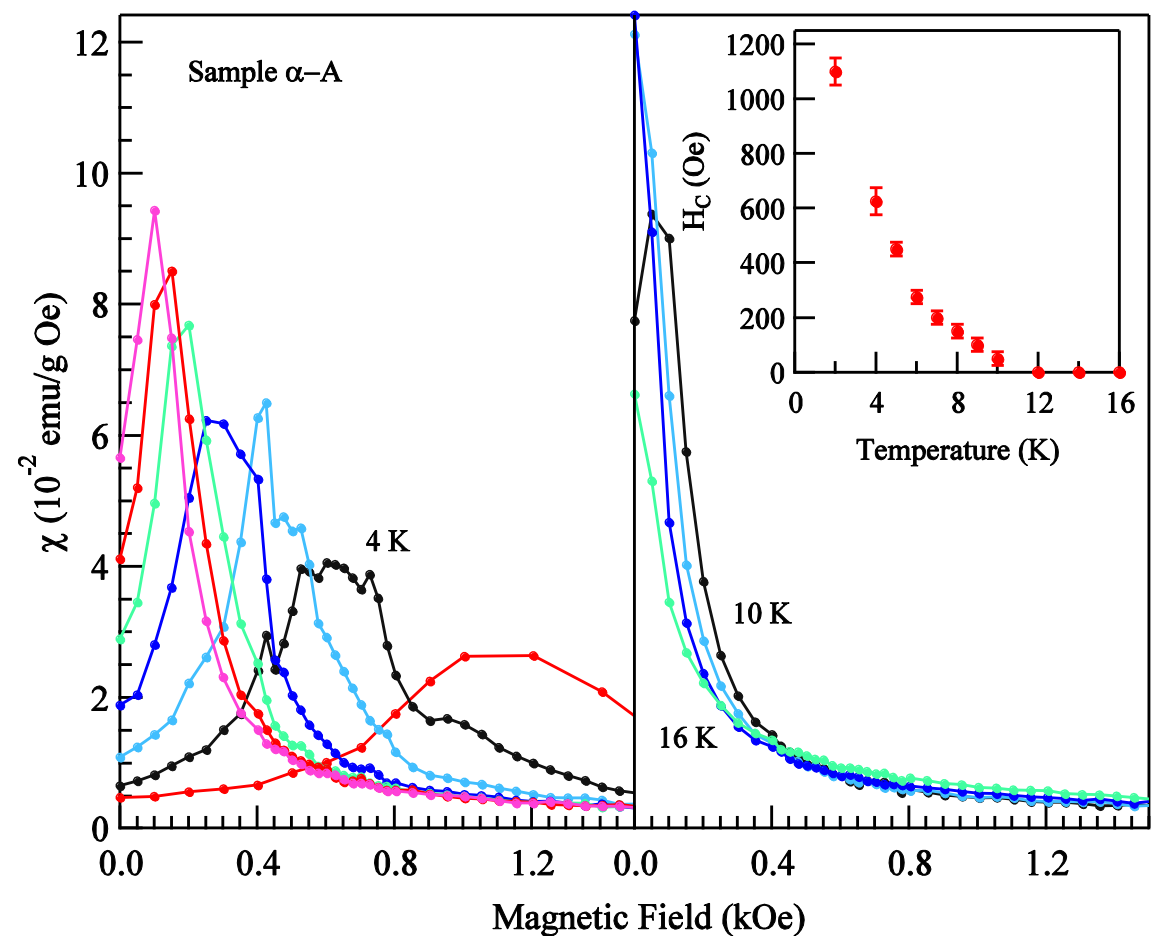

Figure 4.11: Magnetic field variation of susceptibility $\left(\chi=\frac{\partial \mathrm{M}}{\partial \mathrm{H}}\right)$ at different temperatures. The inset shows the temperature variation of the critical field $\left(\mathrm{H}_{\mathrm{C}}\right)$ 


\subsection{Hysteresis Loops}

Magnetic hysteresis curves were measured using the SQUID magnetometer while cooled in the absence of a magnetic field (ZFC) and cooled in a magnetic field of $5 \mathrm{kOe}(\mathrm{FC})$. The hysteresis loops show distinct differences from those in $\beta-\mathrm{Ni}(\mathrm{OH})_{2}$ and other simple ferromagnets. Below $5 \mathrm{~K}$ (shown in Fig. 4.12) the hysteresis loops show a discontinuity at a particular magnetic field. Above $5 \mathrm{~K}$ the magnetic hysteresis loops show the more common smooth curves shown in Fig. 4.13. Hysteresis disappears around 11 K, Fig. 4.14. For the sample cooled in a magnetic field of $5 \mathrm{kOe}$, the hysteresis loops at different temperature are shown in Fig. 4.15 and 4.16. The temperature dependence of the coercivity $\mathrm{H}_{\mathrm{c}}$ and loop shift or exchange bias $\mathrm{H}_{\mathrm{eb}}$ is shown in Fig. 4.17. The exchange bias becomes zero above about $4 \mathrm{~K}$ and $\mathrm{H}_{\mathrm{c}} \rightarrow 0$ at temperature above about $10 \mathrm{~K}$. Both ZFC and FC hysteresis loops show identical results above $\mathrm{T}=4 \mathrm{~K}$. The indication of three distinct regions is consistent between the hysteresis loops and the $\mathrm{M}$ vs. T variations presented earlier. The unusual characteristic of the hysteresis loops below $5 \mathrm{~K}$ is associated with magnetic annealing, while the appearance of coercivity only below $\mathrm{T}_{\mathrm{p}} \simeq 8 \mathrm{~K}$ and its absence for $\mathrm{T}_{\mathrm{C}}>\mathrm{T}>\mathrm{T}_{\mathrm{p}}$ is associated with a blocking temperature usually seen in nanoparticles. These results are discussed in more detail in section 4.9. 


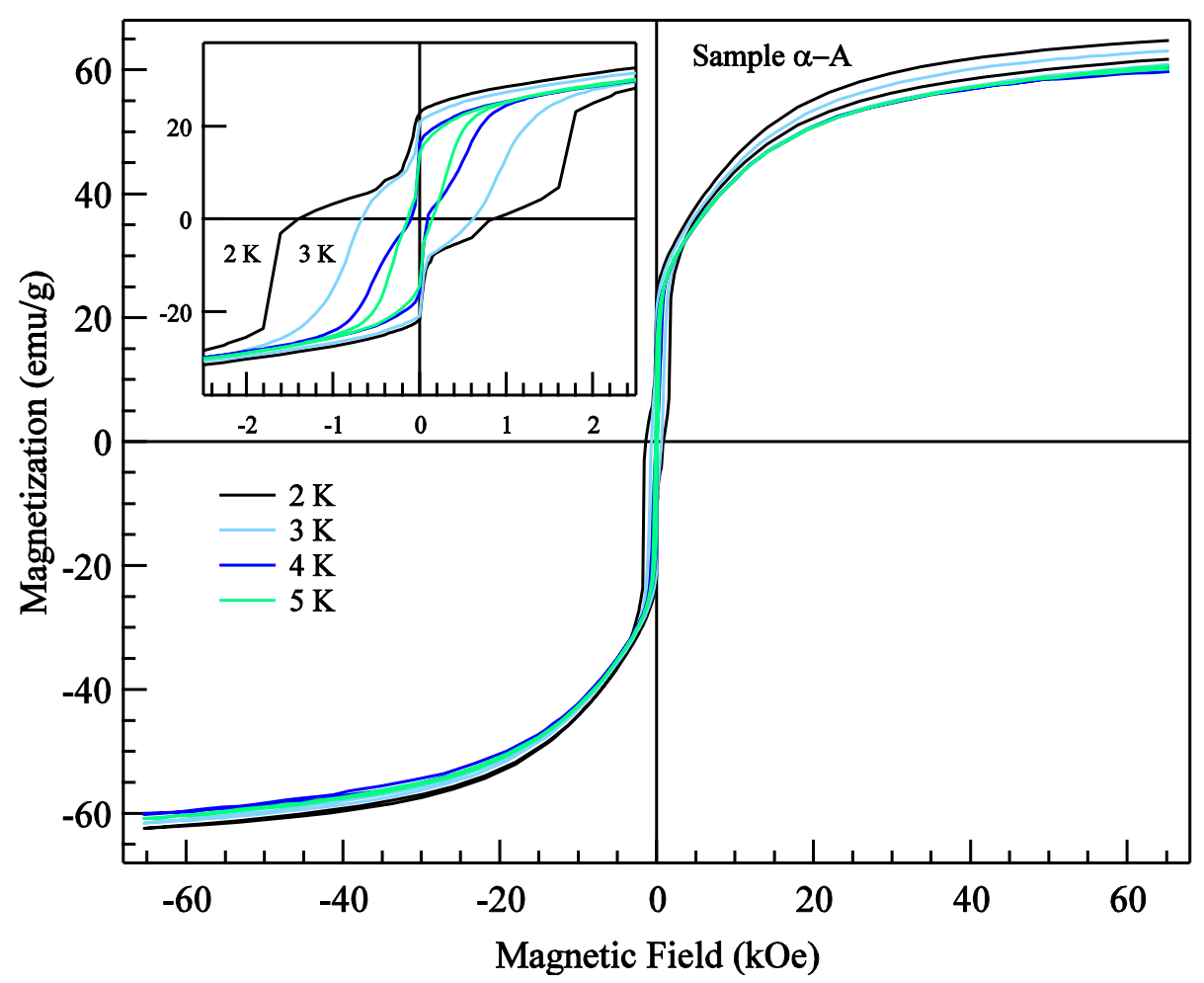

Figure 4.12: Hysteresis curves at $\mathrm{T}=2,3,4$, and $5 \mathrm{~K}$.

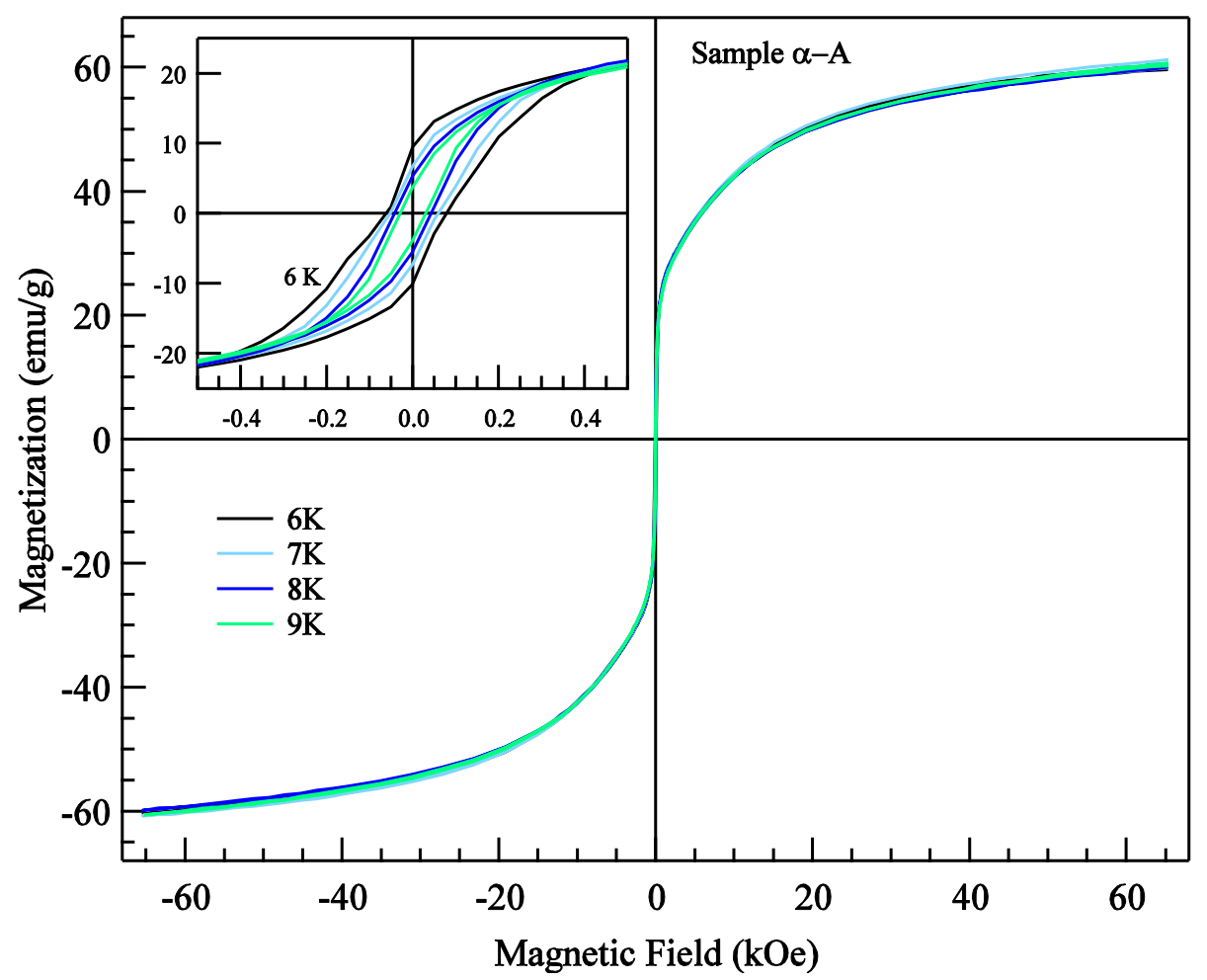

Figure 4.13: Hysteresis curves at $\mathrm{T}=6,7,8$, and $9 \mathrm{~K}$. 


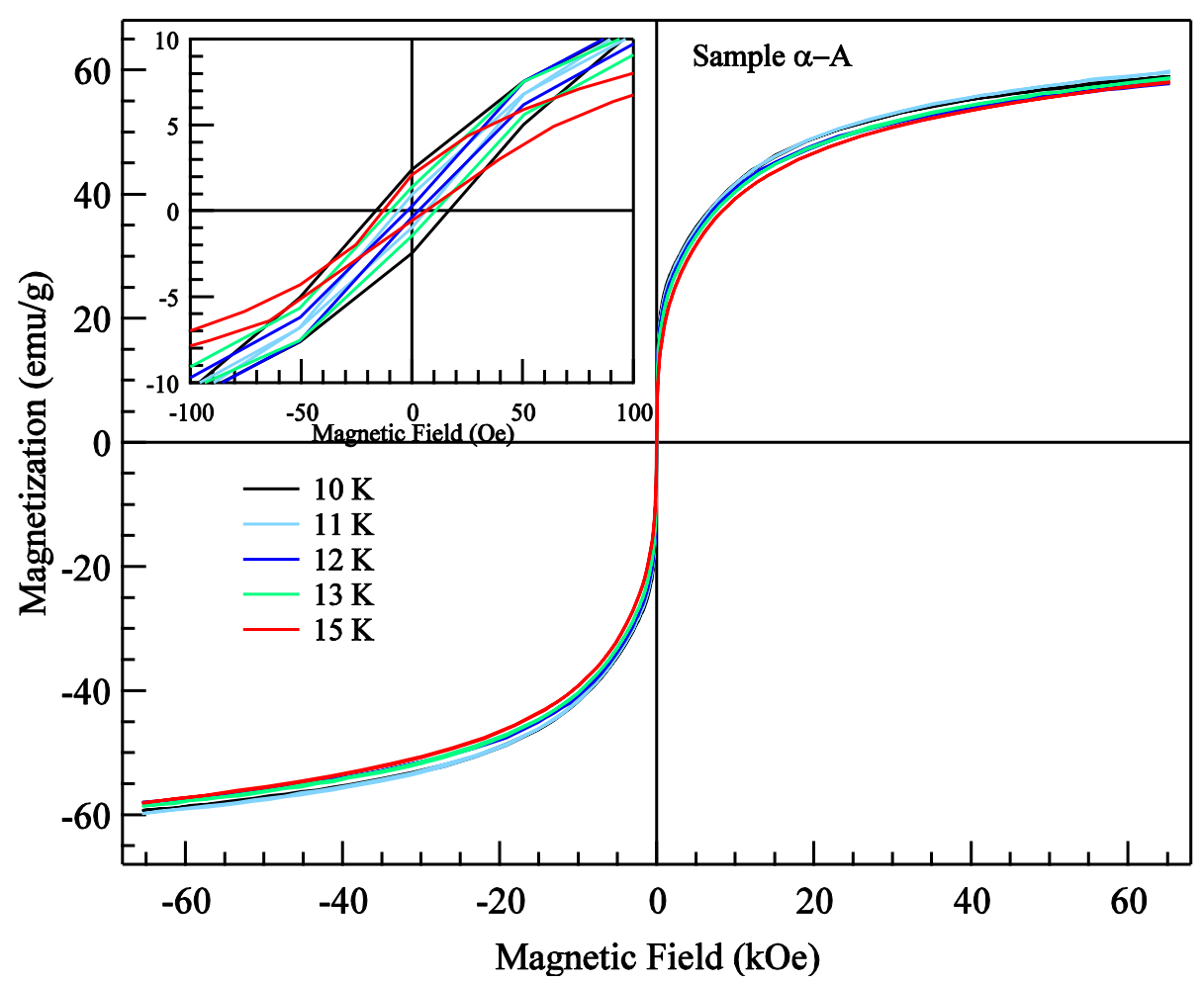

Figure 4.14: Hysteresis curves at $\mathrm{T}=10,11,12,13$, and $15 \mathrm{~K}$.

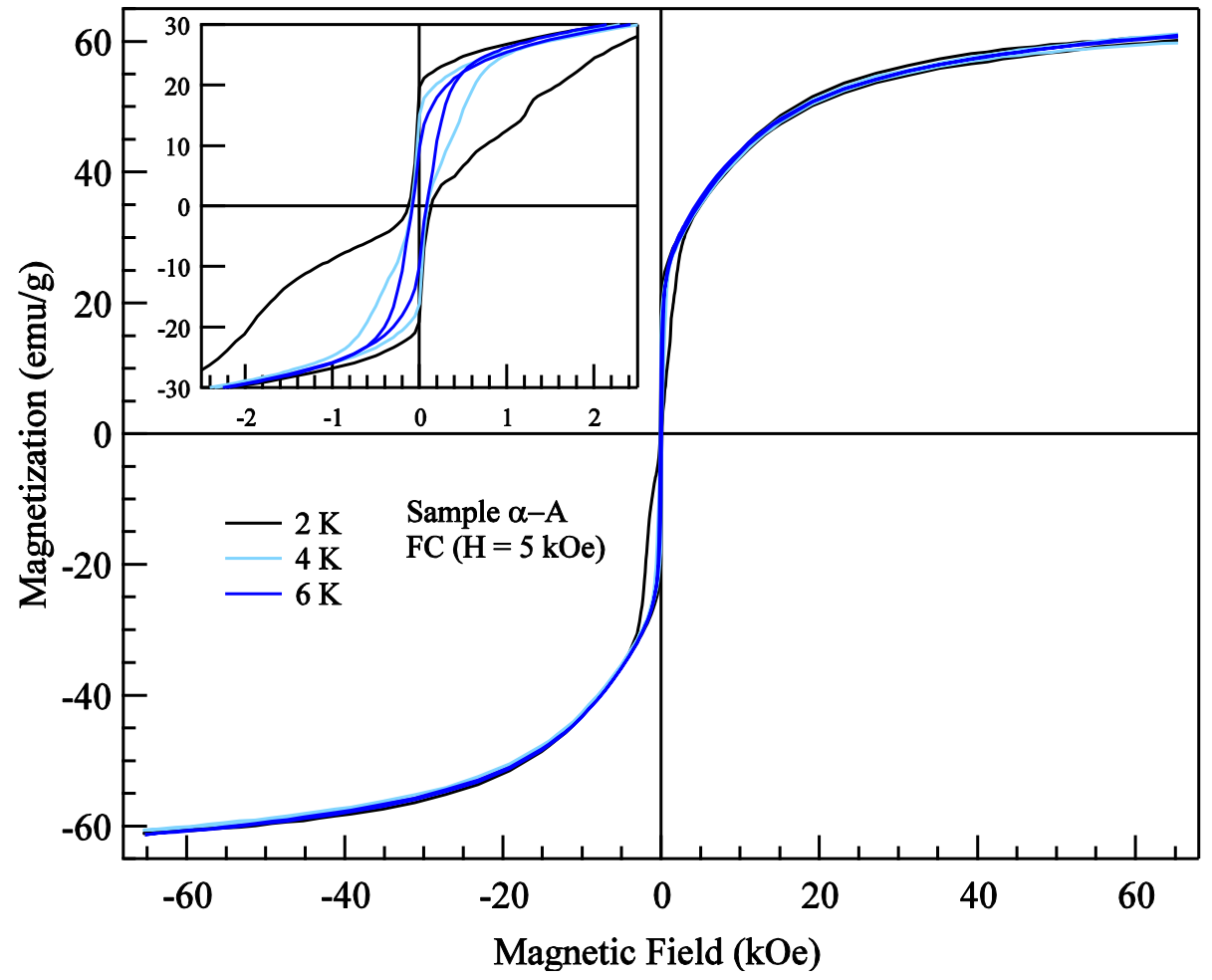

Figure 4.15: Exchange bias curves cooling in $\mathrm{H}=5 \mathrm{kOe}$ at $\mathrm{T}=2,4$, and $6 \mathrm{~K}$. 


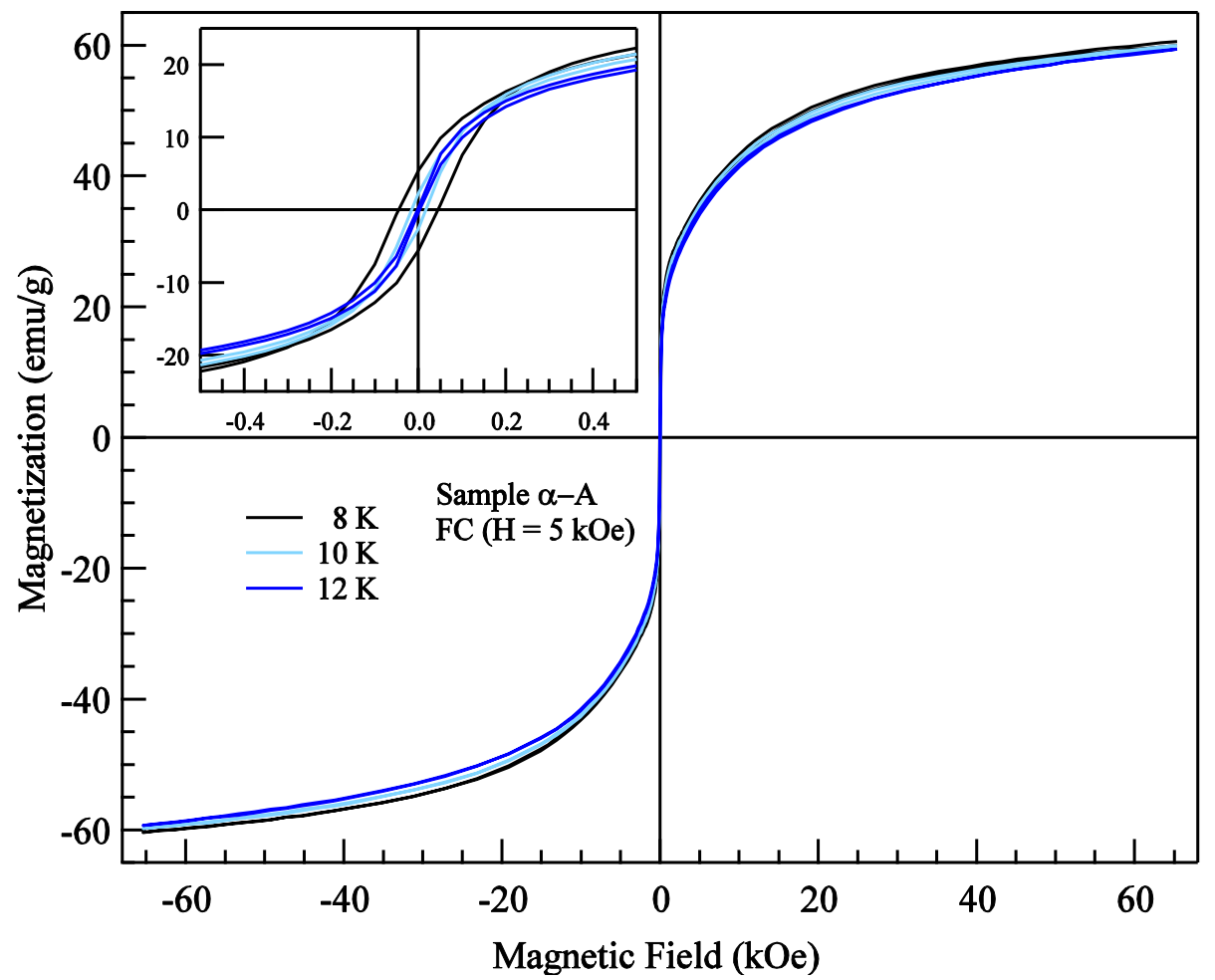

Figure 4.16: Exchange bias curves cooling in $\mathrm{H}=5 \mathrm{kOe}$ at $\mathrm{T}=8,10$, and $12 \mathrm{~K}$.

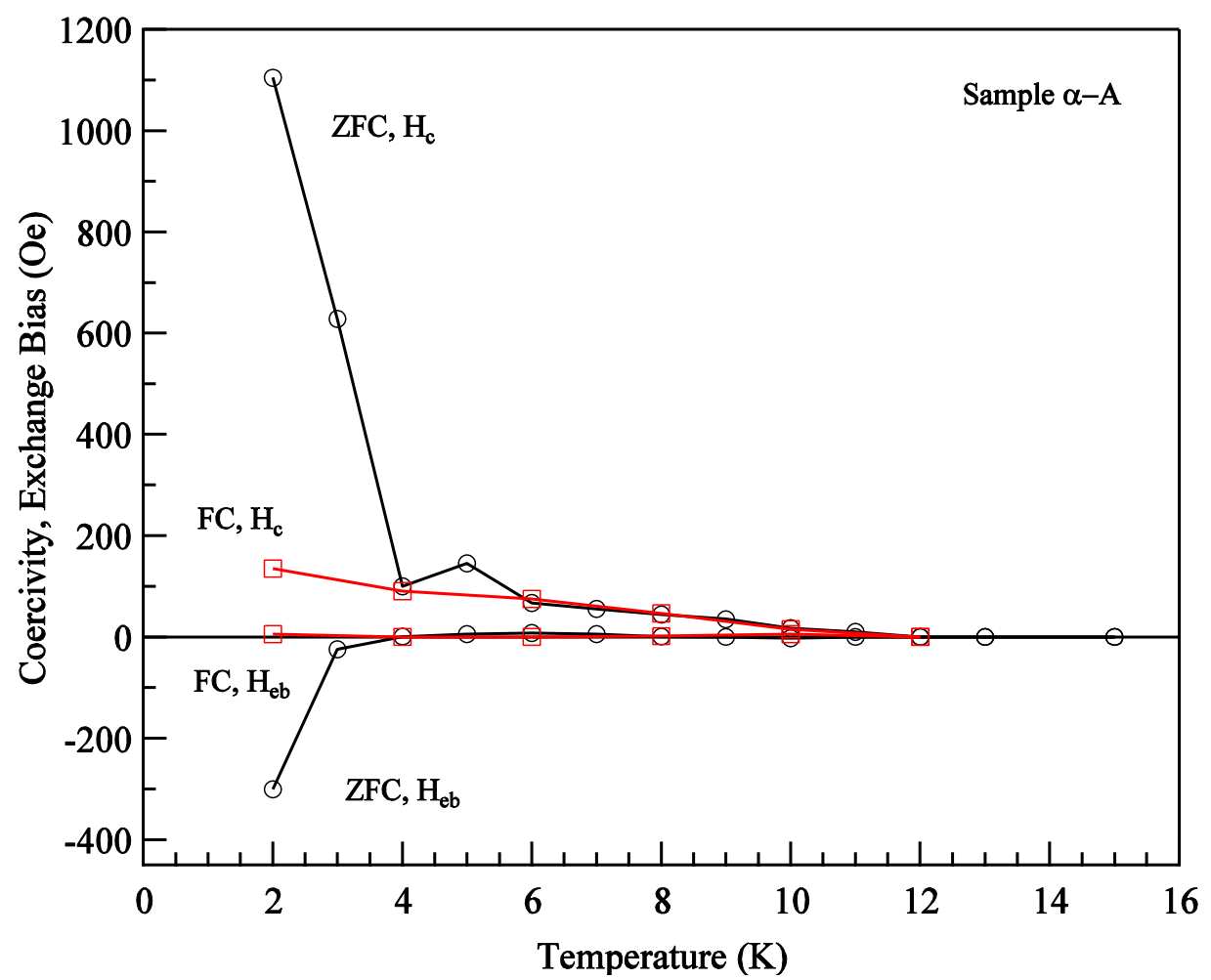

Figure 4.17: Temperature variation of the coercivity $\mathrm{H}_{\mathrm{c}}$ and exchange bias $\mathrm{H}_{\mathrm{eb}}$ for sample $\alpha$-A in ZFC and FC (5 kOe). 


\subsection{Temperature and Magnetic Field Dependence of ac Susceptibility}

To better understand the unusual behavior of the $\mathrm{M}$ vs. $\mathrm{T}$ data with applied magnetic

field, ac susceptibility measurements of $\chi^{\prime}$ and $\chi^{\prime \prime}$ were carried out at four different applied static magnetic fields $\left(\mathrm{H}_{\mathrm{DC}}\right)$ viz. $\mathrm{H}_{\mathrm{DC}}=0,500,800$, and 2000 Oe as shown in Fig. 4.18. At each magnetic field, data were taken for at least two different frequencies between $f=0.1,1.0,100$, 500, and $1000 \mathrm{~Hz}$. For $\mathrm{H}_{\mathrm{DC}}=0$ and $\mathrm{H}_{\mathrm{DC}}=800 \mathrm{Oe}$, RSO measurements were carried out simultaneously to verify the correlation between ac and dc magnetometry. For sample $\alpha-\mathrm{B}$, ac susceptibility data were measured with $\mathrm{H}_{\mathrm{DC}}=20,100$, and 800 Oe at $\mathrm{f}=10$ and $550 \mathrm{~Hz}$. The temperature range covered in these measurements was from $2 \mathrm{~K}$ to about $25 \mathrm{~K}$, Fig. 4.19.

The peak in the out of phase component $\chi^{\prime \prime}$ of the susceptibility (usually associated with magnetic phase transitions and blocking temperatures [Singh et al., 2009]) shows three distinct regions in its temperature dependence, $\mathrm{T}<4 \mathrm{~K}, 4 \mathrm{~K}<\mathrm{T}<15 \mathrm{~K}$, and $\mathrm{T}>15 \mathrm{~K}$. The transition temperature $T_{1}=15 \mathrm{~K}$ can be associated with the $2 \mathrm{D}$ ferromagnetic transition in agreement with $\mathrm{M}$ vs. $\mathrm{T}$ data since it shows only minor variation with frequency $\left(\mathrm{T}_{1}=14.5 \mathrm{~K}\right.$ at $\mathrm{f}=0.1 \mathrm{~Hz}$ and $\mathrm{T}_{1}=15.25 \mathrm{~K}$ at $\mathrm{f}=500 \mathrm{~Hz}$ ) in agreement with a magnetic transition [Binder \& Young, 1986]. This magnetic transition temperature shifts with applied magnetic field, increasing to $\mathrm{T}_{1} \sim 17 \mathrm{~K}$ at $\mathrm{H}=800 \mathrm{Oe}$, also in agreement with ferromagnetic models.

The other two transitions are not well defined at $\mathrm{H}=0 \mathrm{Oe}$, but they become more prevalent for the $\mathrm{H}=500 \mathrm{Oe}$ and 800 Oe cases. $\mathrm{T}_{2}$ is frequency dependent showing $\mathrm{T}_{2} \simeq 5 \mathrm{~K}$ at $\mathrm{f}=0.1 \mathrm{~Hz}$ and $\mathrm{T}_{2} \simeq 8 \mathrm{~K}$ at $\mathrm{f}=1 \mathrm{kHz} . \mathrm{T}_{2}$ also shows a slight $\mathrm{H}_{\mathrm{DC}}$ dependence with $\mathrm{T}_{2} \simeq 7.5 \mathrm{~K}$ at $\mathrm{f}=100 \mathrm{~Hz}$ and $\mathrm{H}_{\mathrm{DC}}=500$ Oe to $\mathrm{T}_{2} \simeq 6.75 \mathrm{~K}$ at $\mathrm{f}=100 \mathrm{~Hz}$ and $\mathrm{H}_{\mathrm{DC}}=800$ Oe. Since $\mathrm{T}_{2}$ depends on both frequency and applied static magnetic field, this transition may be related to a blocking 
temperature $T_{B}$ of the nanoparticles [Singh et al., 2009]. The third transition $T_{3} \simeq 4 \mathrm{~K}$ seems to be another magnetic transition since it shows no dependence on frequency and applied static magnetic field. Note that this transition coincides with the presence of exchange-bias since only below this temperature, exchange bias $\mathrm{H}_{\mathrm{eb}}$ is non-zero (Fig. 4.17). Additional discussion on the interpretation of these results is given in section 4.9. Experimental results on sample $\alpha$-B (Fig. 4.19) are essentially identical to those reported above for sample $\alpha$-A.

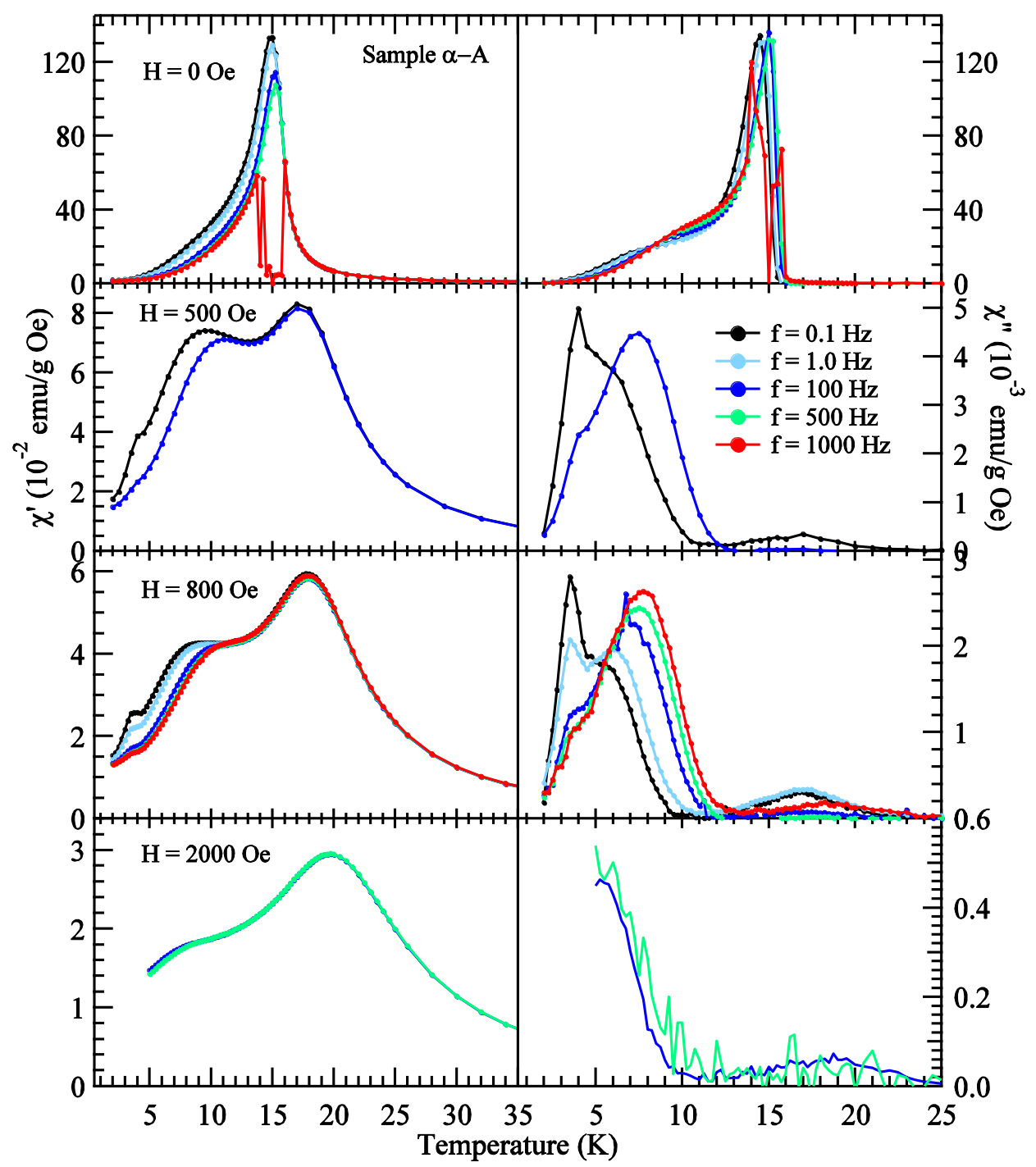

Figure 4.18: AC susceptibility of sample $\alpha-\mathrm{A}$ at $\mathrm{H}_{\mathrm{DC}}=0,500,800,2000$ Oe. With $\mathrm{f}=0.1,1.0,100,500$, and/or $1000 \mathrm{~Hz}$. 


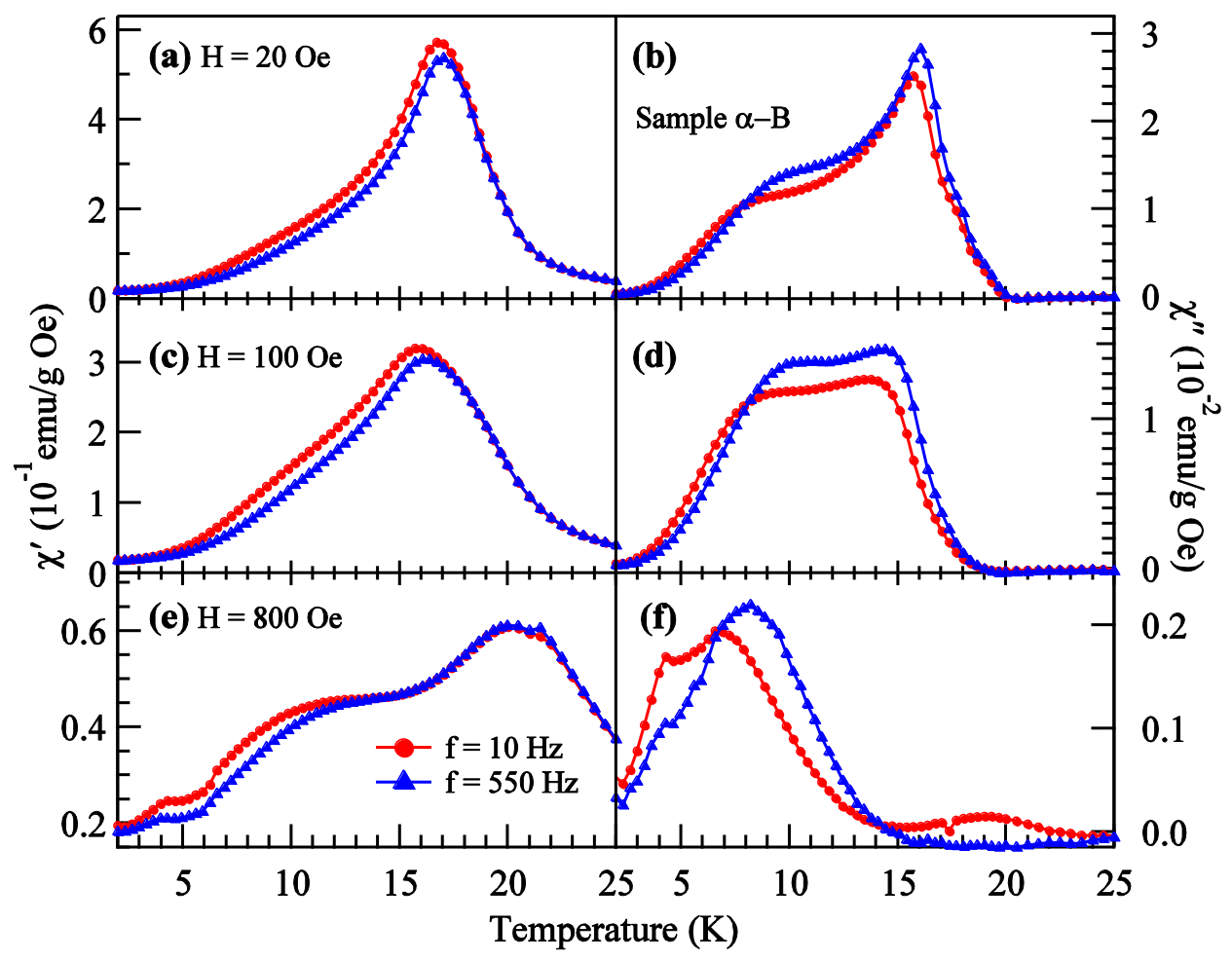

Figure 4.19: AC susceptibility of sample $\alpha-\mathrm{B}$ at $\mathrm{H}_{\mathrm{DC}}=20,100$, and 800 Oe with $\mathrm{f}=10$ and $550 \mathrm{~Hz}$.

\subsection{Discussion and Interpretation}

\subsubsection{Temperature Dependence of Paramagnetic Susceptibility}

Above $\mathrm{T}_{\mathrm{p}}, \mathrm{M}$ vs. $\mathrm{T}$ data are identical for the $\mathrm{ZFC}$ and $\mathrm{FC}$ cases as noted above. Plots of $\mathrm{M}$ vs. $\mathrm{T}$ for $\mathrm{T}>\mathrm{T}_{\mathrm{p}}$ for $\mathrm{H}=50,100,300,800,1000,2500,3000,3500$ Oe are shown in Fig. 4.2. In our preliminary report comparing the nature of magnetism in $\alpha-\mathrm{Ni}(\mathrm{OH})_{2}$ and $\beta-\mathrm{Ni}(\mathrm{OH})_{2}[\mathrm{Rall}$ et al., 2010(a)], the data of $\chi$ vs. T were fit to the Curie-Weiss law: $\chi=\frac{\mathrm{C}}{(\mathrm{T}-\theta)}$ in a plot of $\chi^{-1}$ vs. T. Such a plot shown in Fig. 4.20 yields $\theta=35 \mathrm{~K}$ and $\mathrm{C}=87.4 \times 10^{-4} \mathrm{emu} \mathrm{K} /(\mathrm{g}$ Oe $)$ giving $\mu=3.13 \mu_{\mathrm{B}}$ as the magnetic moment per $\mathrm{Ni}^{2+}$ ions. This large value $\theta=35 \mathrm{~K}$ for $\alpha-\mathrm{Ni}(\mathrm{OH})_{2}$ compared to $\theta=20 \mathrm{~K}$ for $\beta-\mathrm{Ni}(\mathrm{OH})_{2}$ is inconsistent with 2D FM ordering followed by AFM 3D 
ordering as in $\beta-\mathrm{Ni}(\mathrm{OH})_{2}$ since $\mathrm{J}_{2}>0$ is obtained for $\theta=35 \mathrm{~K}$. Using Eqs (3.4) and (3.3) for $\mathrm{T}_{\mathrm{N}}$ and $\theta$ respectively used earlier for $\beta-\mathrm{Ni}(\mathrm{OH})_{2}$ to determine the exchange constants $\mathrm{J}_{1}$ and $\mathrm{J}_{2}$ from the experimentally determined $\mathrm{T}_{\mathrm{N}}=16 \mathrm{~K}$ and $\theta=35 \mathrm{~K}$ for sample $\alpha$-A leads to $J_{1} / k_{\mathrm{B}}=3.2 \mathrm{~K}$ and $J_{2} / k_{\mathrm{B}}=3 J_{3} / k_{\mathrm{B}}=1.2 \mathrm{~K}$. The positive magnitudes of both $\mathrm{J}_{1}$ and $\mathrm{J}_{2}$ implies that $\alpha-\mathrm{Ni}(\mathrm{OH})_{2}$ should be a ferromagnet, opposite to the observation in $\beta-\mathrm{Ni}(\mathrm{OH})_{2}$ yet still showing zero magnetization near $\mathrm{T}=0 \mathrm{~K}$ for $\mathrm{ZFC}$ and $\mathrm{H}_{\mathrm{C}} \simeq 1150$ Oe. However the magnitude of $J_{2} / \mathrm{k}_{\mathrm{B}}=1.2 \mathrm{~K}$ is unrealistically large considering the increased interplanar spacing of $\mathrm{c}=8.6 \AA$ compared to $\mathrm{c}=4.6 \AA$ for $\beta-\mathrm{Ni}(\mathrm{OH})_{2}$ in which $J_{2} / k_{\mathrm{B}}=-0.3 \mathrm{~K}$ was determined [Rall et al., 2010(a)]. An alternative calculation for $\mathrm{J}_{2}$ is given in section 4.9 based on the transition temperature dependence on $\mathrm{J}_{2}$ of a two dimensional Heisenberg lattice.

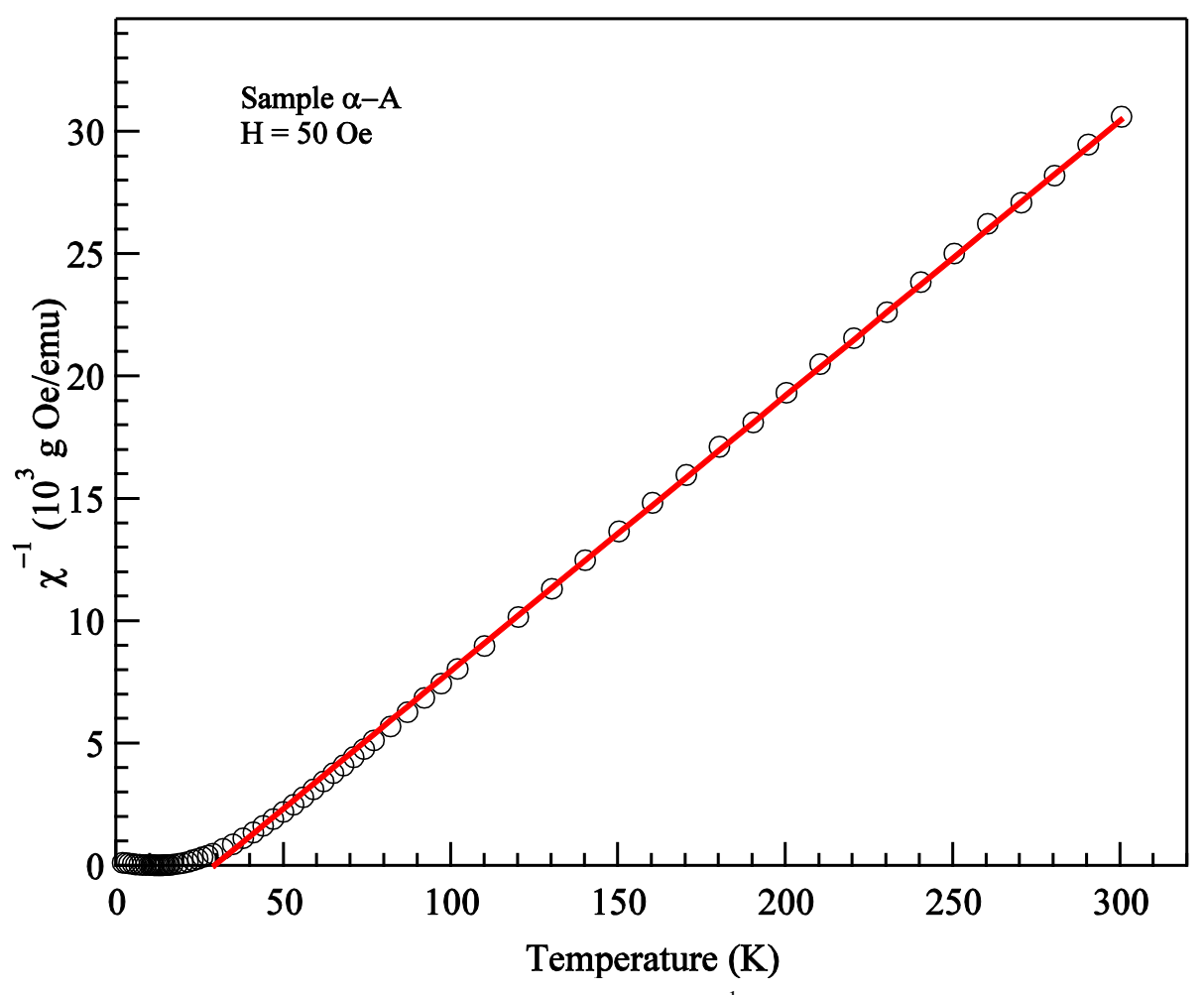

Figure 4.20: Curie - Weiss fit to $\chi^{-1}$ vs. T for sample $\alpha$-A. 


\subsubsection{High Temperature Series (HTS) Fit}

In Fig. 4.21, the data for $\mathrm{T}<150 \mathrm{~K}$ does not fit the linear variation expected from the Curie-Weiss law. A more accurate analysis of $\chi$ vs. $\mathrm{T}$ for $\mathrm{T}>\mathrm{T}_{\mathrm{p}}$ can be made using a fit to a high temperature series (HTS) of the magnetic susceptibility for $S=1$ for a $2 \mathrm{D}$ triangular lattice valid for $\mathrm{Ni}(\mathrm{OH})_{2}$. Following Van Dyke and Camp [1974], the HTS is:

$$
\chi=\frac{2 N_{A} g^{2} \mu_{\mathrm{B}}^{2}}{3 \mathrm{MW} k_{\mathrm{B}} \mathrm{T}} \sum_{n=0}^{8} a_{n}\left(\frac{2 J_{1}}{k_{\mathrm{B}} \mathrm{T}}\right)^{n}
$$

with the leading terms of $a_{n}$ are shown in Table 4.1. It is well known [Seehra, 1969] that just the first two terms of the series yields the Curie-Weiss law. The varied parameters for the fit gives $\mathrm{g}=2.29$ and the intra-layer interaction $J_{1} / k_{\mathrm{B}}=4.38 \mathrm{~K}$. The $\chi$ vs. $\mathrm{T}$ data in

Fig. 4.21 is fit to the HTS down to $50 \mathrm{~K}$ after correcting for the theoretical diamagnetic contribution to the susceptibility. This diamagnetic contribution $\left(\chi_{o}=-0.66 \times 10^{-6} \mathrm{emu} /(\mathrm{g}\right.$ Oe $\left.)\right)$ is expected to be significant in $\alpha-\mathrm{Ni}(\mathrm{OH})_{2}$ due to the increased anionic species. Because of the increasing contributions of the terms greater than the first two terms in Eq. (4.1) for $\alpha-\mathrm{Ni}(\mathrm{OH})_{2}$, the validity of the Curie-Weiss law in this case is only valid for $\mathrm{T}>150 \mathrm{~K}$.

\begin{tabular}{|l|l|}
\hline$a_{0}$ & 1 \\
\hline$a_{1}$ & 4 \\
\hline$a_{2}$ & 14 \\
\hline$a_{3}$ & 46 \\
\hline$a_{4}$ & 145 \\
\hline$a_{5}$ & 446 \\
\hline$a_{6}$ & 1343 \\
\hline$a_{7}$ & 3981 \\
\hline$a_{8}$ & 11663 \\
\hline
\end{tabular}

Table 4.1: Leading coefficient of HTS. 


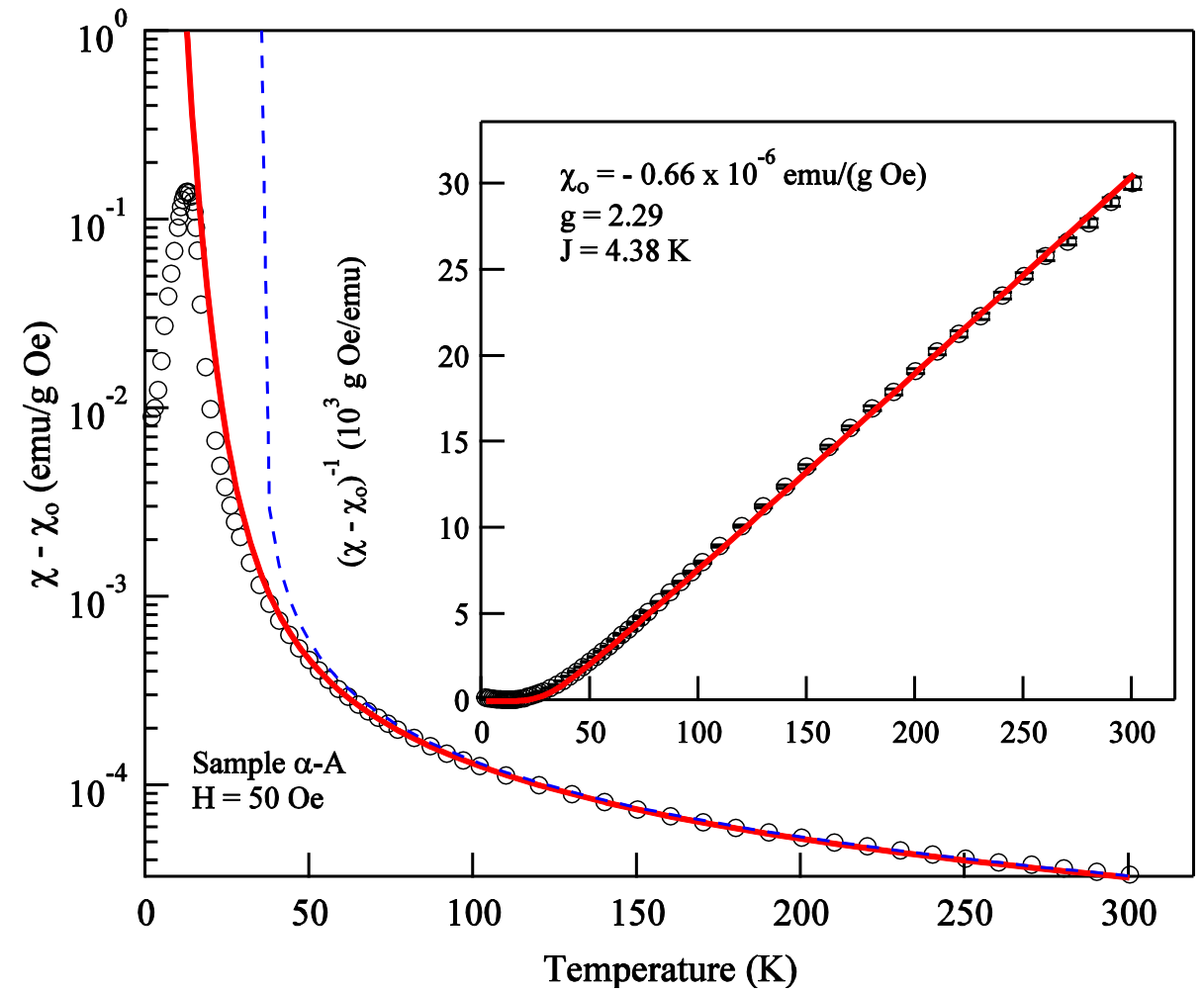

Figure 4.21: $\chi-\chi_{0}$ vs. T for sample $\alpha$-A with $H=50$ Oe. The high temperature data is fit to the HTS of Eq. (4.1) with the dash line representing the Curie-Weiss fit. The inset shows the HTS fit to the $\left(\chi-\chi_{0}\right)^{-1}$ vs. T data.

\subsection{Model for the Nature of Magnetism in $\alpha-\mathrm{Ni}(\mathrm{OH})_{2}$}

A model for the magnetism of $\alpha-\mathrm{Ni}(\mathrm{OH})_{2}$ needs to explain the following facts reported here.

(i) From the Curie-Weiss fit to the high temperature $\chi$ vs. $\mathrm{T}$ data, $\mathrm{T}_{\mathrm{C}} \simeq 16 \mathrm{~K}$, $\theta \simeq 35 \mathrm{~K}, \mu=3.23 \mu_{\mathrm{B}}, \mathrm{g}=2.29$ and $\mathrm{S}=1$ are obtained.

(ii) The magnitude of $\mathrm{T}_{\mathrm{C}} \simeq 16 \mathrm{~K}$ and $\theta \simeq 35 \mathrm{~K}$ yield intra-plane $J_{1} / \mathrm{k}_{\mathrm{B}}=3.2 \mathrm{~K}$ and interplane $J_{2} / k_{\mathrm{B}}=1.2 \mathrm{~K}$, both exchange constants being ferromagnetic.

(iii) In the ac susceptibility measurements, the peak position in $\chi^{\prime \prime}$ yields $\mathrm{T}_{\mathrm{C}} \simeq 16 \mathrm{~K}$ in $\mathrm{H}=0$ but its position shifts to $\mathrm{T}_{\mathrm{C}}=17 \mathrm{~K}$ in $\mathrm{H}=800$ Oe. Also peaks at 
$\mathrm{T}_{\mathrm{C} 2}=8 \mathrm{~K}$ (which is strongly frequency dependent) and a frequency-independent peak at $\mathrm{T}_{\mathrm{C} 3} \simeq 3.5 \mathrm{~K}$ are also observed.

(iv) At lower magnetic fields, $M$ vs. $\mathrm{H}$ yields a critical magnetic field $\mathrm{H}_{\mathrm{C}} \simeq 1150 \mathrm{Oe}$ (Fig. 4.8). The magnitude of $\mathrm{H}_{\mathrm{C}}$ decreases with increase in temperature reaching zero near $10 \mathrm{~K}$.

(v) The saturation magnetization $\mathrm{M}_{\mathrm{S}} \simeq 71 \mathrm{emu} / \mathrm{g}$ at $2 \mathrm{~K}$ is obtained by extrapolating $\mathrm{M}$ vs. $\mathrm{H}$ data to $\mathrm{H} \rightarrow \infty,(1 / H \rightarrow 0)$.

Below we provide arguments and discussion to show that $\alpha-\mathrm{Ni}(\mathrm{OH})_{2}$ is a ferromagnet with $T_{C} \simeq 16 \mathrm{~K}$ in $\mathrm{H}=0$. The transition near $8 \mathrm{~K}$ represents a blocking temperature $\mathrm{T}_{\mathrm{B}}$ because of the nanosize effects and the transition at $3.5 \mathrm{~K}$ is due to magnetic annealing effects of the canted surface spins. The presence of an exchange-bias (loop-shift) shown in Fig. 4.17 below $3.5 \mathrm{~K}$ and the difference in the coercivity $\mathrm{H}_{\mathrm{C}}$ for the $\mathrm{FC}$ and $\mathrm{ZFC}$ sample are definite evidence of magnetic annealing [Punnoose, Seehra, van Tol, \& Brunel, 2005].

Since both $\mathrm{J}_{1}$ and $\mathrm{J}_{2}$ are shown to be positive, only ferromagnetic ordering at $\mathrm{T}_{\mathrm{C}}=16 \mathrm{~K}$ is possible. The magnitude of the saturation magnetization $\mathrm{M}_{\mathrm{S}}$ in the limit $\mathrm{H} \rightarrow \infty$ at $2 \mathrm{~K}$ is equal to $71 \mathrm{emu} / \mathrm{g}$ (Fig. 4.9). For a ferromagnet, $\mathrm{M}_{S}=N g \mu_{\mathrm{B}}\langle\mathrm{S}\rangle$ is the maximum expected value where $N=N_{\mathrm{A}} / \mathrm{MW}_{W}$ is the number of $\mathrm{Ni}^{2+}$ spins per gram. Using $\mathrm{g}=2.29, \mathrm{~S}=1$ and molecular weight of sample $\alpha$-A with formula $\mathrm{Ni}(\mathrm{OH})_{1.23}\left(\mathrm{CH}_{3} \mathrm{COO}\right)_{0.77} \bullet 1.41 \mathrm{H}_{2} \mathrm{O}$ (page 26) to be $150.4 \mathrm{~g} / \mathrm{mol}$ yields $\mathrm{M}_{\mathrm{S}} \simeq 85.0 \mathrm{emu} / \mathrm{g}$. This magnitude of $\mathrm{M}_{\mathrm{S}}$ is about $20 \%$ larger than the measured value of $\mathrm{M}_{\mathrm{S}} \simeq 71 \mathrm{emu} / \mathrm{g}$. Considering the approximation of the Curie-Weiss law and possible errors involved in the experimental determination of $\mathrm{M}_{\mathrm{S}}$ by extrapolation to $1 / \mathrm{H} \rightarrow 0$, the agreement is considered quite good. 
What is the reasoning behind assigning $\mathrm{T}_{\mathrm{C} 2} \simeq 8 \mathrm{~K}$ to be a blocking temperature $\mathrm{T}_{\mathrm{B}}$ ? First, $T_{B}$ is usually less than $T_{C}$. Second, $T_{B}$ is usually magnetic field dependent, shifting to the lower temperatures at higher magnetic fields and coercivity $\mathrm{H}_{\mathrm{c}} \rightarrow 0$ as $\mathrm{T} \rightarrow \mathrm{T}_{\mathrm{B}}^{-}$. The magnetic measurements report here follow the above characteristics of a blocking temperature. Similar frequency and magnetic field dependence of $\mathrm{T}_{\mathrm{B}}$ in nanoparticles of $\mathrm{Ni}$ dispersed in amorphous $\mathrm{SiO}_{2}$ has been reported by Singh et al. [2009, 2010]. These considerations lead to the conclusion that the transition near $8 \mathrm{~K}$ is a blocking temperature.

The transition at $3.5 \mathrm{~K}$ is suggested to likely be from magnetic annealing effects of the canted surface spins in $\alpha-\mathrm{Ni}(\mathrm{OH})_{2}$ due to two observations: (i) the transition temperature is independent of the measuring frequency in the ac susceptibility (Fig. 4.18); and (ii) the disappearance of the loop-shift (exchange bias) in a FC sample and the coercivity becoming cooled-field dependent (Fig. 4.17). The unusual hysteresis loops gives evidence of this magnetic annealing effect similar to those found in metallic alloys [Chikazumi, 1997 p 514]

Since $\alpha-\mathrm{Ni}(\mathrm{OH})_{2}$ orders ferromagnetically at $\mathrm{T}_{\mathrm{C}} \simeq 16 \mathrm{~K}$ as argued above, there can be no magnetic field induced metamagnetic transition from antiferromagnetism to ferromagnetism as in $\beta-\mathrm{Ni}(\mathrm{OH})_{2}$. The source of the field-dependent behavior of $\mathrm{M}$ vs. $\mathrm{H}$ yielding an effective critical field $\mathrm{H}_{\mathrm{C}} \simeq 1150$ Oe is most likely due to uniaxial anisotropy $\mathrm{H}_{\mathrm{A}}$ since the c-axis is so much larger than the a-axis. Magnetic anisotropy leads to the formation of domains. Thus $\mathrm{H}_{\mathrm{C}}=\mathrm{H}_{\mathrm{A}} \simeq 1150$ Oe at $2 \mathrm{~K}$ is the field required to switch the domains parallel to the direction of the applied magnetic field. Similar domain models have been proposed by Drillon and Panissod [1998] to explain the magnetic properties of $\mathrm{Co}(\mathrm{OH})_{2}$. The domains consist of a larger number of spins in the 2D layers. These spins create a large magnetic moment thereby increasing the 
dipole-dipole interaction between the layers. However, for sample $\alpha$-A there is no evidence of having this dipole-dipole induced domain, but the previously stated anisotropy induced magnetic domains.

An estimate of the interlayer coupling $\mathrm{J}_{2}$ can also be determined from the assumption that $3 \mathrm{D}$ ordering and hence $\mathrm{T}_{\mathrm{C}}$ between the ferromagnetic layers is triggered by the interlayer coupling $\mathrm{J}_{2}$. The transition temperature $\mathrm{T}_{\mathrm{C}}$ in such a case given by de Jongh [1990, $\mathrm{p} 138$ ] is:

$$
\mathrm{T}_{C}=\frac{4 \pi J_{1}}{\ln \left(J_{1} / J_{2}\right)}
$$

where $\mathrm{J}_{1}$ is the intra-plane exchange coupling. Using $\mathrm{T}_{\mathrm{C}} \simeq 16 \mathrm{~K}, \mathrm{~J}_{1} / \mathrm{k}_{\mathrm{B}}=4.38 \mathrm{~K}$ from the HTS fit yields $J_{2} / k_{\mathrm{B}}=0.14 \mathrm{~K}$. This magnitude of $\mathrm{J}_{2}$ is close to $J_{2} / k_{\mathrm{B}}=-0.32 \mathrm{~K}$ determined for $\beta-\mathrm{Ni}(\mathrm{OH})_{2}$, although as expected, the sign is positive signifying ferromagnetism in $\alpha-\mathrm{Ni}(\mathrm{OH})_{2}$. This magnitude of $J_{2} / k_{\mathrm{B}}=0.14 \mathrm{~K}$ is smaller than $J_{2} / k_{\mathrm{B}}=1.2 \mathrm{~K}$ estimated earlier using the magnitude of $\theta$. The lower value is perhaps more realistic considering the larger $\mathrm{c}=8.6 \AA \AA$ in $\alpha-\mathrm{Ni}(\mathrm{OH})_{2}$.

In summary, the observations on the magnetic properties of $\alpha-\mathrm{Ni}(\mathrm{OH})_{2}$ reported here are satisfactorily explained on the basis of overall ferromagnetic order modulated by the nanosize effects. Although the 2D ferromagnetic arrangement shown here above $T_{c}$ has been widely accepted, the appearance of three distinct regions has not been reported in any other study on $\alpha-\mathrm{Ni}(\mathrm{OH})_{2}$. 


\section{CHAPTER V}

\section{Comparison, Summary and Conclusion}

\subsection{Comparison of the Magnetism in $\beta-\mathrm{Ni}(\mathrm{OH})_{2}$ and $\alpha-\mathrm{Ni}(\mathrm{OH})_{2}$}

In the preceding chapters experimental results for $\beta-\mathrm{Ni}(\mathrm{OH})_{2}$ (chapter III) and $\alpha-\mathrm{Ni}(\mathrm{OH})_{2}$ (chapter IV) were presented. While individually important, these two systems gives magnetic evolution of nickel hydroxide from the $\beta$-phase to the $\alpha$-phase. Fig. 5.1 shows temperature variation of the magnetic susceptibility $\left(\chi=\frac{M}{H}\right)$ for both $\beta-\mathrm{Ni}(\mathrm{OH})_{2}$ (sample $\beta$-A) and $\alpha-\mathrm{Ni}(\mathrm{OH})_{2}$ (sample $\alpha-\mathrm{A})$. There are distinct differences between the two phases including a lower ordering temperature and the magnitude of the

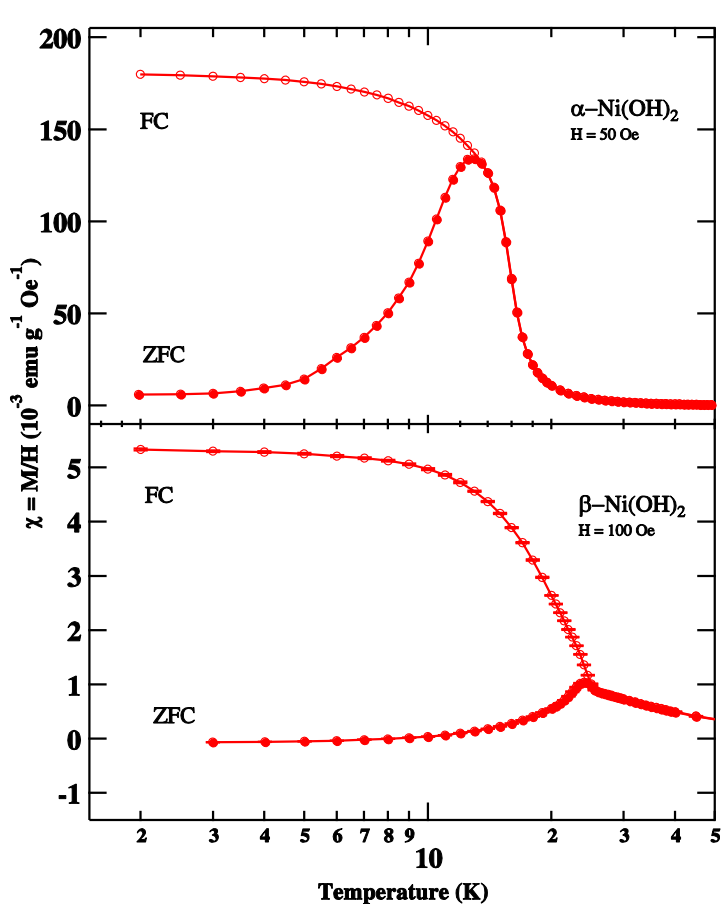
magnetization of the samples. The shift of the

Figure 5.1: Temperature variation of magnetization for sample $\beta$-A and sample $\alpha$-A

peak to lower temperatures is attributed to the system shifting to the ordering temperature of a purely $2 \mathrm{D}$ Ising system.

The magnetic susceptibility of $\alpha-\mathrm{Ni}(\mathrm{OH})_{2}$ below $\mathrm{T}_{\mathrm{C}}$ is 40 times greater than that in $\beta-\mathrm{Ni}(\mathrm{OH})_{2}$ for the field cooled data. Both FC data for $\alpha$-A and $\beta$-A shows characteristics of ferromagnetism while having different mechanism for the ferromagnetic behavior. In $\beta-\mathrm{Ni}(\mathrm{OH})_{2}$ the increase near $T_{p}$ is associated with the partial alignment of the uncompensated surface $\mathrm{Ni}^{2+}$ spins along the applied magnetic field direction; whereas in $\alpha-\mathrm{Ni}(\mathrm{OH})_{2}$, all layers of $\mathrm{Ni}^{2+}$ are 
ferromagnetically aligned with the applied field due to the interlayer ferromagnetic coupling. The larger $\chi(\mathrm{FC})$ at $\mathrm{T}=2 \mathrm{~K}$ is associated with the lower transition in the applied magnetic field needed to alter the magnetic ordering from $55 \mathrm{kOe}$ to $1 \mathrm{kOe}$.

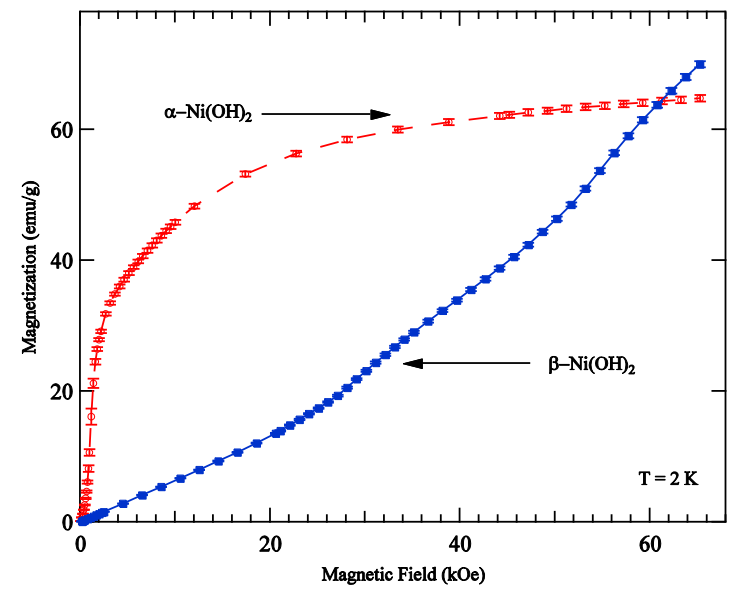

Figure 5.2: $\mathrm{M}$ vs. $\mathrm{H}$ data for $\alpha-\mathrm{Ni}(\mathrm{OH})_{2}$ and $\beta-\mathrm{Ni}(\mathrm{OH})_{2}$ at $\mathrm{T}=2 \mathrm{~K}$.
The M vs. H data (Fig. 5.2) shows a major distinction between the two phases. $\beta-\mathrm{Ni}(\mathrm{OH})_{2}$ is an antiferromagnet with two metamagnetic transitions around $28 \mathrm{kOe}$ and $55 \mathrm{kOe}$ without saturation at $65 \mathrm{kOe}$. On the other hand, $\alpha-\mathrm{Ni}(\mathrm{OH})_{2}$ is more characteristic of ferromagnetism with saturation beginning around $20 \mathrm{kOe}$ and almost reaching saturation at $65 \mathrm{kOe}$.

The hysteresis loops (Fig. 5.3) are also quite different between the two phases. Although antiferromagnetic materials do not typically show hysteresis, $\beta-\mathrm{Ni}(\mathrm{OH})_{2}$ shows remanence and coercivity due to the uncompensated surface $\mathrm{Ni}^{2+}$ spins of the nanoplatelets. On the other hand, $\alpha-\mathrm{Ni}(\mathrm{OH})_{2}$ at $\mathrm{T}=2 \mathrm{~K}$ shows a magnetic annealing like behavior while converting to a ferromagnetic like curve at $\mathrm{T}=6 \mathrm{~K}$. Therefore, the major difference between sample $\beta$-A and sample $\alpha$-A results primarily from the increased

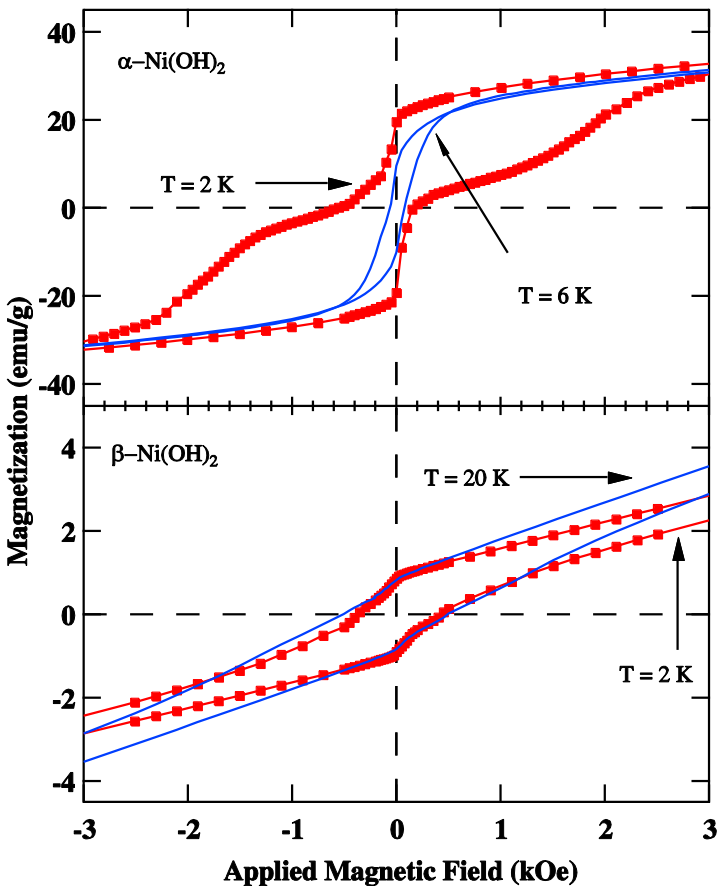

Figure 5.3: Hysteresis curves for both phases at low and higher temperatures. 
interlayer spacing in $\alpha$-A and the resulting FM order compared to AFM order in sample $\beta$-A.

\subsection{Summary}

Bulk $\beta-\mathrm{Ni}(\mathrm{OH})_{2}$ has been synthesized and characterized along with nanoplatelet $\beta-\mathrm{Ni}(\mathrm{OH})_{2}$ obtained from Alfa Aesar. The particle sizes for the two samples are 4 x $40 \mathrm{~nm}$ and 24 x $72 \mathrm{~nm}$ for nano and bulk-like samples, respectively. TEM images of the nanosized sample shows a platelet morphology with thickness of $\sim 4 \mathrm{~nm}$ and edge length of $\sim 40 \mathrm{~nm}$ with the z-axis collinear with the thickness. The bulk-like sample is assumed to have similar morphology due to the non-uniform broadening observed similarly for the nanoparticle sample.

The magnetic properties of the two $\beta-\mathrm{Ni}(\mathrm{OH})_{2}$ samples are presented in chapter III and are summarized here. The peak temperature of the ZFC-FC data shows a shift from $\mathrm{T}_{\mathrm{p}}=26.5 \mathrm{~K}$ for the bulk-like sample to $24.5 \mathrm{~K}$ for the nanoscale sample. This decrease in $\mathrm{T}_{\mathrm{p}}$ is related to a nanosize effect. The $\mathrm{ZFC}$ data for $\mathrm{H}=100 \mathrm{Oe}$ was fit to a Curie-Weiss relation with $\theta=20.5 \mathrm{~K}$ $(16 \mathrm{~K})$ and $\mathrm{C}=112 \times 10^{-4} \mathrm{emu} \mathrm{K} /(\mathrm{g} \mathrm{Oe})\left(149 \times 10^{-4} \mathrm{emu} \mathrm{K} /(\mathrm{g}\right.$ Oe $\left.)\right)$ for nanoscale (bulk-like) sample and giving rise to $\mu=2.92 \mu_{\mathrm{B}}\left(3.33 \mu_{\mathrm{B}}\right)$ and $\mathrm{S}=0.92$ (1.09). With further investigation, the ordering temperatures $\left(\mathrm{T}_{\text {ordering }}=\left(\frac{\partial(\chi \mathrm{T})}{\partial \mathrm{T}}\right)_{\max , \min }\right)$ shows a two step process from antiferromagnetism $\left(\mathrm{T}_{\mathrm{N}}=23 \mathrm{~K}\right)$ to paramagnetism with the intermediary of $2 \mathrm{D}$ ferromagnetism $\left(\mathrm{T}_{\mathrm{c}}=25 \mathrm{~K}\right)$. Using the two sublattice molecular-field model, and the Hamiltonian given in chapter III, the exchange interactions for the nanoplatelet sample are found as $J_{1} / \mathrm{k}_{\mathrm{B}} \simeq 3.25 \mathrm{~K}$, $J_{2} / \mathrm{k}_{\mathrm{B}} \simeq-0.32 \mathrm{~K}$, and $J_{3} / \mathrm{k}_{\mathrm{B}} \simeq-0.11 \mathrm{~K}$, while for the bulk-like sample, $J_{1} / \mathrm{k}_{\mathrm{B}} \simeq 2.67 \mathrm{~K}$, $J_{2} / \mathrm{k}_{\mathrm{B}} \simeq-0.315 \mathrm{~K}$, and $J_{3} / \mathrm{k}_{\mathrm{B}} \simeq-0.105 \mathrm{~K}$ are determined. 
Both the bulk-like and nanosized samples of $\beta-\mathrm{Ni}(\mathrm{OH})_{2}$ have a metamagnetic transition near $\mathrm{H}_{\mathrm{C} 2} \simeq 55 \mathrm{kOe}$, while the nanoplatelets have an additional transition around $28 \mathrm{kOe}$. Using the model described in chapter III, the critical magnetic field is described by $\mathrm{H}_{\mathrm{C} 2}=-\frac{4 S}{\mathrm{~g} \mu_{\mathrm{B}}}\left(J_{2} \mathrm{Z}_{2}+J_{3} \mathrm{Z}_{3}\right)$ which yields $\mathrm{H}_{\mathrm{C} 2} \simeq 48 \mathrm{kOe}$ similar to our experimental results. The additional transition in the nanoplatelet sample at $28 \mathrm{kOe}$ is explained by flipping of the surface spins whose percentage increases in nanoparticles, and it is given by $\mathrm{H}_{\mathrm{C} 1}=1 / 2 \mathrm{H}_{\mathrm{C} 2}$. Using the National High Magnetic Field Laboratory facilities, the saturation magnetization $\mathrm{M}_{\mathrm{S}}=118 \mathrm{emu} / \mathrm{g}$ is determined with $\mathrm{H}_{\mathrm{S}}=150 \mathrm{kOe}$ being the saturation field. These magnitudes of $\mathrm{M}_{\mathrm{S}}$ and saturation field $\mathrm{H}_{\mathrm{S}}$ are in excellent agreement with the calculated magnitudes of $\mathrm{M}_{\mathrm{S}}=118.5 \mathrm{emu} / \mathrm{g}$ and $\mathrm{H}_{\mathrm{S}}=153 \mathrm{kOe}$.

Since the hysteresis is only shown in the nanoplatelet sample, it is associated with the size effects of the system. The model described in chapter III predicts a remanence of $M_{r}=2.2 \mathrm{emu} / \mathrm{g}$ in agreement with our experimental work and also attributes the coercivity $\mathrm{H}_{\mathrm{c}}$ to the uncompensated surface spins.

Samples of $\alpha-\mathrm{Ni}(\mathrm{OH})_{2}$ showed a larger c-axis, $\mathrm{c}=8.6 \AA$, with acetyl anions between the nickel sheets. The morphology, based on the SEM images, shows a flower-like structure with petal thickness of $\sim 10 \mathrm{~nm}$, while the particle is larger around $200 \mathrm{~nm}$.

Details of the magnetic properties of $\alpha-\mathrm{Ni}(\mathrm{OH})_{2}$ are presented in chapter IV. The temperature variation of the magnetization shows a peak temperature at $16 \mathrm{~K}$ for $\mathrm{H}=50$ Oe corresponding to ferromagnetic ordering. As such, the $\mathrm{M}$ vs. $\mathrm{T}$ ZFC data for $\mathrm{T}>50 \mathrm{~K}$ were fit to the $2 \mathrm{D}$ Ising $\mathrm{S}=1$ high temperature series giving $\mathrm{g}=2.29$ and the in-plane ferromagnetic interaction of $J_{1} / \mathrm{k}_{\mathrm{B}} \simeq 4.38 \mathrm{~K}$. Based on the Heisenberg $2 \mathrm{D}$ to $3 \mathrm{D}$ transition of the ordering 
temperature, the interplanar exchange interaction was determined to be $J_{2} / k_{\mathrm{B}}=0.14 \mathrm{~K}$. The

ordering temperatures given by $\frac{\partial(\chi \mathrm{T})}{\partial \mathrm{T}}$ shows a two step process different from $\beta-\mathrm{Ni}(\mathrm{OH})_{2}$ seen by the large magnetic field dependence of the lower transition. The magnetic field dependence of the lower temperature is also evident by the ZFC non-uniform broadening of the peak. The ac susceptibility gives evidence for two magnetic regimes below the FM ordering. Below $T_{p}$ particle size effects are seen with a blocking temperature highly dependent on the applied magnetic field and the measuring frequency. The system also exhibits magnetic annealing behavior due to the canted surface spin below $\mathrm{T}_{\mathrm{m}} \simeq 3.5 \mathrm{~K}$. This gives rise to exchange bias below $3.5 \mathrm{~K}$ and a hysteresis loop evident of spin pinning.

\subsection{Suggestions for Further Studies}

(1) The present study in $\beta-\mathrm{Ni}(\mathrm{OH})_{2}$ has pretty well established the nature of its magnetism and how the nanosize affects the measured properties. Additional studies could be carried out on $\beta-\mathrm{Ni}(\mathrm{OH})_{2}$ with systematic variation in the particle size and morphology [Dong, Chu, \& Sun, 2008]. The different morphologies provide a direct avenue to explore the uncompensated surface spins in this model even when the dimensions are of the nanoscale. Controlled synthesis of particle size and morphology will be an experimental challenge due to the high crystalline anisotropy which prefers the hexagonal platelet morphology.

(2) For $\alpha-\mathrm{Ni}(\mathrm{OH})_{2}$, studies in a bulk sample as well as variation of the magnetic properties with particle size may provide interesting results. Again synthesis of particles of desired size and morphology may present an important challenge. Also measurements of 
magnetization in magnetic fields higher than $65 \mathrm{kOe}$ might provide more accurate values of saturation magnetization and ac susceptibility measurements with varying DC magnetic fields could be useful to more accurately determine the transition with existing theory.

(3) For $\alpha-\mathrm{Ni}(\mathrm{OH})_{2}$ variations in the magnetic properties with change in the c-axis by incorporating different ligands might present an interesting case study to get a more thorough and accurate representation of the evolution of magnetism from $\beta$-phase to large c-axis $\alpha$-phase.

(4) Further studies into the layered hydroxide metals can be useful in determining applications for multifunctional devices. For example, the incorporation of bioluminescent molecules between the layers may provide interesting results for the control of light through other means, such as magnetism. 


\section{REFERENCES}

Babu, S., \& Seehra, M.S. (1996). Carbon, 34(10), 1259-1265.

Bienenstock, A. (1966). Journal of Applied Physics, 37(3), 1459-1461. doi: 10.1063/1.1708515

Binder, K., \& Young, A.P. (1986). Reviews of Modern Physics, 58(4), 801-976. doi: 10.1103/RevModPhys.58.801

Bragg, E.E., \& Seehra, M.S. (1973). Physical Review B, 7(9), 4197-4202. doi: 10.1103/PhysRevB.7.4197

Brechignuc, C., Houdy, P., \& Lehmani, M. (Eds.). (2007). Nanomaterials and Nanochemistry. New York: Springer.

Cheng, M-Y, \& Hwang, B-J (2009). Journal of Colloid and Interface Science, 337, 265-271. doi: 10.1016/j.jcls.2009.05.008

Chikazumi, S. (1997). Physics of Ferromagnetism. New York: Oxford University Press Inc.

Dai, J., Li, S.F.Y., Xiao, T.D., Wang, D.M., \& Reisner, D.E. (2000). Journal of Power Sources, 89(1), 40-45.

Darby, M.I. (1967). British Journal of Applied Physics, 18(10), 1415-1417. doi: 10.1088/0508$3443 / 18 / 10 / 307$

Drillon, M., \& Panissod, P. (1998). Journal of Magnetism and Magnetic Materials, 188(1-2), 9399. doi: 10.1016/S0304-8853(98)00180-2

de Jesus, J.C., González, I., Quevedo, A., \& Puerta, T. (2005). Journal of Molecular Catalysis A: Chemical, 228, 283-291. doi: 10.1016/j.molcata.2004.09.065

de Jongh, L.J. (Ed.). (1990). Magnetic Properties of Layered Transition Metal Compounds. Boston: Kluwer Academic. 
Demessence, A., Rogez, G., \& Rabu, P. (2006). Chemistry of Materials, 18, 3005-3015. doi: $10.1021 / \mathrm{cm} 060366 \mathrm{w}$

Dong, L., Chu, Y., \& Sun, W. (2008). Chemical European Journal, 14, 5064-5072. doi: 10.1002/chem..200701627

Enoki, T., \& Tsujikawa, I. (1975). Journal of the Physical Society of Japan, 39, 317-323. doi: 10.1143/JPSJ.39.317

Enoki, T., \& Tsujikawa, I. (1978). Journal of the Physical Society of Japan, 45, 1515-1519. doi: 10.1143/JPSJ.45.1515

Falk, S., \& Salkin, A. (1969). Alkaline Storage Batteries. New Yok: Wiley.

Fisher, M.E. (1962). Philosophy Magazine, 7, 1731.

Fox, P.F., \& Guttmann, A.J. (1973). Journal of Physics C: Solid State Physics, 6(5), 913-931. doi: $10.1088 / 0022-3719 / 6 / 5 / 020$

Genin, P., Delahaye-Vidal, A., Portemer, F., Tekaia-Elhsissen, K., \& Figlarz, M. (1991) European Journal of Solid State Inorganic Chemistry, 28, 505.

Jayashree, R.S., Kamath, P.V., \& Subbanna, G.N. (2000). Journal of the Electrochemical Society. 147(6), 2029-2032.

Kiani, M.A., Mousavi, M.F., \& Ghasemi, S. (2010). Journal of Power Sources, 195(17), 57945800. doi: 10.1016/j.jpowsour.2010.03.080

Klug, H.P., * Alexander, L.E. (1954). X-ray Diffraction Procedures. New York: John Wiley \& Sons.

Kurmoo, M., Day, P., Derory, A., Estournès, C., Poinsot, R., Stead, M., \& Kepert, C.J. (1999). Journal of Solid State Chemistry, 145, 452-459. doi: 10.1006/jssc.1999.8147 
Laget, V., Rouba, S., Rabu, P. Hornick, C., \& Drillon, M. (1996). Journal of Magnetism and Magnetic Materials, 154(1), L7-L11.

Li, Y., Xie, X., Liu, J., Cai, M., Rogers, J. \& Shen, W. (2008). Chemical Engineering Journal, 136(2-3), 398-408. doi: 10.1016/j.cej.2007.06.001

Martinez, B., Obradors, X., Balcels, Ll, Rouanet, A., \& Monty, C. (1998). Physical Review Letters, 80(1), 181-184. doi: 10.1103/PhysRevLett.80.181

Materials Science and Engineering Department, "Scanning Electron Microscopy," Iowa State Univeristy, http://mse.iastate.edu/microscopy/.

Miyamoto, H. (1966). Bulletin of the Institute for Chemical Research, Kyoto University, 44(5), 420-429.

Miyamoto, H. (1976). Materials Research Bulletin, 11(6), 599-607.

Morrish, A. (2001). The Physical Principles of Magnetism. New York: The Institute of Electrical and Electronics Engineers, Inc.

Olivia, P., Leonardi, J., Laurent, J.F., Delmas, C., Braconnier, J.J., Figlarz, M., Fiévet, F., \& de Guibert, A. (1982). Journal of Power Sources, 8(2), 229-255.

Owens, F.J., \& Poole Jr., C.P. (2008). The Physics and Chemistry of Nanosolids. New Jersy: John Wiley \& Sons, Inc.

Poul, L., Jouini, N., \& Fiévet F. (2000). Chemistry of Materials, 12(10), 3123-3132. doi: $10.1021 / \mathrm{cm} 991179 \mathrm{j}$

Punnoose, A., Seehra, M.S., von Tol, J., \& Brunel, L.C. (2005). Journal of Magnetism and Magnetic Materials, 288, 168-172.

Rabu, P., \& Drillon, M. (2003). Advanced Engineering Materials, 5(4), 189-210. doi: 10.1002/adem.200310082 
Radha, A.V., Kamath, P.V., \& Subbanna, G.N. (2003). Materials Research Bulletin, 38(5), 731740. doi: 10.1016/S0025-5408(03)0070-9

Rall, J.D., Seehra, M.S., \& Choi, E.S. (2010(a)). Physical Review B, 82, 184403 (1-9). doi: 10.1103/PhysRevB.82.184403

Rall, J.D., Seehra, M.S., Shah, N., \& Huffman, G.P. (2010(b)). Journal of Applied Physics, 107, 09B511. doi: 10.1063/1.3358015

Ramesh, T.N., \& Kamath, P.V. (2008). Materials Research Bulletin, 43(12), 3227. doi: 10.1016/j.materresbull.2008.02.024

Ren, J., Zhou, Z., Gao, X.P., \& Yan, J. (2006). Electrochimica Acta, 52(3), 1120-1126. doi: 10.1016/j.electacta.2006.07.028

Rouba, S., Rabu, P., Ressouche, E., Regnault, L-P, \& Drillon, M. (1996). Journal of Magnetism and Magnetic Materials. 163(3), 365-372.

Scholtz, R., \& Uhlig, S. (2000). Introduction to X-ray Fluroescence. New York: Bruker AXS Inc.

Seehra, M.S. (1969). Physics Letters A, 28(11), 754-755. doi: 10.1016/0375-960(69)90603-3

Seehra, M.S., \& Pavlovic, A.S. (1993). Carbon, 31(4), 557-564.

Seehra, M.S., Roy, P., Raman, A., \& Manivannan, A. (2004). Solid State Communications, 130(9), 597-601. doi: 10.1016/j.ssc.2004.03.022

Singh, V., Seehra, M.S., \& Bonevich, J. (2009). Journal of Applied Physics, 105, 07B518. doi: $10.1063 / 1.3073949$

Skalyo Jr., J., Cohen, A.F., Friedberg, S.A., \& Griffiths, R.B. (1967). Physical Review, 164(2), 705-709. doi: 10.1103/PhysRev.164.705 
Srinivassan, G., and Seehra, M.S. (1984). Physical Review B, 29(11), 6295-6298. doi: 10.1103/PhysRevB.29.6295

Szytula, A., Murasik, A., \& Balanda, M. (1971). Physica Status Solidi (b), 43(1), 125-128. doi:10.1002/pssb.2220430113

Taibi, M., Ammar, S., Noureddine, J., Fiévet, F., Molinié, P., \& Drillon, M. (2002). Journal of Materials Chemistry, 12, 3238-3244. doi: 10.1039/B204087E

Takada, T., Bando, Y., Kiyama, M., Miyamoto, H., \& Sato, T. (1966). Journal of the Physical Society of Japan, 21, 2726-2726. doi: 10.1143/JPSJ.21.2726

Tiwari, S.D., \& Rajeev, K.P. (2008). Physical Review B, 77(22), 224430-1 - 22430-6. doi: 10.1103/PhysRevB.77.24430

Van Dyke, J.P., \& Camp, W.J. (1974). Physical Review B, 9(7), 3121-3125. doi: 10.1103/PhysRevB.9.3121

Wang, X., Luo, H., Parkhutik, P.V., Millan, A-C, \& Matveeva, E. (2003). Journal of Power Sources, 115(1), 153-160. doi: 10.1016/S0378-7753(02)00649-3

Williamson, G.K., \& Hall, W.H. (1953). Acta Meallurgica, 1(1), 22-31. doi: 10.1016/0016160(53)90006-6

Wolf, W.P., \& Wyatt, A.F.G. (1964). Physical Review Letters, 13(12), 368-370. doi: 10.1103/PhysRevLett.13.368

Yang, L-X, Zhu, Y-J, Tong, H., Liang, Z-H, Li, L., \& Zhang, L. (2007). Journal of Solid State Chemistry, 180(8), 2095-2101. doi: 10.1016/j.jssc.2007.05.009 


\section{APPENDIX A \\ Supplemental Material for Synthesis and Characterization}

This appendix contains calculations and additional measurements from chapter II (synthesis and characterization)

\section{A.1 Synthesis Calculations}

$\underline{\beta-\mathrm{Ni}(\mathrm{OH})_{2}} \underline{\text { sample } \beta \text {-B }}$

Nickel Nitrate: $\mathrm{Ni}\left(\mathrm{NO}_{3}\right)_{2} \bullet 6 \mathrm{H}_{2} \mathrm{O}$, Molecular Weight $(\mathrm{MW})=290.83 \mathrm{~g} / \mathrm{mol}$

Sodium Hydroxide: $\mathrm{Na}(\mathrm{OH}), \mathrm{MW}=40 \mathrm{~g} / \mathrm{mol}$

Molarity $(\mathrm{M})=\mathrm{mol} / \mathrm{L}=$ weight $/(\mathrm{MW} * \mathrm{~L})$

0.1M Nickel Nitrate $=$ x g nickel nitrate $/(290.83 \mathrm{~g} / \mathrm{mol} 0.125 \mathrm{~L})$

$$
\mathrm{x}=3.64 \mathrm{~g} \mathrm{Ni}\left(\mathrm{NO}_{3}\right)_{2} \bullet 6 \mathrm{H}_{2} \mathrm{O} \text { in } 125 \mathrm{ml} \text { of water }
$$

$4 \mathrm{M} \mathrm{NaOH}=x \operatorname{g~NaOH} /(40 * 0.5 \mathrm{~L})$

$$
\mathrm{x}=80 \mathrm{~g} \mathrm{NaOH} \text { in } 500 \mathrm{ml} \mathrm{H}_{2} \mathrm{O}
$$

$\underline{\alpha-\mathrm{Ni}(\mathrm{OH})_{2}}$

Nickel Acetate: $\mathrm{Ni}\left(\mathrm{CH}_{3} \mathrm{COO}\right)_{2} \bullet x \mathrm{H}_{2} \mathrm{O}, \mathrm{MW}=249 \mathrm{~g} / \mathrm{mol}$

sample $\alpha$-A: $0.1 \mathrm{M} \mathrm{Ni}\left(\mathrm{CH}_{3} \mathrm{COO}\right)_{2} \bullet x \mathrm{H}_{2} \mathrm{O}=x \mathrm{~g} \mathrm{Ni}\left(\mathrm{CH}_{3} \mathrm{COO}\right)_{2} \bullet x \mathrm{H}_{2} \mathrm{O} /(249$

$\mathrm{g} / \mathrm{mol} 0.1 \mathrm{~L})$

$\mathrm{x}=2.49 \mathrm{~g} \mathrm{Ni}\left(\mathrm{CH}_{3} \mathrm{COO}\right)_{2} \bullet x \mathrm{H}_{2} \mathrm{O}$ in $100 \mathrm{ml}$ of ethylene glycol

sample $\alpha$-B: $0.1 \mathrm{M} \mathrm{Ni}\left(\mathrm{CH}_{3} \mathrm{COO}\right)_{2} \bullet x \mathrm{H}_{2} \mathrm{O}=x \mathrm{~g} \mathrm{Ni}\left(\mathrm{CH}_{3} \mathrm{COO}\right)_{2} \bullet x \mathrm{H}_{2} \mathrm{O} /(249$

$$
\mathrm{g} / \mathrm{mol} * .075 \mathrm{~L})
$$




$$
\mathrm{x}=1.87 \mathrm{~g} \mathrm{Ni}\left(\mathrm{CH}_{3} \mathrm{COO}\right)_{2} \bullet x \mathrm{H}_{2} \mathrm{O} \text { in } 75 \mathrm{ml} \text { of ethylene glycol }
$$

\section{A.2 TGA Calculations}

Theoretical calculations

$$
\begin{aligned}
& \mathrm{Ni}(\mathrm{OH})_{2} \rightarrow \mathrm{NiO}+\mathrm{H}_{2} \mathrm{O}(g) \\
& \mathrm{Ni}(\mathrm{OH})_{2}, \mathrm{MW}=92.7 \mathrm{~g} / \mathrm{mol} \\
& \mathrm{NiO}, \mathrm{MW}=74.7 \\
& 1 \mathrm{~mol} \mathrm{Ni}(\mathrm{OH})_{2}=92.7 \mathrm{~g} \\
& 1 \mathrm{~mol} \mathrm{NiO}=74.7 \mathrm{~g} \\
& \frac{\text { initial }- \text { final }}{\text { initial }} \times 100 \\
& \frac{92.7-74.7}{92.7} \times 100=19 \%
\end{aligned}
$$

$\underline{\text { Sample } \beta-\mathrm{A}}$

Initial: $\mathrm{Ni}(\mathrm{OH})_{2} \bullet x \mathrm{H}_{2} \mathrm{O}, \mathrm{MW}=92.7 \mathrm{~g} / \mathrm{mol}+\mathrm{x} *(18 \mathrm{~g} / \mathrm{mol})$

Intermediate: $\mathrm{Ni}(\mathrm{OH})_{2}, \mathrm{MW}=92.7 \mathrm{~g} / \mathrm{mol}$

Final: NiO, MW 74.7 t/mol

$$
\begin{aligned}
& \frac{\text { initial }- \text { intermediate }}{\text { initial }} \times 100=\frac{92.7+18 x-92.7}{92.7} \times 100=2.73 \\
& x=0.144 \mathrm{~mol} \mathrm{H}_{2} \mathrm{O}
\end{aligned}
$$

$\underline{\text { Sample } \beta-B}$

Initial: $\mathrm{Ni}(\mathrm{OH})_{2} \bullet x \mathrm{H}_{2} \mathrm{O}, \mathrm{MW}=92.7+18 \mathrm{x}$

Intermediate: $\mathrm{Ni}(\mathrm{OH})_{2}, \mathrm{MW}=92.7 \mathrm{~g} / \mathrm{mol}$

Final: $\mathrm{NiO}, \mathrm{MW}=74.7 \mathrm{~g} / \mathrm{mol}$ 


$$
\begin{aligned}
& \frac{\text { initial }- \text { intermediate }}{\text { initial }} \times 100=\frac{92.7+18 x-92.7}{92.7} \times 100=1.92 \\
& x=0.101 \mathrm{~mol} \mathrm{H}_{2} \mathrm{O}
\end{aligned}
$$

$\underline{\alpha-\mathrm{Ni}(\mathrm{OH})_{2}}$

$$
\begin{aligned}
\text { Initial: } & \mathrm{Ni}(\mathrm{OH})_{2-x}\left(\mathrm{CH}_{3} \mathrm{COO}\right)_{x} \bullet n \mathrm{H}_{2} \mathrm{O} \\
& \mathrm{MW}=92.7 \mathrm{~g} / \mathrm{mol}+\mathrm{n} *(18 \mathrm{~g} / \mathrm{mol})+\mathrm{x} *(42 \mathrm{~g} / \mathrm{mol})
\end{aligned}
$$

Intermediate: $\mathrm{Ni}(\mathrm{OH})_{2-x}\left(\mathrm{CH}_{3} \mathrm{COO}\right)_{x}, \mathrm{MW}=92.7 \mathrm{~g} / \mathrm{mol}+\mathrm{x}^{*}(42 \mathrm{~g} / \mathrm{mol})$

Final: $\mathrm{NiO}, \mathrm{MW}=74.7 \mathrm{~g} / \mathrm{mol}$

Sample $\alpha-\mathrm{A}$

$$
\begin{aligned}
& \frac{\text { initial }- \text { intermediate }}{\text { initial }} \times 100=\frac{92.7+18 n+42 x-92.7}{92.7} \times 100=17 \\
& \frac{\text { initial }- \text { final }}{\text { initial }} \times 100=\frac{92.7+42 x-74.7}{92.7} \times 100=49.7
\end{aligned}
$$

From these two equation,

$$
n=1.06-0.48 x \text { and } 21.1 x+9.05 n=28.07
$$

Therefore, $x=0.77 \mathrm{~mol}\left(\mathrm{CH}_{3} \mathrm{COO}\right)^{-}$and $\mathrm{n}=1.43 \mathrm{~mol} \mathrm{H}_{2} \mathrm{O}$

\section{$\underline{\text { Sample } \alpha-B}$}

$$
\begin{aligned}
& \frac{\text { initial }- \text { intermediate }}{\text { initial }} \times 100=\frac{92.7+18 n+42 x-92.7}{92.7} \times 100=16 \\
& \frac{\text { initial }- \text { final }}{\text { initial }} \times 100=\frac{92.7+42 x-74.7}{92.7} \times 100=45.9
\end{aligned}
$$

From these two equation,

$$
x=2.25 n-2.21 \text { and } 22.7 x+9.738 n=24.55
$$

Therefore, $x=0.55 \mathrm{~mol}\left(\mathrm{CH}_{3} \mathrm{COO}\right)^{-}$and $\mathrm{n}=1.23 \mathrm{~mol} \mathrm{H}_{2} \mathrm{O}$ 


\section{A.3 Temperature Programmed Reduction (TPR)}

Temperature Programmed Reduction (TPR) is mainly used to determine the oxidation state of metals and find the temperature at which the compound reduces. This is done by heating a sample in an argon/hydrogen mixture. The TPR of sample $\beta$-A, Fig. A.1,shows the hydroxide metal goes through only one transition from nickel hydroxide to nickel. The temperature at which this occurs is also similar to the reduction of nickel hydroxide to nickel oxide in air. Without an intermediate, there is a pathway more direct to create nanoparticle samples of nickel with similar morphology to nickel hydroxide. The temperature $\sim 240 \mathrm{C}$ is much lower than the nickel oxide to nickel reduction. This could be useful to reduce the agglomeration of particles when using higher heat and hence create smaller nanoparticles to study.

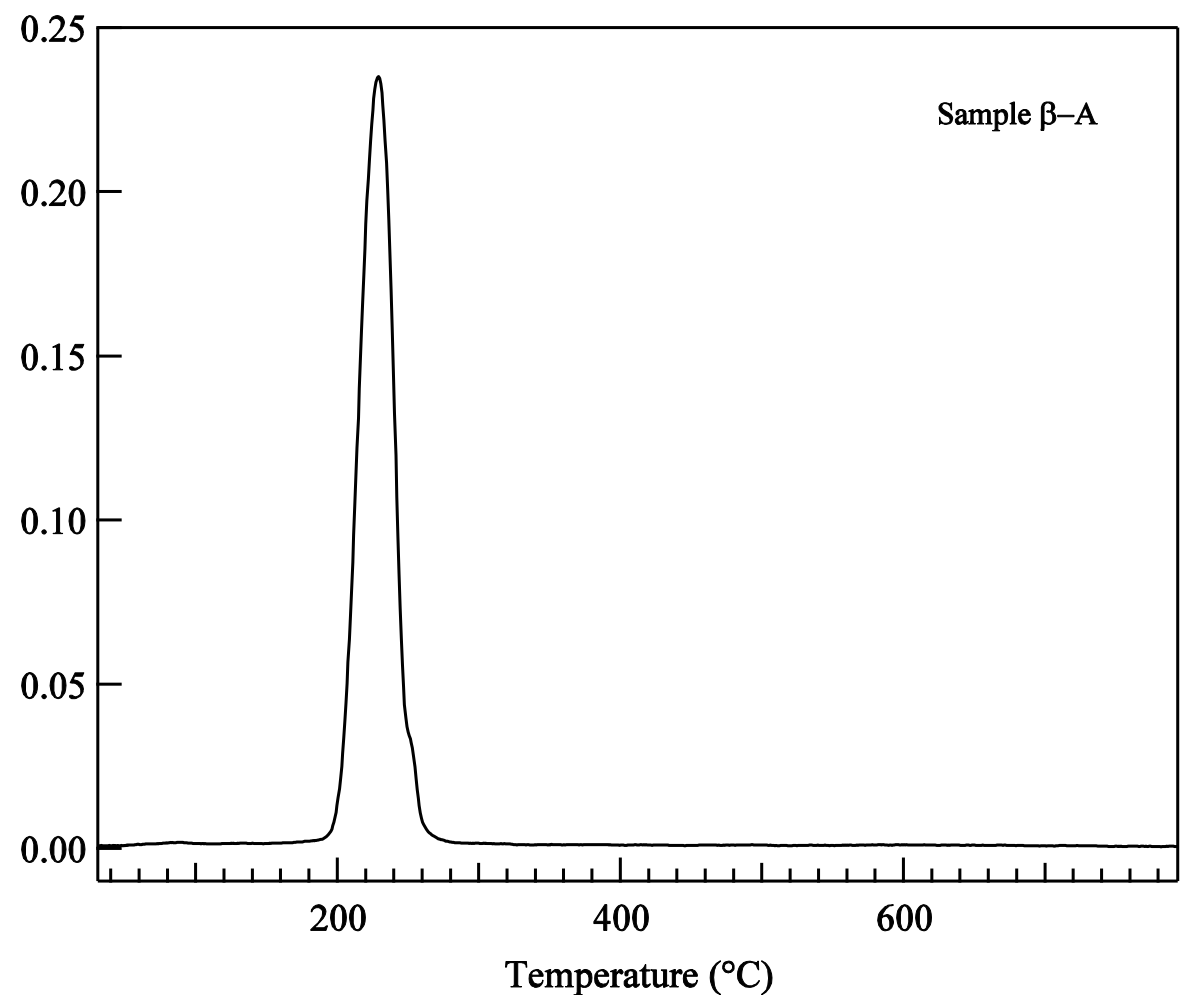

\footnotetext{
John H. 